NBER WORKING PAPER SERIES

A NEOCLASSICAL THEORY OF LIQUIDITY TRAPS

Sebastian Di Tella

Working Paper 24205

http://www.nber.org/papers/w24205

NATIONAL BUREAU OF ECONOMIC RESEARCH
1050 Massachusetts Avenue
Cambridge, MA 02138
January 2018

The author declares that he has no relevant or material financial interests that relate to the research described in this paper. The views expressed herein are those of the author and do not necessarily reflect the views of the National Bureau of Economic Research.

NBER working papers are circulated for discussion and comment purposes. They have not been peer-reviewed or been subject to the review by the NBER Board of Directors that accompanies official NBER publications.

(C) 2018 by Sebastian Di Tella. All rights reserved. Short sections of text, not to exceed two paragraphs, may be quoted without explicit permission provided that full credit, including () notice, is given to the source. 
A Neoclassical Theory of Liquidity Traps

Sebastian Di Tella

NBER Working Paper No. 24205

January 2018

JEL No. E3,E4,E5

\section{$\underline{\text { ABSTRACT }}$}

This paper provides an equilibrium theory of liquidity traps and the real effects of money. Money provides a safe store of value that prevents interest rates from falling enough during downturns, and the economy enters a persistent slump with depressed investment. This is an equilibrium outcome-prices are flexible, markets clear, and inflation is on target-but it's not efficient. Investment is too high during booms and too low during liquidity traps. Although money has large real effects, monetary policy is ineffective - the zero lower bound is not binding, money is superneutral, and Ricardian equivalence holds. The optimal allocation requires the Friedman rule and a tax/subsidy on capital.

Sebastian Di Tella

Stanford University

Graduate School of Business

655 Knight Way

Stanford, CA 94305

and NBER

sditella@stanford.edu 


\title{
A Neoclassical Theory of Liquidity Traps
}

\author{
Sebastian Di Tella* \\ Stanford University
}

November 2017

\begin{abstract}
This paper provides an equilibrium theory of liquidity traps and the real effects of money. Money provides a safe store of value that prevents interest rates from falling enough during downturns, and the economy enters a persistent slump with depressed investment. This is an equilibrium outcome - prices are flexible, markets clear, and inflation is on target - but it's not efficient. Investment is too high during booms and too low during liquidity traps. Although money has large real effects, monetary policy is ineffective - the zero lower bound is not binding, money is superneutral, and Ricardian equivalence holds. The optimal allocation requires the Friedman rule and a tax/subsidy on capital.
\end{abstract}

\section{Introduction}

Liquidity traps occur when money prevents interest rates from falling enough during downturns, and the economy enters a persistent slump with depressed investment. They are associated with some of the deepest and most persistent slumps in history. Japan has arguably been experiencing one for almost 20 years, and the US and Europe since the 2008 financial crisis. But how can money have such large and persistent real effects?

This paper provides an equilibrium theory of liquidity traps and the real effects of money. I show that liquidity traps arise naturally in a monetary economy with incomplete idiosyncratic risk sharing, even if prices are completely flexible. To fix ideas, consider a simple AK growth model with log utility over consumption and money, and incomplete idiosyncratic risk sharing. During downturns idiosyncratic risk goes up and makes risky capital less attractive. Without money, real interest rates would fall and keep investment at the first-best level. But money prevents equilibrium interest rates from falling enough, depressing investment.

The liquidity trap is an equilibrium outcome - prices are flexible, markets clear, and inflation is on target. In contrast to conventional models of liquidity traps, the zero lower bound is not binding, money is superneutral, and Ricardian equivalence holds. The real effects of money become

*I'd like to thank Manuel Amador, Narayana Kocherlakota, Pablo Kurlat, Yuliy Sannikov, Chris Tonetti, Chad Jones, Adrien Auclert, Arvind Krishnamurthy, Bob Hall, and John Taylor. email: sditella@stanford.edu. 
gradually larger as interest rates fall and the value of liquidity rises. The competitive equilibrium is inefficient - investment is too high during booms and too low during liquidity traps. However, while money can have large real effects, monetary policy is ineffective. The optimal allocation requires the Friedman rule and a tax or subsidy on capital. When investment is too low, subsidize it. When it's too high, tax it.

How can money affect real interest rates and investment? The key insight is that money provides a safe store of value that improves idiosyncratic risk sharing, and its value endogenously rises during liquidity traps. Better risk sharing weakens agents' precautionary saving motive, which keeps real interest rates high and investment depressed relative to the economy without money. The value of money is the present value of expenditures on liquidity services, and it becomes very large when interest rates fall. In particular, if risk is high enough the real interest rate can be very negative without money, but must remain above the growth rate if there is money. The value of liquidity endogenously grows, raising the equilibrium real interest rate and depressing investment until this condition is satisfied. The result is a liquidity trap.

What makes money special? Is this about money or is it really about safe assets? Agents can trade risk-free debt, but it doesn't produce a liquidity trap. Neither does a diversified (safe) equity index. I also allow for safe government debt and deposits. They produce a liquidity trap only to the extent that they have a liquidity premium. To see why, notice that safe assets without a liquidity premium must be backed by payments with equal present value. Agents own the assets but also the liabilities, so the net value is zero. But the value of liquid assets, net of the value of the payments backing them, is equal to the present value of their liquidity premium. This is what allows them to serve as a store of value and improve risk sharing in general equilibrium. Agents with a bad shock can sell part of their liquid assets to agents with a good shock in order to reduce the volatility of their consumption.

Money, and more generally safe assets with a liquidity premium, are special because they are simultaneously safe (no idiosyncratic risk) and have a positive net value. There are many assets that have positive net value, such as capital, housing, or land. But the starting point of this paper is that real investments are risky and idiosyncratic risk sharing is incomplete. For example, agents must buy a particular house or plot of land, whose value has significant idiosyncratic risk that can't be fully shared. There are also safe financial assets, such as AAA corporate debt, but their net value is zero (someone owes the asset). Safe assets with a liquidity premium have the rare combination of safety and positive net value that allow them to function as a safe store of value.

How quantitatively important is the role of liquid assets as a safe store of value? Quite small during normal times, but very large during liquidity traps. The net value of liquid assets is equal to the present value of expenditures on liquidity services. During normal times when interest rates are high their value is relatively small, close to the expenditure share on liquidity services (around 1.7\% by my calculations), and can be safely ignored. But during those relatively rare occasions when the real interest rate becomes persistently very low relative to the growth rate of the economy, their value can become very large. And these are precisely the events we are interested in studying. In 
fact, the liquidity trap survives even in the cashless limit where expenditures on liquidity services vanish, and is robust to different specifications of money demand.

The inefficiency in this economy comes from hidden trade. ${ }^{1}$ I microfound the incomplete idiosyncratic risk sharing with a fund diversion problem with hidden trade. The competitive equilibrium is the outcome of allowing agents to write privately optimal long-term contracts in a competitive market. I then characterize the optimal allocation by a planner who faces the same environment, and show how it can be implemented with a tax or subsidy on capital. The competitive equilibrium is inefficient because private contracts don't internalize that when they make their consumption and investment decisions, they are affecting prices, such as the interest rate, and therefore the hidden-trade incentive-compatibility constraints of other contracts.

The model is driven by countercyclical idiosyncratic risk shocks for the sake of concreteness. But an increase in risk aversion is mathematically equivalent; it will also raise the risk premium and precautionary motives. Higher risk aversion can represent wealth redistribution from risk tolerant to risk averse agents after bad shocks (see Longstaff and Wang (2012)) or weak balance sheets of specialized agents who carry out risky investments (see He and Krishnamurthy (2013) and He et al. (2015)). It can also capture habits (Campbell and Cochrane (1999)) or higher ambiguity aversion after shocks that upend agents' understanding of the economy (see Barillas et al. (2009)). Here I focus on simple countercyclical risk shocks with homogenous agents, but these are potential avenues for future research.

I first study a simple stationary model and do comparative statics across balanced growth paths for different levels of idiosyncratic risk in Section 2. I characterize the optimal allocation in Section 3. This simple environment captures most of the economic intuition and can be solved with pencil and paper. I then introduce aggregate risk shocks in a dynamic model in Section 4 and characterize the competitive equilibrium as the solution to a simple ODE. Section 5 discusses the link to a bubble theory of money, and the relationship between the mechanism in this paper and sticky-price models of the zero lower bound. In the Appendix I consider a cash-in-advance version of the model and a general CES demand for money, and I also solve the model with Epstein-Zin preferences. The Online Appendix has the technical details of the contractual environment.

New Keynesian models of the zero lower bound. The mainstream view of liquidity traps focuses on the role of the zero lower bound on nominal interest rates in New Keynesian models with nominal rigidities, starting with the seminal work of Krugman et al. (1998). ${ }^{2}$ If there is money in the economy the nominal interest rate cannot be negative. So if the natural interest rate (the real interest rate with flexible prices) is very negative, the central bank must either abandon its inflation target or allow the economy to operate with an output gap (or both).

In contrast, this paper argues that liquidity traps are not essentially about nominal rigidities and the zero lower bound. Money makes the natural rate positive, and the depressed investment does

\footnotetext{
${ }^{1}$ See Farhi et al. (2009), Kehoe and Levine (1993), Di Tella (2016).

${ }^{2}$ Eggertsson et al. (2003), Werning (2011), Eggertsson and Woodford (2004), Eggertsson and Krugman (2012), Svensson (2000), Caballero and Simsek (2017).
} 
not reflect a negative output gap, but rather the real equilibrium effects of money. An attractive feature of the mechanism here is that the liquidity trap is a gradual phenomenon. The real effects of money become larger as the value of liquidity endogenously rises. While there is a zero lower bound on the nominal interest rate, it's not binding and it doesn't play any important role in the liquidity trap. In fact, since money is superneutral, changing the inflation target will always fix the zero lower bound problem, but it will have no real effects. And under the Friedman rule, the zero lower bound is never binding.

The two approaches are complementary. In the short-run prices may very well be sticky, markets segmented, and information imperfect. I abstract from these issues to focus on the underlying frictionless aspects of liquidity traps. The model in this paper can be regarded as the frictionless version of a richer model with short-run frictions. For example, in the model consumption is countercyclical in the very short-run, for well understood reasons. Importantly, this is not a model of short-run fluctuations, but rather of persistent slumps associated with liquidity traps.

The results in this paper have an important take-away for New Keynesian models of the zero lower bound. Introducing money into an economy doesn't just place a lower bound on interest rates - it also raises the natural interest rate. To the extent that the natural rate is positive the central bank will be able to reproduce the flexible-price equilibrium, hitting the inflation target and zero output gap, even if the economy is in a liquidity trap. But it may not be optimal. Investment is too depressed during a liquidity trap, so unless an investment subsidy is used to obtain the optimal allocation, reproducing the flexible-price allocation is suboptimal. I conjecture that stimulating investment with low interest rates may be the optimal monetary policy in that situation, but this is beyond the scope of this paper.

Other literature review. Buera and Nicolini (2014) provide a flexible-price model of the zero lower bound, based on borrowing constraints and lack of Ricardian equivalence. Aiyagari and McGrattan (1998) study the role of government debt in a model with uninsurable labor income and binding borrowing constraints. In contrast, here Ricardian equivalence holds (agents have the natural borrowing limit), the zero lower bound is not binding, and money is superneutral. Changing the amount of government debt can only affect the liquidity premium on government debt and other assets, but not the real side of the economy. Changing the inflation target raises nominal interest rates and fixes the zero lower bound problem, but doesn't have any real effects. It is easy to break Ricardian equivalence and superneutrality, but they are useful theoretical benchmarks that highlight that the real effects of money don't hinge on a fiscal side.

There is a large literature on risk or uncertainty shocks both in macro and finance. ${ }^{3}$ The setting here is closest to Di Tella (2017), who shows that risk shocks that increase idiosyncratic risk can help explain the concentration of aggregate risk on the balance sheets of financial intermediaries and create financial crises. Here I remove intermediaries and introduce money, and show that these

\footnotetext{
${ }^{3}$ Bloom (2009), Bloom et al. (2012), Campbell et al. (2001), Bansal and Yaron (2004), Bansal et al. (2014), Campbell et al. (2012), Christiano et al. (2014).
} 
risk shocks may also be responsible for liquidity traps. This may explain why liquidity traps and financial crises often appear together.

Cochrane (2011) highlights the role of time-varying risk premia in asset prices, and therefore investment. The driving force behind the liquidity trap in this paper is a time-varying idiosyncratic risk premium. But a high risk premium is not enough to depress investment. The real interest rate could drop enough to absorb the hit, leaving asset prices and investment unaffected. This paper provides a theory of why the equilibrium real interest rate will not drop enough, so that a high risk premium will be reflected in lower investment.

The liquidity premium is the focus of a large literature that micro-founds the role of money as a means of exchange in a search-theoretic framework. ${ }^{4}$ Here I use money in the utility function as a simple and transparent way to introduce money into the economy (I also solve a cash-in-advance version in the Appendix). The purpose of this paper is not to provide a new explanation for why people hold money in equilibrium, but rather to understand how money can produce liquidity traps and have real effects. However, a more micro-founded account of the liquidity premium can help understand how it is affected by aggregate shocks and policy interventions.

There is also a large literature modeling money as a bubble in the context of OLG or incomplete risk sharing models. ${ }^{5}$ The closest paper is Brunnermeier and Sannikov (2016b), who use a similar environment with incomplete idiosyncratic risk sharing to study the optimal inflation rate. ${ }^{6}$ An important contribution of that paper is to develop a version of the Bewley (1980) model of bubble money that is tractable and yields closed-form solutions. They find that countries with high risk should have a higher inflation rate. In contrast, here bubbles are ruled out, money is superneutral, and the focus is on how money can produce liquidity traps. ${ }^{7}$ I study some of the differences and similarities of the bubble and liquidity views of money and how they relate to the issue of liquidity traps in Section 5.

The contractual environment micro-founding the incomplete idiosyncratic risk sharing with a fund diversion problem with hidden trade is based on Di Tella and Sannikov (2016), who study a more general environment. ${ }^{8}$ Di Tella (2016) uses a similar contractual environment to study optimal financial regulation, but does not allow hidden savings or investment. Instead, it focuses on the externality produced by hidden trade in capital assets by financial intermediaries. That externality is absent in this paper because the price of capital is always one (capital and consumption goods can be transformed one-to-one).

\footnotetext{
${ }^{4}$ See Kiyotaki and Wright (1993), Lagos and Wright (2005), Aiyagari and Wallace (1991), Shi (1997).

${ }^{5}$ See Samuelson (1958), Bewley (1980), Diamond (1965), Tirole (1985), Asriyan et al. (2016), Santos and Woodford (1997)

${ }^{6}$ Brunnermeier and Sannikov (2016a) use a similar environment but focus on the role of financial intermediaries.

${ }^{7}$ In their model money is a bubble and is introduced proportionally to wealth, so higher inflation acts as a subsidy to saving. Here bubbles are explicitly ruled out and money is introduced in a lump-sum, non-distortionary way.

${ }^{8}$ Cole and Kocherlakota (2001) study an environment with hidden savings and risky exogenous income, and find that the optimal contract is risk-free debt. Here we also have risky investment.
} 


\section{Baseline model}

In this section I introduce the baseline stationary model. It's a simple AK growth model with money in the utility function and incomplete idiosyncratic risk sharing. The equilibrium is always a balanced growth path, and to keep things simple I will consider completely unexpected and permanent risk shocks that increase idiosyncratic risk (comparative statics across balanced growth paths). In Section 4 I will introduce the fully dynamic model with aggregate risk shocks.

\section{$2.1 \quad$ Setting}

The economy is populated by a continuum of agents with $\log$ preferences over consumption $c$ and real money $m \equiv M / p$

$$
U(c, m)=\mathbb{E}\left[\int_{0}^{\infty} e^{-\rho t}\left((1-\beta) \log c_{t}+\beta \log m_{t}\right) d t\right]
$$

Money and consumption enter separately, so money will be superneutral. Money in the utility function is a simple and transparent way of introducing money in the economy. ${ }^{9}$ As we'll see, what matters is that money has a liquidity premium.

Agents can continuously trade capital and use it to produce consumption $y_{t}=a k_{t}$, but it is exposed to idiosyncratic "quality of capital" shocks. The change in an agent's capital over a small period of time is

$$
d \Delta_{i, t}^{k}=k_{i, t} \sigma d W_{i, t}
$$

where $k_{i, t}$ is the agent's capital (a choice variable) and $W_{i, t}$ an idiosyncratic Brownian motion. Idiosyncratic risk $\sigma$ is a constant here, but we will look at comparative statics of the equilibrium with respect to changes in $\sigma$. This is meant to capture a shock that makes capital less attractive and drives up its risk premium. Later we will introduce a stochastic process for $\sigma$ and allow for aggregate shocks to $\sigma$.

Idiosyncratic risk washes away in the aggregate, so the aggregate capital stock $k_{t}$ evolves

$$
d k_{t}=\left(x_{t}-\delta k_{t}\right) d t
$$

where $x_{t}$ is investment. The aggregate resource constraint is

$$
c_{t}+x_{t}=a k_{t}
$$

where $c_{t}$ is aggregate consumption.

Money is printed by the government and transferred lump-sum to agents. In order to eliminate any fiscal policy, there are no taxes, government expenditures, or government debt; later I will introduce safe government debt and taxes. For now money is only currency, but later I will add

\footnotetext{
${ }^{9}$ In the Appendix I also solve the model with a cash-in-advance constraint and a more general CES utility function.
} 
deposits and liquid government bonds. The total money stock $M_{t}$ evolves

$$
\frac{d M_{t}}{M_{t}}=\mu_{M} d t
$$

The central bank chooses $\mu_{M}$ endogenously to deliver a target inflation rate $\pi$. This means that in a balanced growth path $\mu_{M}=\pi+$ growth rate.

Markets are incomplete in the sense that idiosyncratic risk cannot be shared. They are otherwise complete. Agents can continuously trade capital at equilibrium price $q_{t}=1$ (consumption goods can be transformed one-to-one into capital goods, and the other way around) and debt with real interest rate $r_{t}=i_{t}-\pi$, where $i_{t}$ is the nominal interest rate. There are no aggregate shocks for now; I will add them later and assume that markets are complete for aggregate shocks.

Total wealth is $w_{t}=k_{t}+m_{t}+h_{t}$, which includes the capitalized real value of future money transfers

$$
h_{t}=\int_{t}^{\infty} e^{-\int_{t}^{s} r_{u} d u} \frac{d M_{s}}{p_{s}}
$$

The dynamic budget constraint for an agent is ${ }^{10}$

$$
d w_{t}=\left(r_{t} w_{t}+k_{t} \alpha_{t}-c_{t}-m_{t} i_{t}\right) d t+k_{t} \sigma d W_{t}
$$

with solvency constraint $w_{t} \geq 0$, where $\alpha_{t} \equiv a-\delta-r_{t}$ is the excess return on capital. Each agent chooses a plan $(c, m, k)$ to maximize utility $U(c, m)$ subject to the budget constraint (4).

Remark. As in Brunnermeier and Sannikov (2016b) and Angeletos (2006), this setting has several features that make it very tractable and easy to solve in closed-form with pencil and paper. Uninsurable idiosyncratic risk comes from tradable capital, rather than non-tradable labor income. Together with homothetic preferences, this produces policy functions linear in wealth, which eliminate the need to keep track of the whole wealth distribution and yields closed-form expressions. ${ }^{11}$

\subsection{Balanced Growth Path Equilibrium}

A BGP equilibrium will be scale invariant to aggregate capital $k_{t}$, so we can normalize all variables by $k_{t}$; e.g. $\hat{m}_{t}=m_{t} / k_{t}$. A Balanced Growth Path Equilibrium consists of a real interest rate $r$, investment $\hat{x}$, and real money $\hat{m}$ satisfying

$$
\begin{array}{rr}
r=\rho+(\hat{x}-\delta)-\sigma_{c}^{2} & \text { Euler equation } \\
r=a-\delta-\sigma_{c} \sigma & \text { Asset Pricing }
\end{array}
$$

\footnotetext{
${ }^{10}$ This is equivalent to defining financial wealth $\tilde{w}_{t}=k_{t}+m_{t}+d_{t}$, where $d_{t}$ is risk-free debt (in zero net supply), and using the dynamic budget constraint $d \tilde{w}_{t}=\left(d_{t} r_{t}+k_{t}(a-\delta)-m_{t} \pi-c_{t}\right) d t+k_{t} \sigma d W_{t}$, and the natural debt limit is $\underline{\tilde{w}}_{t}=-h_{t}$, so that $\tilde{w}_{t} \geq \underline{\tilde{w}}_{t}$. This is equivalent to (4) with $w_{t}=\tilde{w}_{t}+h_{t} \geq 0$.

${ }^{11}$ Angeletos (2006) does not have money. Brunnermeier and Sannikov (2016b) develop a tractable version of the Bewley (1980) model of bubble money. They introduce money proportionally to wealth. Here bubbles are explicitly ruled out and money is introduced lump-sum. I discuss the similarities and differences between the bubble and liquidity views of money in Section 5.
} 


$$
\begin{array}{rrr}
\sigma_{c} & \equiv \frac{k_{t}}{k_{t}+m_{t}+h_{t}} \sigma=(1-\lambda) \sigma & \text { Risk Sharing } \\
\lambda & \equiv \frac{m_{t}+h_{t}}{k_{t}+m_{t}+h_{t}}=\frac{\rho \beta}{\rho-((1-\lambda) \sigma)^{2}} & \text { Value of Liquidity } \\
\hat{m} & =\frac{\beta}{1-\beta} \frac{a-\hat{x}}{r+\pi} & \text { Money }
\end{array}
$$

As well as $i=r+\pi>0$ and $r>(\hat{x}-\delta)$. These last conditions make sure money demand is well defined and rule out bubbles.

Equation (5) is the usual Euler equation. $\hat{x}-\delta$ is the growth rate of the economy and therefore consumption, and $\sigma_{c}^{2}$ is the precautionary saving motive. The more risky consumption is, the more agents prefer to postpone consumption and save. Equation (6) is an asset pricing equation for capital. Agents can choose to invest their savings in a risk-free bond (in zero net supply) and earn $r$, or in capital and earn the marginal product net of depreciation $a-\delta$. The last term $\alpha=\sigma_{c} \sigma$ is the risk premium on capital. Because the idiosyncratic risk in capital cannot be shared, agents will only invest in capital if it yields a premium to compensate them.

Equation (7) is agents' exposure to idiosyncratic risk. Because of homothetic preferences each agent consumes proportionally to his wealth, and his exposure to idiosyncratic risk comes from his investment in capital. In equilibrium, the portfolio weight on capital is $k_{t} / w_{t}=k_{t} /\left(k_{t}+m_{t}+h_{t}\right)=$ $(1-\lambda)$ where we define $\lambda \equiv\left(m_{t}+h_{t}\right) / w_{t}$ a s t he s hare of w ealth in m oney ( present a nd future). $\lambda$ captures the value of liquidity in the economy, and (8) gives us an equation for $\lambda$ in terms of parameters. Finally, (9) is an expression for real money balances. Because of the log preferences agents devote a fraction $\beta$ of expenditures to liquidity and $1-\beta$ to consumption. Using $i=r+\pi$ and the resource constraint (2), we obtain (9).

The BGP has a simple structure. We can solve (8) for $\lambda$, plug into (7) to obtain $\sigma_{c}$, then plug into (6) to obtain $r$, and plug into (5) to obtain $\hat{x}$. Finally, once we have the real part of the equilibrium, we use (9) to obtain $\hat{m}$.

The share of wealth in money $\lambda$ captures the value of liquidity in the economy, and plays a central role. Money provides a safe store of value that improves risk sharing, and it is worth the present value of expenditures on liquidity services. From the definition of $h$ we obtain after some algebra and using the No-Ponzi conditions, ${ }^{12}$

$$
m_{t}+h_{t}=m_{t}+\int_{t}^{\infty} e^{-r(s-t)} \frac{d M_{s}}{p_{s}}=\int_{t}^{\infty} e^{-r(s-t)} m_{s} i d s=\frac{m_{t} i}{r-(\hat{x}-\delta)}
$$

Because of log preferences, we get $m_{t} i=\rho \beta\left(k_{t}+m_{t}+h_{t}\right)$ which yields

$$
\lambda \equiv \frac{m_{t}+h_{t}}{k_{t}+m_{t}+h_{t}}=\frac{\rho \beta}{r-(\hat{x}-\delta)}
$$

Finally, use the Euler equation (5) and the definition of $\sigma_{c}$ in (7) to obtain (8).

\footnotetext{
${ }^{12}$ Write $m_{t}+\int_{t}^{\infty} e^{-r(s-t)} \frac{d M_{s}}{p_{s}}=m_{t}+\int_{t}^{\infty} e^{-r(s-t)} d m_{s}+\int_{t}^{\infty} e^{-r(s-t)} m_{s} \pi_{s} d s=\lim _{T \rightarrow \infty} e^{-r(T-t)} m_{T}+$ $\int_{t}^{\infty} e^{-r(s-t)} m_{s}\left(r_{s}+\pi_{s}\right) d s$, and use the No-Ponzi condition to eliminate the limit.
} 


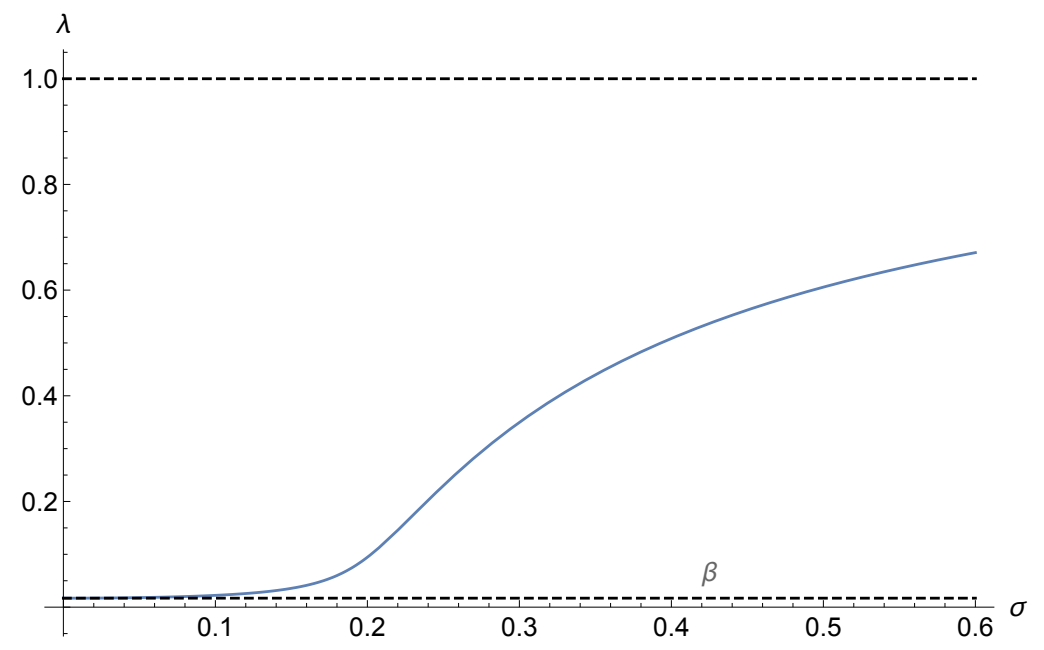

Figure 1: The value of liquidity $\lambda$ as a function of $\sigma$. Parameters: $a=1 / 10, \rho=4 \%, \pi=2 \%$, $\delta=1 \%, \beta=1.7 \%$.

How big is the value of liquidity $\lambda$ ? In normal times when the real interest rate is high relative to the growth rate of the economy, $r \gg \hat{x}-\delta$, the value of liquidity $\lambda$ is small, close to the expenditure share on liquidity services $\beta$. To fix ideas, use a conservative estimate of $\beta=1.7 \%$. ${ }^{13}$ But when the real interest rate $r$ is small relative to the growth rate of economy $\hat{x}-\delta$, the value of liquidity can be very large (in the limit $\lambda \rightarrow 1$ ). This happens when idiosyncratic risk $\sigma$ is large - while capital is discounted with a large risk premium, liquidity is discounted only with the risk-free rate, which must fall when idiosyncratic risk $\sigma$ is large. Figure 1 shows the non-linear behavior of $\lambda$ as a function of $\sigma$. This is an important insight - the value of liquidity may be small in normal times, but can become quite large during periods of low interest rates such as liquidity traps. ${ }^{14}$

Proposition 1. For any $\beta>0$, the value of liquidity $\lambda$ is increasing in idiosyncratic risk $\sigma$, and ranges from $\beta$ when $\sigma=0$ to 1 as $\sigma \rightarrow \infty$. Furthermore, idiosyncratic consumption risk $\sigma_{c}=(1-\lambda) \sigma$ is also increasing in $\sigma$, and ranges from 0 when $\sigma=0$ to $\sqrt{\rho(1-\beta)}$ when $\sigma \rightarrow \infty$. For $\beta=0$, $\lambda=0$.

\section{$2.3 \quad$ Non-monetary economy}

As a benchmark, consider a non-monetary economy where $\beta=0$. In this case, $\hat{m}=\hat{h}=0$ and therefore $\lambda=0$. The BGP equations simplify to $r=a-\delta-\sigma^{2}$ and $\hat{x}=a-\rho$.

Higher idiosyncratic risk $\sigma$, which makes investment less attractive, is fully absorbed by a lower real interest rate $r$ (and therefore lower nominal interest rate $i=r+\pi$ ), but a constant investment

\footnotetext{
${ }^{13}$ As Section 2.5 shows, $\beta$ is the expenditure on liquidity premium across all assets, including deposits and treasuries. Say checking and savings accounts make up $50 \%$ of gdp and have an average liquidity premium of $2 \%$. Krishnamurthy and Vissing-Jorgensen (2012) report expenditure on liquidity provided by treasuries of $0.25 \%$ of gdp. Consumption is $70 \%$ of gdp. This yields $\beta=1.7 \%$.

${ }^{14}$ It's worth stressing that the value of liquidity includes not only the value of money $m_{t}$, but also future money $h_{t}$. As Figure 2 shows, most of the value of liquidity is in the future, $h_{t}$.
} 

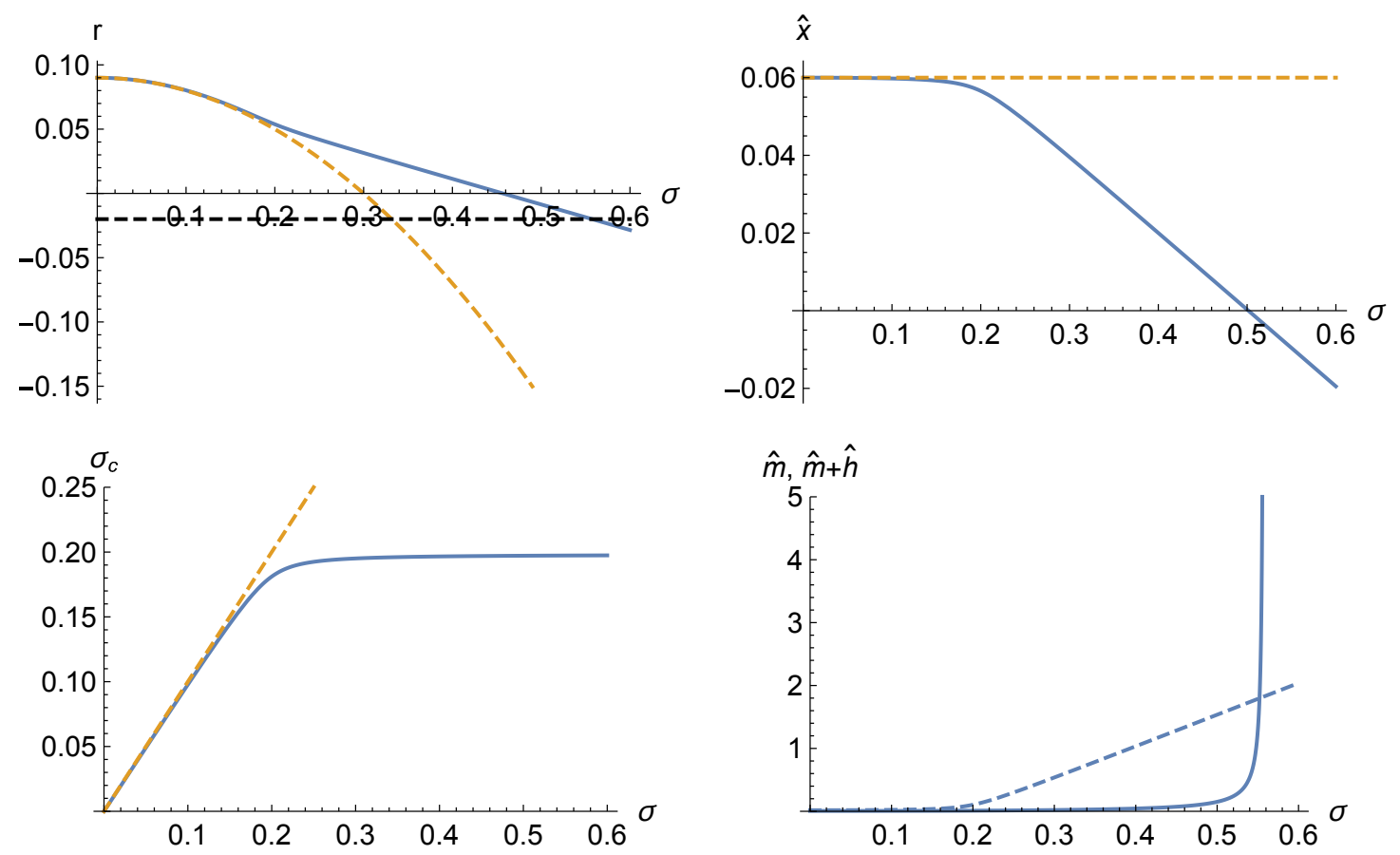

Figure 2: Real interest rate $r$, investment $\hat{x}$, idiosyncratic consumption risk $\sigma_{c}$, and monetary variables $\hat{m}$ (solid) and $\hat{m}+\hat{h}$ (dashed) as functions of idiosyncratic risk $\sigma$, in the non-monetary economy (dashed orange) and the monetary economy (solid blue). The lower bound on the real interest rate $-\pi$ is dashed in black. Parameters: $a=1 / 10, \rho=4 \%, \pi=2 \%, \delta=1 \%, \beta=1.7 \%$

rate $\hat{x}$ and growth $\hat{x}-\delta$. Figure 2 shows the equilibrium values of $r$ and $\hat{x}$ in a non-monetary economy for different $\sigma$ (dashed line).

Proposition 2. Without money $(\beta=0)$, after an increase in idiosyncratic risk $\sigma$ the real interest rate $r$ falls but investment $\hat{x}$ remains at the first-best level.

We can understand the response of the non-monetary economy to higher risk $\sigma$ in terms of the risk premium and the precautionary motive. Use the Euler equation (5) and asset pricing equation (6) to write

$$
\begin{gathered}
r=a-\delta-\underbrace{\sigma_{c} \sigma}_{\text {risk pr. }} \\
\hat{x}=\underbrace{a-\rho}_{\text {first best }}+\underbrace{\sigma_{c}^{2}}_{\text {prec. mot. }}-\underbrace{\sigma_{c} \sigma}_{\text {risk pr. }}=a-\rho
\end{gathered}
$$

Larger risk $\sigma$ makes capital less attractive, so the risk premium $\alpha=\sigma_{c} \sigma$ goes up. Other things equal this depresses investment. But with higher risk the precautionary saving motive $\sigma_{c}^{2}$ also becomes larger. Agents face more risk and therefore want to save more. Other things equal, this lowers the real interest rate and stimulates investment. Without money $\sigma_{c}=(1-\lambda) \sigma=\sigma$, so the precautionary motive and the risk premium cancel each other out and we get the first best level of investment $\hat{x}=a-\rho$ for any level of idiosyncratic risk $\sigma$ (this doesn't mean that this level of investment is optimal with $\sigma>0$ ). 
This is a well known feature of preferences with intertemporal elasticity of one (in the Appendix I solve the model with general Epstein-Zin preferences). ${ }^{15}$ For our purposes, it provides a clean and quantitatively relevant benchmark where higher idiosyncratic risk that makes investment less attractive is completely absorbed by lower real interest rates which completely stabilize investment. But notice in Figure 2 that the real interest rate $r$ could become very negative; in particular, we may need $r \leq \hat{x}-\delta$. This is not a problem without money because capital is risky, but it will be once we introduce money, which is safe, because its value would blow up if $r \leq \hat{x}-\delta$.

\subsection{Monetary economy}

Now consider the monetary economy with $\beta>0$, also shown in Figure 2. Money has large real effects. When $\sigma$ goes up, money prevents the real interest rate $r$ from falling as much as in the non-monetary economy. Instead, investment $\hat{x}$ falls and the economy enters a persistent slump. ${ }^{16}$ In particular, without money the real interest rate could be very negative for high $\sigma$, but with money it must remain above the growth rate of the economy.

The value of liquidity $\lambda$ captures the real effects of money. There are two steps: (i) money serves as a safe store of value and improves risk sharing, so a large value of liquidity $\lambda$ keeps the real interest high relative to the non-monetary economy and depresses investment; and (ii) the value of liquidity $\lambda$ endogenously rises during downturns when $\sigma$ is high. The result is a liquidity trap - the real interest rate doesn't fall as much as it would without money, and investment falls instead.

To understand step (i) use the Euler equation (5), the asset pricing equation (6), and the risk sharing equation (7) to obtain an expression for $r$ and $\hat{x}$ in terms of $\sigma$ and $\lambda$ :

$$
\begin{gathered}
r=a-\delta-\underbrace{(1-\lambda) \sigma^{2}}_{\text {risk pr. }} \\
\hat{x}=\underbrace{a-\rho}_{\text {first best }}+\underbrace{(1-\lambda)^{2} \sigma^{2}}_{\text {prec. mot. }}-\underbrace{(1-\lambda) \sigma^{2}}_{\text {risk pr. }}=a-\rho-\rho \frac{\lambda-\beta}{1-\lambda}
\end{gathered}
$$

Expressions (14) and (15) show that a larger value of liquidity $\lambda$ raises the real interest rate and depresses investment. What is going on is that a large value of liquidity $\lambda$ improves idiosyncratic risk sharing, $\sigma_{c}=(1-\lambda) \sigma$. Essentially, agents with bad shocks sell part of their money holdings to buy more capital and consumption goods from agents with good shocks. As a result, the volatility in their consumption and capital is smaller. Better risk sharing dampens both the risk premium $\sigma_{c} \sigma$ (raising $r$ ) and the precautionary saving motive $\sigma_{c}^{2}$-but crucially, it dampens the precautionary motive more. Intuitively, the risk premium comes from the risk of a marginal increase in capital

\footnotetext{
${ }^{15}$ Although the real interest rate $r$ always falls with higher risk $\sigma$, without money investment $\hat{x}$ may go up or down depending on whether intertemporal elasticity is lower or higher than one. But for relevant parameter values the role of money is the same as in the baseline model with log preferences: it prevents interest rates from falling during downturns and depresses investment relative to the non-monetary economy, producing a liquidity trap.

${ }^{16}$ Since output is fixed in the short-run, lower investment implies higher consumption. This is a well understood feature of this simple environment. This is not a model of high-frequency business cycles; it's a model of persistent slumps produced by liquidity traps.
} 
holdings, while the precautionary motive comes from the average risk in an agent's portfolio, that now includes safe money. Money creates a wedge between the marginal and average risk that weakens the precautionary motive relative to the risk premium. Since the risk premium reduces investment and the precautionary motive increases it, a large value of liquidity $\lambda$ depresses investment.

To understand step (ii), notice that the value of liquidity $\lambda$ grows during downturns with high $\sigma$, as shown in Figure 1. The value of liquidity $\lambda$ is equal to the present value of expenditures on liquidity services, as expression (11) indicates. When idiosyncratic risk $\sigma$ rises, the real interest rate falls relative to the growth rate of the economy because the precautionary motive rises (see the Euler equation (5)), so this present value becomes very large. It's important to stress that the value of liquidity $\lambda$ includes not only current real money balances $m$ but also future money $h$. As Figure 2 shows, most of the value of liquidity is in the future, $h$.

Incomplete idiosyncratic risk sharing is essential to the mechanism. If risk sharing is perfect or if there is no idiosyncratic risk, $\sigma=0$, the monetary economy behaves exactly like the non-monetary one (classical dichotomy). During normal times when idiosyncratic risk $\sigma$ is small, the role of money is small and can be safely ignored. But it can become very large during periods of high idiosyncratic risk.

Proposition 3. With money $(\beta>0)$ after an increase in idiosyncratic risk $\sigma$ the real interest rate $r$ falls less than in the economy without money $(\beta=0)$, and investment $\hat{x}$ falls instead, while the value of liquidity $\lambda$ and real money balances $\hat{m}$ increase with $\sigma$.

(Classical Dichotomy) If $\sigma=0$, the real interest rate $r$ and investment $\hat{x}$ are the same in the monetary and non-monetary economies, even though $\lambda=\beta>0$.

It is tempting to interpret the depressed investment as substitution from risky capital to safe money as a savings device; i.e., when capital becomes more risky, it is more attractive to invest in the safe asset. But this is misleading because the economy cannot really invest in money. Goods can be either consumed or accumulated as capital - money is not a substitute for investment in risky capital. What money does is improve how the idiosyncratic risk in capital is shared. Agents with bad shocks use part of their money holdings to buy more capital from those with good shocks. ${ }^{17}$ As a result of this risk sharing, the economy substitutes along the consumption-investment margin. To drive home this point, notice that in a model with risky and safe capital (but no money), an increase in risk will typically reduce risky investment but increase the safe one. Money depresses all investment, which is an important feature of liquidity traps. ${ }^{18}$

It's worth pointing out that because output is fixed in the very short run by the AK technology, consumption is negatively correlated with investment in the short run. Over time as the economy shifts to a BGP with lower investment and growth, the correlation becomes positive. This is not a model of short-run fluctuations, but rather of persistent slumps. In the short-run nominal rigidities, segmented markets, or informational frictions can play an important part.

\footnotetext{
${ }^{17}$ They are not self-insuring in autarky by holding a less risky form of capital. They are sharing idiosyncratic risk.

${ }^{18}$ The liquidity trap is essentially about an intertemporal wedge. From the point of view of a frictionless model, investment is too low.
} 
Superneutrality and the zero lower bound. While the presence of money has very large real effects, money is still neutral and superneutral. Doubling the amount of money would just double prices, leaving all real variables unaffected. Demand for money $\hat{m}$ grows during liquidity traps as the nominal interest rate $i=r+\pi$ falls. A central bank that targets inflation must increase the money supply endogenously to keep prices on path. If it didn't, prices would fall, but the real allocation wouldn't change. The inflation target itself doesn't affect any real variable except real money holdings $m$. It simply does not appear in equations (14), (15), and (8). As a result, the optimal inflation target is given by the Friedman rule, $i=r+\pi \approx 0$. It maximizes agents' utility from money $m$ without affecting any other real variable.

It is easy to break the superneutrality, but it is a useful theoretical benchmark that highlights that the liquidity trap does not hinge on violating money neutrality and superneutrality. ${ }^{19}$ Here super-neutrality comes from log preferences, which imply a demand elasticity of money of one. Recall that the value of liquidity is equal to the present value of expenditures on liquidity services $m \times i$. With log preferences a higher nominal interest rate $i$ reduces real money holdings $m$ proportionally, so that $m \times i$ doesn't change. As a result, $\lambda$ is not affected and neither is any real variable. ${ }^{20}$

In contrast to New Keynesian models with nominal rigidities, the zero lower bound on the nominal interest rate, $i=r+\pi \geq 0$, doesn't really play any essential role in the liquidity trap. The liquidity trap is a gradual phenomenon, and real effects of money grow as the value of liquidity rises. While the presence of money creates this lower bound on interest rates, it also raises the equilibrium interest rate so that the zero lower bound is not binding. As Figure 2 shows, the zero lower bound is not binding except for very large levels of idiosyncratic risk $\sigma{ }^{21}$ When the zero lower bound is binding, the central bank is simply unable to deliver the promised inflation target. But the focus and contribution of this paper is the wide parameter region where the zero lower bound is not binding, and yet we have a liquidity trap. What's more, since money is superneutral, changing the inflation target will always "fix" the zero lower bound problem, but it will have no effects on the real side of the liquidity trap. In fact, under the optimal monetary policy, $i \approx 0$, the zero lower bound is never a problem.

\subsection{Understanding the mechanism}

Is the liquidity trap really about money, or is it actually about safe assets? Here I'll show that it's about safe assets with a liquidity premium. Agents can trade risk-free debt, but it doesn't produce a liquidity trap. Neither does a diversified (safe) equity index. We can also add safe government debt and deposits. They only produce a liquidity trap to the extent that they have a liquidity premium.

To understand the role of the liquidity premium, notice that safe assets without a liquidity

\footnotetext{
${ }^{19}$ In the Appendix I solve the model with a) a CES demand structure for money and b) a cash-in-advance constraint. In both cases inflation targets have real effects because the expenditure share on liquidity services depends on the nominal interest rate.

${ }^{20}$ This may seem puzzling at first. How can $m$ fall but $\lambda$ remain constant? Recall that $\lambda=(m+h) /(k+m+h)$ includes not only current real money balances $m$, but also future money $h$. As we change the inflation target and $i$, $m$ and $h$ move in opposite directions.

${ }^{21}$ Of course, this depends on the inflation target $\pi$. If $\pi$ is sufficiently negative the ZLB will be binding for all $\sigma$.
} 
premium must be backed by payments with the same present value. Agents may hold the safe assets, but they are also directly or indirectly responsible for the payments backing them. The net value is zero, so they cannot function as a safe store of value. In contrast, assets with a liquidity premium have a value greater than the present value of payments backing them. The difference is the present value of the liquidity premium. This is what makes them a store of value that can improve idiosyncratic risk sharing. Essentially, agents with a bad shock can sell part of their liquid assets to agents with a good shock to reduce the volatility of their consumption. And the net value of these safe liquid assets increases dramatically when the real interest rate becomes very low. This is the origin of liquidity traps.

Money, and safe liquid assets more generally, are special because they are both i) safe, and ii) have positive net value because they have a liquidity premium. This allows them to serve as a store of value that improves risk sharing and creates a liquidity trap. There are many assets that have positive net value, such as capital, housing, or land. But the starting point in this paper is that real investments are risky, and risk sharing is incomplete. For example, an agent can buy a particular plot of land, whose value has significant idiosyncratic risk that can't be fully shared. There are also many safe financial assets, such as AAA corporate debt. But since they don't have a liquidity premium, their net value is zero and they don't produce liquidity traps.

It's worth stressing that this is a general equilibrium mechanism. The only reason agents hold money is because it provides liquidity services. From an agent's point of view, risk-free bonds are just as good as a store of value for risk sharing purposes, and they pay interest on top. But agents can't all hold risk-free bonds as a safe store of value. Someone must take the other side and issue risk-free debt. In general equilibrium the real interest rate adjusts to ensure this. Money, and safe liquid assets, have positive net value, so they can improve idiosyncratic risk sharing in general equilibruim.

How does money improve risk sharing? To understand how money improves risk sharing, integrate an individual agent $i$ 's dynamic budget constraint (4) to obtain ${ }^{22}$

$$
\mathbb{E}^{\tilde{Q}}\left[\int_{0}^{\infty} e^{-\int_{0}^{t} r_{u} d u}\left(c_{i t}+m_{i t} i_{t}\right) d t\right] \leq w_{0}=k_{0}+\int_{0}^{\infty} e^{-\int_{0}^{t} r_{u} d u} m_{t} i_{t} d t
$$

Here for simplicity I assume every agent owns an equal part of the aggregate endowment of capital and money. On the left hand side we have the present value of his expenditures on consumption goods and money services. On the right hand side we have the aggregate wealth in the economy, $k_{0}+m_{0}+h_{0}$. The left hand side is evaluated with an equivalent martingale measure $\tilde{Q}$ that captures the market incompleteness; i.e. such that $W_{i t}+\int_{0}^{t}\left(\alpha_{u} / \sigma\right) d u$ is a martingale. A risky consumption plan costs less because it can be dynamically supported with risky investment in capital that yields an excess return $\alpha$. The endowment of money on the rhs is safe, however.

With perfect risk sharing, $\sigma=0$, we have $\alpha_{t}=0$, so market clearing $\int m_{i t} d i=m_{t}$ means

\footnotetext{
${ }^{22}$ The intertemporal budget constraint (16) is equivalent to the dynamic budget constraint (4) with incomplete risk sharing if shorting capital $k_{t}<0$ is allowed. This is not required in equilibrium of course.
} 
that money drops out of the budget constraint in equilibrium; i.e. $\mathbb{E}^{\tilde{Q}}\left[\int_{0}^{\infty} e^{-\int_{0}^{t} r_{u} d u} m_{i t} i_{t} d t\right]=$ $\int_{0}^{\infty} e^{-\int_{0}^{t} r_{u} d u} m_{t} i_{t} d t$. Money is worth more than the payments backing it because it has a liquidity premium (that's why it appears on the rhs), but agents spend on holding money exactly that amount, so it cancels out of the budget constraint and has no effects on the equilibrium.

But if idiosyncratic risk sharing is imperfect, the excess return then is positive, $\alpha_{t}>0$. Then even if in equilibrium agents must hold all the money, $\int m_{i t} d i=m_{t}$, the present value of expenditures on money services under $\tilde{Q}$ is less than the value of the endowment of money services (which is not risky), $\mathbb{E}^{\tilde{Q}}\left[\int_{0}^{\infty} e^{-\int_{0}^{t} r_{u} d u} m_{i t} i_{t} d t\right]<\int_{0}^{\infty} e^{-\int_{0}^{t} r_{u} d u} m_{t} i_{t} d t$. As a result, money does not drop out of the budget constraint, and they can use the extra value to reduce the risk in their consumption $c_{i t}$.

To make this clear, agents could choose safe money holdings $m_{i t}=m_{t}$ if they wanted, in which case money would indeed drop out. This corresponds to never trading any money; just holding their endowment. But they are better off trading their money contingent on the realization of their idiosyncratic shocks. They get a risky consumption of money services $m_{i}$, but reduce the risk in their consumption $c_{i}$. So an agent with a bad idiosyncratic shock in his risky capital can sell part of his money to an agent with a good idiosyncratic shock. Both are better off. The agent with a bad shock gets more consumption and capital than without trading, but less money; the agent with the good shock less consumption and capital, but more money.

Government debt, deposits, and Ricardian equivalence. Now let's introduce safe government debt and bank-issued deposits. Both may have a liquidity premium. ${ }^{23}$ The bottom line is that government debt and deposits only produce a liquidity trap if they have a liquidity premium.

Let $b_{t}$ be the real value of government debt, and $d \tau$ lump-sum taxes. The government's budget constraint is ${ }^{24}$

$$
\begin{gathered}
d b_{t}=b_{t}\left(i_{t}^{b}-\pi\right) d t-d \tau_{t}-\frac{d M_{t}}{p_{t}} \\
d m_{t}=\frac{d M_{t}}{p_{t}}-\pi m_{t} d t
\end{gathered}
$$

where $i_{t}^{b}$ is the nominal interest rate on government bonds; I allow for the possibility that $i_{t}^{b}<i_{t}$ so that government debt also has a liquidity premium. The government has a no-Ponzi constraint $\lim _{T \rightarrow \infty} e^{-\int_{0}^{T} r_{s} d s}\left(b_{T}+m_{T}\right)=0$. Integrating both equations we obtain

$$
m_{t}+b_{t}=\int_{t}^{\infty} e^{-\int_{t}^{s} r_{u} d u}\left(m_{s} i_{s}+b_{s}\left(i_{s}-i_{s}^{b}\right)\right) d s+\int_{t}^{\infty} e^{-\int_{t}^{s} r_{u} d u} d \tau_{s}
$$

The government's total debt is $b_{t}+m_{t}$, and it must cover it with the present value of future taxes plus what it will receive because its liabilities $b_{t}$ and $m_{t}$ provide liquidity services. When agents hold money, they are effectively paying the government $m_{t} i_{t}$ for its liquidity services (the forgone interest); when they hold government debt they are paying $b_{t}\left(i_{t}-i_{t}^{b}\right)$. In particular, if government

\footnotetext{
${ }^{23}$ Krishnamurthy and Vissing-Jorgensen (2012) show that US Treasuries have a liquidity or convenience yield over equally safe private debt.

${ }^{24}$ In the baseline model without government debt, we have $b_{t}=0$ and $d \tau_{t}=d M_{t} / p_{t}$.
} 
debt is as liquid as money, $i_{t}^{b}=0$, the only thing that matters is the sum $\left(m_{t}+b_{t}\right) i_{t}$.

There are also banks that can issue deposits $d_{t}$ that pay interest $i_{t}^{d}<i_{t}$. Banks are owned by households. The net worth of a bank is $n_{t}$ and follows the dynamic budget constraint

$$
d n_{t}=n_{t} r_{t}+d_{t}\left(i_{t}-i_{t}^{d}\right) d t-d f_{t}
$$

where $f_{t}$ are the cumulative dividend payments to shareholders. The bank earns a profit from the spread between the interest it pays on deposits $i_{t}^{d}$ and the interest rate at which it can invest, $i_{t}$. Using the transversality condition $\lim _{T \rightarrow \infty} e^{-r T} n_{T}=0$ we can price the bank at $v_{t}:{ }^{25}$

$$
v_{t}=n_{t}+\int_{t}^{\infty} e^{-\int_{t}^{s} r_{u} d u} d_{s}\left(i_{s}-i_{s}^{d}\right) d s
$$

The market value of the bank includes its net worth today, plus the present value of profits from the interest rate spread on deposits, $d_{t}\left(i_{t}-i_{t}^{d}\right)$.

Total wealth is $w_{t}=\left(k_{t}-a_{t}\right)+d_{t}+v_{t}+m_{t}+\left(b_{t}-\int_{t}^{\infty} e^{-\int_{t}^{s} r_{u} d u} d \tau_{s}\right)$, where $a_{t}$ is the bank's assets. Households own all the capital, money, and government debt (minus the present value of taxes), except for whatever assets the bank holds. They also hold bank debt (deposits) $d_{t}$, and bank equity $v_{t}$ (so they indirectly own the assets that the bank owns). Since the bank's net worth is $n_{t}=a_{t}-d_{t}$, we have $v_{t}+d_{t}-a_{t}=v_{t}-n_{t}=\int_{t}^{\infty} e^{-\int_{t}^{s} r_{u} d u} d_{s}\left(i_{s}-i_{s}^{d}\right) d s$. And $m_{t}+b_{t}-\int_{t}^{\infty} e^{-\int_{t}^{s} r_{u} d u} d \tau_{s}=\int_{t}^{\infty} e^{-\int_{t}^{s} r_{u} d u}\left(m_{s} i_{s}+b_{s}\left(i_{s}-i_{s}^{b}\right)\right) d s$. So total wealth is

$$
w_{t}=k_{t}+\int_{t}^{\infty} e^{-\int_{t}^{s} r_{u} d u}\left(m_{s} i_{s}+b_{s}\left(i_{s}-i_{s}^{b}\right)+d_{s}\left(i_{s}-i_{s}^{d}\right)\right) d s
$$

Total wealth is capital plus the present value of expenditures on liquidity services, which now include money, liquid government bonds, and deposits (each weighted by its corresponding liquidity premium). Government debt and deposits therefore only have an effect to the extent that they have a liquidity premium. Safe government or private debt without a liquidity premium cancels out and has no effects.

The corresponding expression for $\lambda$ is

$$
\lambda=\frac{m_{t} i+b_{t}\left(i-i^{b}\right)+d_{t}\left(i-i^{d}\right)}{r-(\hat{x}-\delta)} \frac{1}{w_{t}}=\frac{\rho \beta}{r-(\hat{x}-\delta)}
$$

where $\beta$ should be interpreted as the expenditure share on liquidity services across all assets, $\beta=$ $\left(m_{t} i+b_{t}\left(i-i^{b}\right)+d_{t}\left(i-i^{d}\right)\right) /$ total expenditure. In the special case without deposits or government debt we recover expression (11).

The easiest way to introduce government debt and deposits with a liquidity premium is to put

\footnotetext{
${ }^{25}$ Write $n_{t}=\int_{t}^{\infty} e^{-\int_{t}^{s} r_{u} d u} d f_{s}-\int_{t}^{\infty} e^{-\int_{t}^{s} r_{u}} d u d_{s}\left(i_{s}-i_{s}^{d}\right) d s+\lim _{T \rightarrow \infty} e^{-r T} n_{T}$, and use $v_{t}=\int_{t}^{\infty} e^{-\int_{t}^{s} r_{u} d u} d f_{s}$ to obtain $v_{t}=n_{t}+\int_{t}^{\infty} e^{-\int_{t}^{s} r_{u} d u} d_{s}\left(i_{s}-i_{s}^{d}\right) d s$.
} 
them into the utility function

$$
(1-\beta) \log \left(c_{t}\right)+\beta \log (A(m, b, d))
$$

where $A(m, b, d)$ is an homogenous aggregator. Agents will devote a fraction $\beta$ of expenditures to the liquid aggregate, $\beta=\left(m_{t} i+b_{t}\left(i-i^{b}\right)+d_{t}\left(i-i^{d}\right)\right) /$ total expenditures. As a result, we don't need to change anything in our baseline model. We just need to reinterpret $\beta$ as the fraction of expenditures on liquidity services across all assets. ${ }^{26}$

Ricardian equivalence holds in this economy. If government debt doesn't have a liquidity premium, changing $b_{t}$ (and adjusting taxes to service this debt) has no effects on the economy. If government debt has a liquidity premium, then changing $b_{t}$ can have an effect on the liquidity premium of government debt and perhaps other assets as well. But it will not have any effect on the real side of the economy.

Proposition 4. (Ricardian Equivalence) With log preferences for liquidity, changes in government debt $b_{t}$ have no effects on the real interest rate $r$, investment $\hat{x}$, or the value of liquidity $\lambda$. Changes in $b$ can only affect the liquidity premiums of different assets.

To see this, notice that the expenditure share on liquidity services across all assets is a constant, $\beta$, and this is the only way that liquid government debt can affect the economy. For example, if the liquidity aggregator is Cobb-Douglas, $A(m, b, d)=m^{\epsilon_{m}} b^{\epsilon_{b}} d^{\epsilon_{d}}$ with $\epsilon_{m}+\epsilon_{b}+\epsilon_{d}=1$, then the expenditure share on liquidity services from each asset class is fixed; e.g. $b_{t}\left(i-i^{b}\right)$ /expenditures $=$ $\epsilon_{b} \beta$. Changing $b_{t}$ only affects the liquidity premium on government bonds, but not on deposits or money.

As with superneutrality, Ricardian equivalence can be broken here if we move away from the log utility over liquidity (see Appendix for CES and cash-in-advance formulations). But it's a useful theoretical benchmark that shows that the liquidity trap does not hinge on violating Ricardian equivalence.

Equity markets. But what about equity markets? The starting point in this paper is that capital is risky, and idiosyncratic risk sharing is incomplete. But if agents can hold a diversified (safe) market index, can this function as a safe store of value and produce a liquidity trap? Here I'll show that while issuing equity improves risk sharing, it does not produce a liquidity trap.

In the baseline model agents cannot issue any equity. Let's say instead that they must retain a fraction $\phi \in(0,1)$ of the equity, and can sell the rest to outside investors. Issuing outside equity improves idiosyncratic risk sharing, of course. Outside investors can fully diversify across all agents' equity, creating a safe market index worth $(1-\phi) k_{t}$. If agents could sell all the equity, $\phi=0$, we would obtain the first best with perfect risk sharing; with $\phi>0$ we have incomplete idiosyncratic risk sharing.

\footnotetext{
${ }^{26}$ With $i_{t}-i_{t}^{d}>0$ banks have incentives to supply as much deposits as possible. I'm not providing a theory of what limits them (perhaps capital requirements), but it doesn't matter. Regardless of how we fill in the details of how banks operate, the expenditure share on liquidity services across all assets will be $\beta$.
} 
Since agents can finance an extra unit of capital partly with outside equity, the effective risk of capital for an agent is $\phi \sigma$. In fact, we can obtain the competitive equilibrium by replacing $\sigma$ by $\phi \sigma$ in (5)-(9). The dynamic budget constraint is now ${ }^{27}$

$$
d w_{t}=\left(r_{t} w_{t}+k_{t} \alpha_{t}-c_{t}-m_{t} i_{t}\right) d t+k_{t} \phi \sigma d W_{t}
$$

The risk premium is $\alpha_{t}=\sigma_{c}(\phi \sigma)$, and the volatility of consumption is $\sigma_{c}=k_{t} /\left(k_{t}+m_{t}+h_{t}\right) \times(\phi \sigma)=$ $(1-\lambda)(\phi \sigma)$. The value of liquidity is given by $\lambda=\frac{\rho \beta}{\rho-((1-\lambda) \phi \sigma)^{2}}$.

But while equity improves risk sharing, it does not produce a liquidity trap. In particular, without money, $\beta=0$, an increase in idiosyncratic risk $\sigma$ is fully absorbed by lower real interest rates $r=a-\delta-(\phi \sigma)^{2}$, but investment remains at the first best $\hat{x}=a-\rho$. The reason is that issuing equity improves risk sharing in a way that affects the marginal risk from an extra unit of capital and the average risk in agent's portfolio equally. As a result, it dampens the risk premium $\sigma_{c} \phi \sigma=(\phi \sigma)^{2}$ and the precautionary motives $\sigma_{c}^{2}=(\phi \sigma)^{2}$ equally, canceling out. And the value of equity is backed by the firm's assets, so it's not a positive net value. The aggregate wealth in the economy is still given by the right hand side of (16), but the total value of capital is split into inside and outside equity $k_{t}=\phi k_{t}+(1-\phi) k_{t}{ }^{28}$ In particular, the value of the market index does not blow up to infinity as $r$ approaches the growth rate $\hat{x}-\delta$, as the value of liquidity does. ${ }^{29}$

Cashless limit. The liquidity trap does not hinge on a large expenditure share on liquidity services $\beta$-it survives even in the cashless limit $\beta \rightarrow 0$. As explained in Section 2.2, the value of money $\lambda$ is the present value of expenditures on liquidity discounted at the risk-free rate. When the real interest rate is high relative to the growth rate of the economy, $\lambda$ is small; close to the expenditure share on liquidity services $\beta$. But when the real interest rate is very close to the growth rate of the economy, $\lambda$ can become very large regardless of how small $\beta$ is. This can be seen very clearly in equation (11). It's all about the denominator.

So if we take the cashless limit, $\beta \rightarrow 0$, the competitive equilibrium will not always converge to that of the non-monetary economy with $\beta=0$. For $\sigma$ such that in the non-monetary economy the real interest rate is above the growth rate, the monetary economy will indeed converge to the non-monetary one as $\beta \rightarrow 0$. But for $\sigma$ such that in the non-monetary economy the real interest rate is equal or below the growth rate of the economy, this cannot happen. As the real interest rate drops and approaches the growth rate of the economy, the value of liquidity $\lambda$ blows up to keep $r$ above $\hat{x}-\delta$, no matter how small $\beta$ is. As a result, we get a liquidity trap even in the cashless limit

\footnotetext{
${ }^{27}$ Equity can be diversified so its return must be $r$. In equilibrium agents are holding $w_{t}=n_{t}+m_{t}+h_{t}+e_{t}$ where $n_{t}=\phi k_{t}$ is the inside equity in their firm that they retain, and $e_{t}=(1-\phi) k_{t}$ is the diversified outside equity in other agents' firms. Total equity $n_{t}+e_{t}=k_{t}$; since there are no adjustment costs, Tobin's q is 1 here. Both inside and outside equity yield $r$, but the inside equity has idiosyncratic risk (outside equity also has id. risk but it gets diversified). Agents therefore also get a wage or bonus as CEO of their firm to compensate them for the undiversified idiosyncratic risk, $k_{t} \alpha_{t}$.

${ }^{28}$ More generally, if firms use debt, $k_{t}=n_{t}+e_{t}+d_{t}$, where $n_{t}$ is inside equity, $e_{t}$ is outside equity, and $d_{t}$ is debt. All the financial claims on firms add up to the value of their assets.

${ }^{29}$ Total equity is always worth total capital, whose price takes into account its uninsurable idiosyncratic risk. As $\sigma$ grows and $r$ drops, insider wages or bonuses $\alpha k_{t}$ increase to compensate for the idiosyncratic risk.
} 

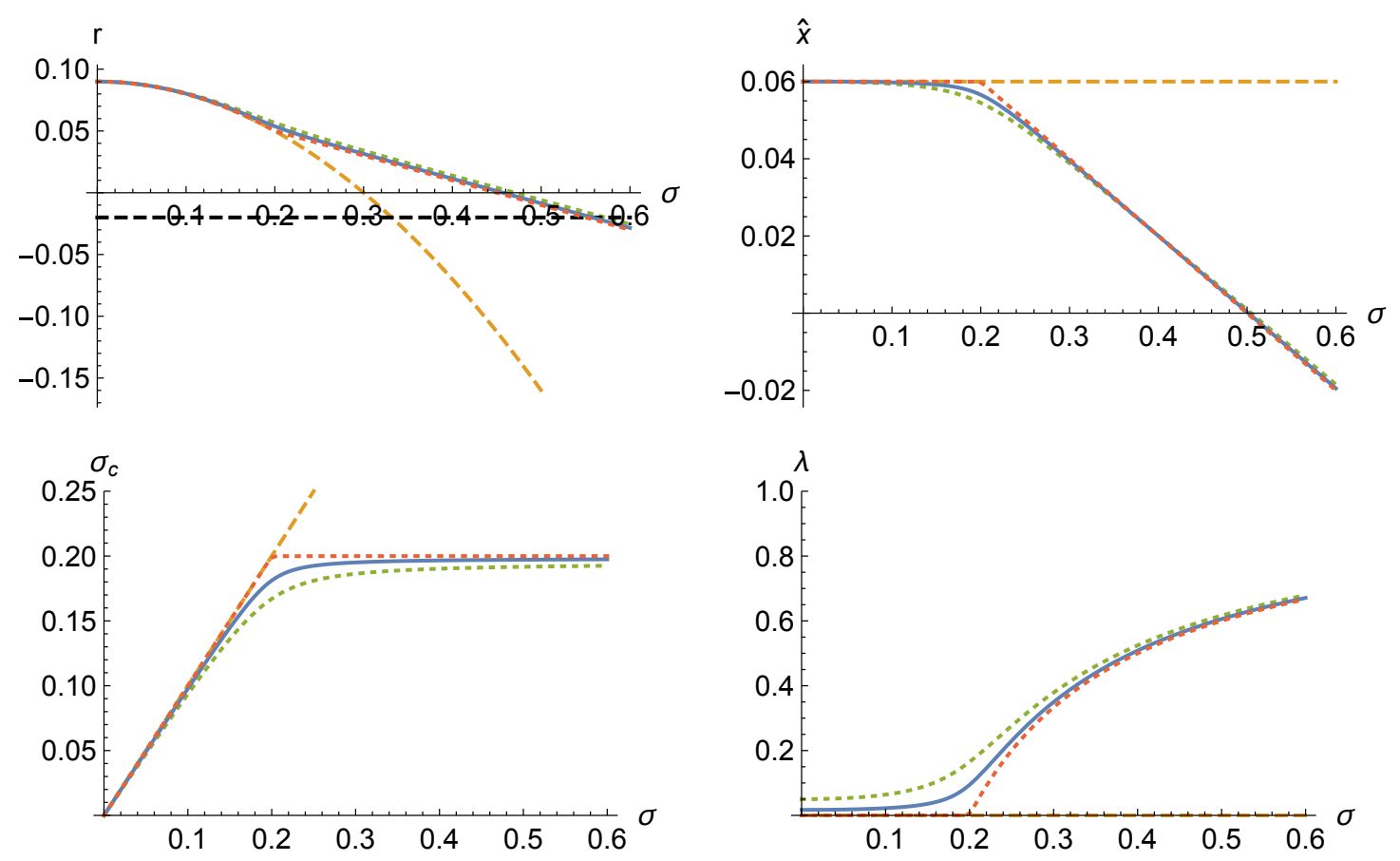

Figure 3: (Cashless limit) The real interest rate $r$, investment $\hat{x}$, idiosyncratic consumption risk $\sigma_{c}$, and value of liquidity $\lambda$ as function of $\sigma$, for $\beta=5 \%$ (dotted green), $\beta=1.7 \%$ (solid blue-baseline case), $\beta=0.01 \%$ (dotted red), and $\beta=0$ (dashed orange -non-monetary economy). Other parameters: $a=1 / 10, \rho=4 \%, \pi=2 \%, \delta=1 \%$.

$\beta \rightarrow 0$, with high interests rates and depressed investment relative to the non-monetary economy. Figure 3 shows the convergence to the cashless limit.

Proposition 5. If $\sigma<\sqrt{\rho}$ then as $\beta \rightarrow 0$ the competitive equilibrium converges to that of a nonmonetary economy with $\beta=0$. But if $\sigma \geq \sqrt{\rho}$ the liquidity trap survives even in the cashless limit $\beta \rightarrow 0$. The real interest rate is high and investment low relative to the non-monetary economy with $\beta=0$.

It is important to make sure we are not violating any Ponzi conditions. Proposition 1 ensures that $\sigma_{c}^{2}=((1-\lambda) \sigma)^{2}<\rho$ for all $\sigma$ and any $\beta>0$, so the Euler equation (5) guarantees that $r>\hat{x}-\delta$. But what happens if $\beta=0$ ? Then the only value of $\lambda$ that satisfies the No-Ponzi condition is $\lambda=0$. If $\sigma \geq \sqrt{\rho}$ the limit of the monetary equilibrium as $\beta \rightarrow 0$ would be an equilibrium of the non-monetary economy with $\beta=0$ except for the No-Ponzi conditions. In other words, the monetary economy, which cannot have bubbles, converges to a bubbly equilibrium of the non-monetary economy. I will discuss the link with bubbles in detail in Section 5.

Alternative specifications of money demand: CES and cash-in-advance. The cashless limit also shows that the liquidity trap does not hinge on log preferences with a constant expenditure share on liquidity services $\beta$. In the Appendix I solve the model with CES preferences and demand elasticity of money $\eta<1$, and with a cash-in-advance constraint. In both cases, the only 
modification is that the expenditure share on liquidity services $\tilde{\beta}(i)$ becomes a function of the nominal interest rate, with $\tilde{\beta}(i) \rightarrow 0$ as $i \rightarrow 0$. I show that the liquidity trap survives in these settings. Even if we lower the inflation target to reduce the nominal interest rate $i \rightarrow 0$, the liquidity trap survives, essentially for the same reason as in the cashless limit. ${ }^{30}$

An analogy with a safe tree. The main assumption in this paper is that real investments are risky and this risk cannot be fully shared. But to understand the role of money as a store of value, it is useful to study what would happen if there was a safe tree. There are similarities and differences with how money works in the model.

Let's introduce an infinitely-lived safe tree as close as possible to money. Suppose the economy has a tree that produces a safe flow of fruit (apples), that enters the utility function analogously to money,

$$
\mathbb{E}\left[\int_{0}^{\infty} e^{-\rho t}\left((1-\beta) \log c_{t}+\beta \log a_{t}\right) d t\right]
$$

where $c_{t}$ represents the consumption goods produced by (risky) capital, and $a_{t}$ represents apples produced by the tree. The tree cannot be produced and apples cannot be used to produce capital. The tree does not enter the resource constraint for goods in any way, just like money.

Households will devote a fraction $\beta$ of their expenditures to apples, $p_{a t} a_{t}$, and the value of the tree will be

$$
q_{t}=\int_{t}^{\infty} e^{-\int_{t}^{s} r_{u} d u} p_{a s} a_{s} d s
$$

This is analogous to expression (10) for the value of money. Total wealth in the economy will therefore be $w_{t}=k_{t}+q_{t}$. In a BGP, the value of the tree $q_{t}$ grows at the same rate as capital, and ${ }^{31}$

$$
\frac{q_{t}}{w_{t}}=\frac{\rho \beta}{r-(\hat{x}-\delta)}
$$

which is analogous to expression (11) for $\lambda$.

Idiosyncratic risk in consumption will be $\sigma_{c}=(1-\lambda) \sigma$, so the model will behave exactly like the baseline model with money. The safe tree has positive net value, so it will improve risk sharing and depress investment in risky capital $\hat{x}$. And its value goes up during downturns when $\sigma$ goes up, so we will have an "apple trap" where the real interest rate $r$ does not fall enough and investment $\hat{x}$ in risky capital is depressed, relative to the economy without an apple tree.

But there are two issues with this analogy. First, the price of the safe apple tree would go up. If the safe tree can be produced, investment in the tree will go up. Instead of a liquidity trap where all investment is depressed, we would get a reallocation of investment from risky capital to the safe tree-from risky to safe capital. An important feature of liquidity traps is that all real investment is depressed (or the value of all real assets if they are in fixed supply); the only thing that goes up

\footnotetext{
${ }^{30}$ In the CIA case we can actually set $i=0$, but doing this requires $r=\hat{x}-\delta$ if $\sigma>\sqrt{\rho}$, so we get a bubble. This is not surprising, since as $\beta \rightarrow 0$ the monetary economy approaches the non-monetary economy with a bubble. See the Appendix for details, and Section 5 for a discussion of the link with bubbles.

${ }^{31}$ Write $q_{t} / w_{t}=\left(1 / w_{t}\right) \int_{t}^{\infty} e^{-r(s-t)} \rho \beta w_{s} d s=\left(\rho \beta w_{t} / w_{t}\right) \int_{t}^{\infty} e^{-r(s-t)} e^{(\hat{x}-\delta)(s-t)} d s$.
} 
in value is liquidity, which is not a real asset. So safe capital wouldn't produce a liquidity trap with depressed investment overall, but rather a sectoral reallocation from risky to safe capital.

The bigger point is that there is no such thing as safe real investment. This is the starting point of this paper. Most real investments - capital, land, housing - are indeed very risky. ${ }^{32}$ A possible exception is something like gold, which is safe and easy to store. And in fact, the value of gold did increase during liquidity traps such as the Great Depression. In the past gold was used as money so its value contained a liquidity premium, and it may have played an important role. ${ }^{33}$ Nowadays the value of gold is relatively small and can largely be ignored.

\section{$3 \quad$ Efficiency}

In this Section I study the efficiency properties of the monetary competitive equilibrium. Money provides a safe store of value that prevents the real interest rate from falling and depresses investment. This is costly because we get low investment, but in exchange we get better idiosyncratic risk sharing. Is the competitive equilibrium getting this tradeoff right?

I first micro-found the reduced-form incomplete risk sharing constraint with a moral hazard problem with hidden trade, so that the competitive equilibrium studied in Section 2 would be the result of allowing agents to write privately optimal contracts. I then characterize the optimal allocation in this environment.

The takeaway is that the monetary competitive equilibrium is inefficient. When idiosyncratic risk $\sigma$ is low (good times), there is too little risk sharing and investment is too high. But when idiosyncratic risk is high, there is too much risk sharing and investment is too low. Ultimately, the inefficiency comes from the presence of hidden trade in the environment. But implementing the optimal allocation does not involve monetary policy (recall that changing inflation targets has no real effects). The optimal allocation can be implemented with a tax or subsidy to capital, which internalizes the externality.

\subsection{Setting}

I provide the micro-foundations for the reduced-form incomplete idiosyncratic risk sharing assumed in the baseline model in a setting with moral hazard and hidden trade. ${ }^{34}$ See the Online Appendix for technical details.

Agents can write complete, long-term contracts with full commitment. A contract $\mathcal{C}=(c, m, k)$ specifies how much the agent should consume $c_{t}$, hold money $m_{t}$, and capital $k_{t}$, as functions of his report of his own idiosyncratic shock $Y_{t}=W_{t}-\int_{0}^{t} \frac{s_{u}}{\sigma} d u$. The problem is that the shock $W_{t}$ itself is not observable, so the agent can misreport at rate $s_{t}$. If the principal sees low returns reported, he doesn't know if the true returns were low or the agent was misreporting.

\footnotetext{
${ }^{32}$ It's not crucial for the argument here that there be literally no safe real investments, just that in practice the main source of safe positive net value is liquidity.

${ }^{33}$ See Bemanke and James (1991) and Eichengreen and Sachs (1985).

${ }^{34}$ The environment is based on Di Tella and Sannikov (2016).
} 
Misreporting allows the agent to divert returns to a private account. Importantly, the agent doesn't have to immediately consume what he steals. He has access to hidden trade that allows him to choose his actual consumption $\tilde{c}$, money $\tilde{m}$, and capital $\tilde{k}$. His hidden savings $n$ satisfy a dynamic budget constraint

$$
d n_{t}=\left(n_{t} r_{t}+c_{t}-\tilde{c}_{t}+\left(m_{t}-\tilde{m}_{t}\right) i_{t}+\left(\tilde{k}_{t}-k_{t}\right) \alpha_{t}+k_{t} s_{t}\right) d t+\left(\tilde{k}_{t}-k_{t}\right) \sigma d W_{t}
$$

with solvency constraint $n_{t} \geq \underline{n}_{t}$, where $\underline{n}_{t}$ is the natural debt limit. ${ }^{35}$ It is without loss of generality to implement no stealing and hidden trades in the optimal contract. A contract is incentive compatible if

$$
(c, m, k, 0) \in \arg \max _{(\tilde{c}, \tilde{m}, \tilde{k}, s)} U(\tilde{c}, \tilde{m}) \quad s t:
$$

An incentive compatible contract is optimal if it minimizes the cost of delivering utility to the agent:

$$
J\left(u_{0}\right)=\min _{(c, m, k) \in I C} \mathbb{E}\left[\int_{0}^{\infty} e^{-r t}\left(c_{t}+m_{t} i_{t}-k_{t} \alpha_{t}\right) d t\right] \quad s t: \quad U(c, m) \geq u_{0}
$$

In general this could be a difficult problem to solve, because the hidden trade gives the agent a very rich set of deviations. However, in this case the optimal contract can be characterized in a straightforward way, as the solution to the portfolio problem in Section 2. We say that contract $(c, m, k)$ solves the portfolio problem for some $w_{0}>0$ if it maximizes $U(c, m)$ subject to the dynamic budget constraint (4).

Proposition 6. Let $(c, m, k)$ be an optimal contract for initial utility $u_{0}$, with cost $J\left(u_{0}\right)$. Then $(c, m, k)$ solves the portfolio problem for $w_{0}=J\left(u_{0}\right)$.

Conversely, let $(c, m, k)$ solve the portfolio problem for some $w_{0}>0$. If in addition $\lim _{t \rightarrow \infty} \mathbb{E}\left[e^{-r t} w_{t}\right]=$ $0,{ }^{36}$ then $(c, m, k)$ is an optimal contract for initial utility $u_{0}$ with $J\left(u_{0}\right)=w_{0}$.

Proof. See Online Appendix.

Proposition 6 means that the competitive equilibrium characterized in Section 2 can also be interpreted as the outcome of allowing agents to write privately optimal contracts in this environment. The intuition is easy to grasp. The principal can consume, save, and invest on his own, so the principal essentially has no tools he can use to discipline the agent, and can only give him risk-free debt. Under those conditions, the optimal contract is implemented by letting the agent choose his consumption-portfolio plan on his own. This also ensures global incentive compatibility.

\footnotetext{
${ }^{35}$ The natural debt limit is $\underline{n}_{t}=\max _{s} \mathbb{E}^{\tilde{Q}}\left[\int_{t}^{\infty} e^{-\int_{t}^{u}}\left(c_{u}\left(Y^{s}\right)+m_{u}\left(Y^{s}\right) i_{u}+k_{u}\left(Y^{s}\right) s_{u}\right) d u\right]$. This is the maximum amount the agent can pay back for sure. See Online Appendix for details.

${ }^{36}$ This condition will always be satisfied in equilibrium.
} 
To understand this environment, write the local incentive compatibility constraints. ${ }^{37}$

$$
\begin{aligned}
\sigma_{c t} & =\rho(1-\beta) c_{t}^{-1} k_{t} \sigma & & \text { "skin in the game" } \\
\mu_{c t} & =r_{t}-\rho+\sigma_{c t}^{2} & & \text { Euler equation } \\
\alpha_{t} & =\sigma_{c t} \sigma & & \text { demand for capital } \\
m_{t} / c_{t} & =\beta /(1-\beta) i_{t}^{-1} & & \text { demand for money }
\end{aligned}
$$

The "skin in the game" constraint (22) says that the agent must be exposed to his own idiosyncratic risk to align incentives. The agent could always misreport a lower return and consume those funds, so incentive compatibility requires that the present value of his consumption goes down by $k_{t} \sigma$ after bad reported outcomes $Y_{t}$. The skin in the game constraint is expressed in terms of the volatility of his consumption $\sigma_{c t}$. If he steals a dollar, he won't consume the dollar right away; he will consume it only at rate $\rho(1-\beta) .{ }^{38}$ So his consumption must be exposed to his idiosyncratic shock as in (22). This is costly, of course. In the first best we would have perfect idiosyncratic risk sharing, $\sigma_{c t}=0$, but we need to expose the agent to risk to align incentives.

The other IC constraints (23), (24), and (25) come from the agent's ability to save at the riskfree rate, secretly invest in capital, and choose his money holdings, respectively. Ultimately they arise from agents' ability to secretly trade amongst themselves. These constraints are binding. The principal would like to front-load the agent's consumption to relax the idiosyncratic risk sharing problem, as can be seen in (22). By distorting the intertemporal consumption margin he can relax the risk sharing one. But the agent has access to hidden savings, so the principal must respect his Euler equation. Even then, if the agent couldn't secretly invest in capital or choose his money holdings, the principal could use this to provide better incentives. In particular, he would like to promise less capital and risk in the future and after bad outcomes. This relaxes the agent's precautionary motive and makes it cheaper for the principal to provide incentives. But he cannot do this because the agent can secretly invest in capital on his own. The same intuition goes for his money holdings.

The tradeoff between intertemporal consumption smoothing and idiosyncratic risk sharing captured in the skin in the game constraint (22) is central to the liquidity trap. First, we'd like to see how this constraint manifests in the competitive equilibrium. Write $\sigma_{c t}=(1-\lambda) \sigma=\left(k_{t} / w_{t}\right) \sigma$; using $c_{t}=\rho(1-\beta) w_{t}$, we obtain equation (22). Now, when the value of liquidity $\lambda$ goes up and improves risk sharing, it is moving the equilibrium along this IC constraint. ${ }^{39}$ In equilibrium this must be consistent with individual optimization, captured by the risk premium and the precautionary

\footnotetext{
${ }^{37}$ The competitive equilibrium and the planner's allocation will be BGPs, but it is important to allow for timevarying allocations and prices.

${ }^{38}$ An equivalent derivation: the agent's continuation utility if he doesn't misbehave, $U_{t}$, follows a promise-keeping constraint $d U_{t}=\left(\rho U_{t}-\left(\beta \log \left(c_{t}\right)+(1-\beta) \log \left(m_{t}\right)\right)\right) d t+\sigma_{U t} d W_{t}$. If he misreports he can immediately consume what he stole (he is indifferent at the margin) and obtain utility $(1-\beta) c_{t}^{-1} k_{t}$, so incentive compatibility requires $\sigma_{U t}=$ $(1-\beta) c_{t}^{-1} k_{t} \sigma$. Because the agent can secretly save and invest, his continuation utility must be $U_{t}=A+\frac{1}{\rho} \log \left(c_{t}\right)$, so we get $\sigma_{c t}=\rho \sigma_{U t}$.

${ }^{39}$ It's not the $\beta$ that improves risk sharing; it is fixed as $\sigma$ goes up, and the liquidity trap survives in the cashless limit with $\beta \rightarrow 0$. It's the distortions in the intertemporal consumption smoothing margin.
} 
motive. As we'll see, the planner will choose a different point on this IC constraint.

All these conditions are only necessary, and are derived from considering local, single deviations by the agent. Establishing global incentive compatibility is difficult in general, but in this environment it's straightforward. Because the optimal contract coincides with the optimal portfolio problem where the agent essentially does what he wants, global incentive compatibility is ensured.

\section{$3.2 \quad$ Planner's problem}

The planner faces the same environment with moral hazard and hidden trade. ${ }^{40}$ An allocation is a plan for each agent $\left(c_{i}, m_{i}, k_{i}\right)$ and aggregate consumption $c$, investment $x$, and capital $k$ satisfying the resource constraints (1), (2), $c_{t}=\int_{0}^{1} c_{i, t} d i$ and $k_{t}=\int_{0}^{1} k_{i, t} d i$. An allocation is incentive compatible if there exist processes for real interest rate $r$, nominal interest rate $i$, and idiosyncratic risk premium $\alpha$, such that (20) holds for each agent. An incentive compatible allocation is optimal if there is no other incentive compatible allocation that weakly improves all agents' utility and at least one strictly so.

The local IC constraints are necessary for an incentive compatible allocation. But the thing to notice is that constraints (23), (24), and (25) involve prices that the planner doesn't take as given. What these constraints really say is that all agents must be treated the same, or else they would engage in hidden trades amongst themselves. This is why the planner can improve over the competitive equilibrium. For example, the planner realizes that he can change the growth rate of all agents' consumption at the same time, without creating any incentives to engage in hidden trades. So all agents get the same $\mu_{c}, \sigma_{c}, m / c$, and $k / c$, and only differ in the scale of their contract, corresponding to how much initial utility they get. The only true constraint for the planner is the skin in the game constraint (22), which can be re-written using the resource constraints as

$$
\sigma_{c}=\frac{\rho(1-\beta)}{a-\hat{x}_{t}} \sigma
$$

The planner's problem then boils down to choosing the aggregate consumption $c$, investment $x$, and real money balances $m$ to maximize the utility of all agents. Using the aggregate resource constraints (1) and (2), and the incentive compatibility constraints, we can write the planner's objective function

$$
\begin{gathered}
\mathbb{E}\left[\int_{0}^{\infty} e^{-\rho t}\left((1-\beta) \log \left(c_{i, t}\right)+\beta \log \left(m_{i, t}\right)\right) d t\right] \\
=\mathbb{E}\left[\int_{0}^{\infty} e^{-\rho t}\left(\log \left(k_{0}\right)+\log \left(a-\hat{x}_{t}\right)+\beta \log \left(\frac{\beta i_{t}^{-1}}{1-\beta}\right)+\frac{\hat{x}_{t}-\delta-\frac{\sigma_{c t}^{2}}{2}}{\rho}\right) d t\right]
\end{gathered}
$$

The planner's problem then is to choose a process for $\hat{x}$ and $i$ to maximize (27) subject to (26).

\footnotetext{
${ }^{40} \mathrm{It}$ is natural to wonder if the planner could simply refuse to enforce debt contracts in order to eliminate hidden trade. Here I'm assuming the hidden trade is a feature of the environment that the planner cannot change; e.g. agents may have a private way of enforcing debt contracts. As we'll see, the hidden trade constraints are already not binding for the planner, so he wouldn't gain anything from doing this. And we wouldn't learn a lot from pointing out that the planner could do better if he can change the environment.
} 
First, it is optimal to set $i \approx 0$ (Friedman rule). ${ }^{41}$ This maximizes the utility from money, and costs nothing. Second, the FOC for $\hat{x}_{t}$ is

$$
\begin{gathered}
\frac{1}{\rho}=\frac{1}{a-\hat{x}_{t}}+\left(\frac{\rho(1-\beta) \sigma}{a-\hat{x}_{t}}\right)^{2} \frac{1}{a-\hat{x}_{t}} \\
\Longrightarrow \hat{x}=\underbrace{a-\rho}_{\text {first best }}-\sigma_{c}^{2}
\end{gathered}
$$

where recall that $\sigma_{c}=\frac{\rho(1-\beta) \sigma}{a-\hat{x}}$. The lhs in (28) captures the benefit of having more capital forever. The rhs captures the cost of increasing investment. The first term is the utility loss from reducing consumption. The second term captures the loss from worse idiosyncratic risk sharing. A more backloaded consumption path makes fund diversion more attractive, and therefore tightens the IC constraint (22). If we didn't have this second term (if we had complete risk sharing), then we would obtain $\hat{x}=a-\rho$, the first best investment. But the planner realizes that he can improve risk sharing if he is willing to distort the intertemporal consumption margin. Private contracts also realize this, but they are constrained by agents' access to hidden trade. They must respect agents' Euler equation (23) and demand for capital (24) taking $r$ and $\alpha$ as given; the planner can distort all the agents' consumption path and improve idiosyncratic risk sharing. This is the source of inefficiency in this economy, ultimately arising from hidden trade. ${ }^{42}$

The planner reduces investment $\hat{x}$ to improve idiosyncratic risk sharing $\sigma_{c}$. This tradeoff is more attractive when idiosyncratic risk $\sigma$ is higher. So investment $\hat{x}$ falls with $\sigma$, but idiosyncratic consumption risk $\sigma_{c}$ goes up less than proportionally to $\sigma$. In the background, the real interest rate $r$ falls with $\sigma$.

Proposition 7. In the planner's optimal allocation, an increase in idiosyncratic risk $\sigma$ depresses investment $\hat{x}$ and the real interest rate $r$, and increases idiosyncratic consumption risk $\sigma_{c}$, but less than proportionally, i.e. $\sigma_{c} / \sigma$ falls. When $\sigma=0$ we have the first best investment and risk sharing, with $\sigma_{c}=0, \hat{x}=a-\rho$, and $r=a-\delta$.

\subsection{Competitive equilibrium vs. planner's allocation}

Money provides a safe store of value that improves risk sharing but depresses investment. This is the same tradeoff that the planner considers, but the competitive equilibrium doesn't do it efficiently. When idiosyncratic risk $\sigma$ is low, money provides too little insurance and investment $\hat{x}$ is too high; when idiosyncratic risk is large, money provides too much insurance and investment is too low.

\footnotetext{
${ }^{41}$ Because of the log preferences we can't set $i=0$ because we would get infinite utility. But $i=0$ is optimal in a limiting sense.

${ }^{42}$ See Kehoe and Levine (1993) and Farhi et al. (2009). Di Tella (2016) has a similar contractual setting with hidden trade but without hidden savings. Instead, there is an endogenous price of capital. There is an externality because the private benefit of the hidden action depends on the value of assets. This is absent here because the equilibrium price of capital is always one. But the externality here, produced by hidden intertemporal trade, is absent from that paper.
} 

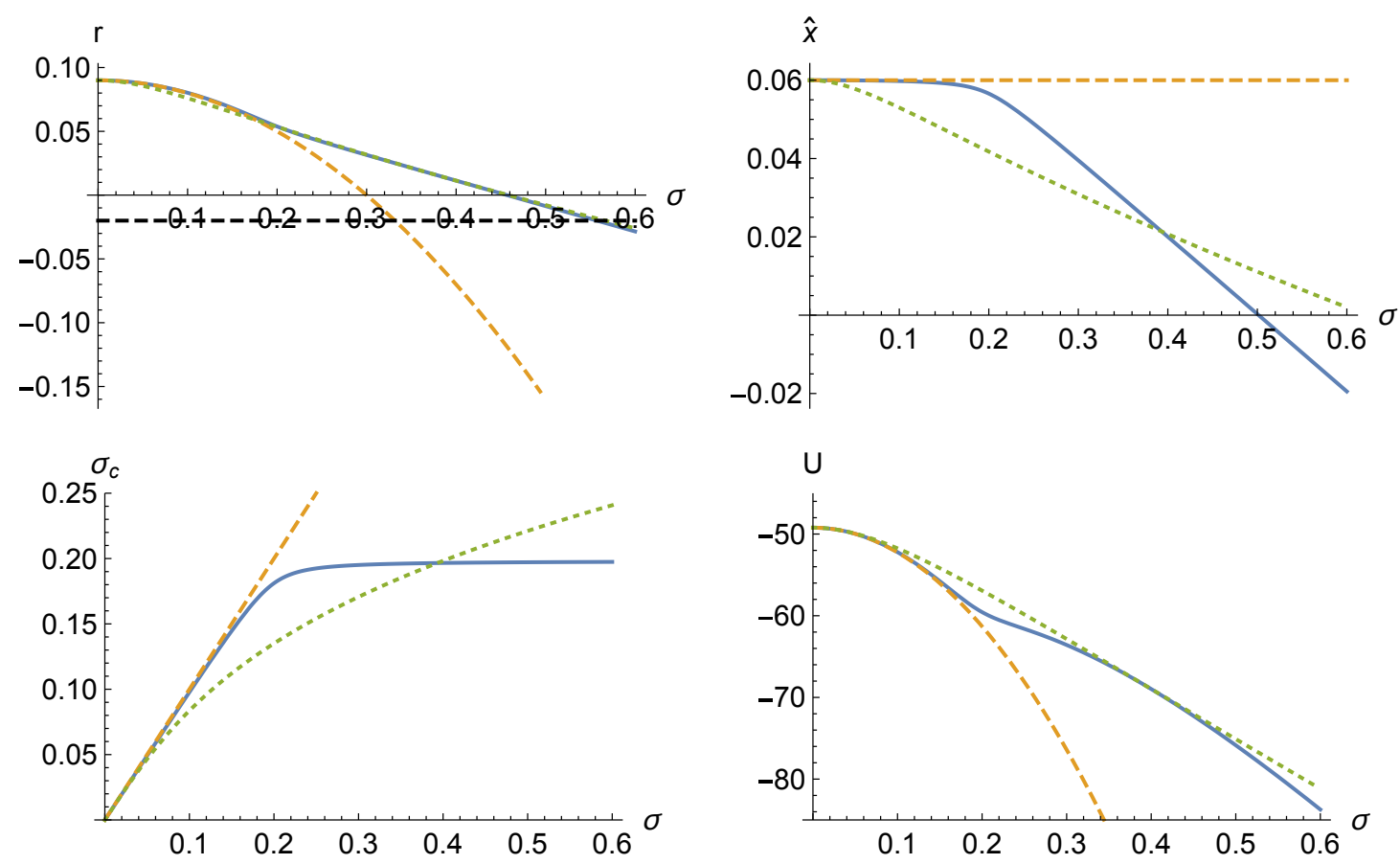

Figure 4: Interest rate $r$, investment $\hat{x}$, idiosyncratic risk $\sigma_{c}$, and utility from consumption in the non-monetary economy (dashed orange), monetary competitive equilibrium (solid blue), and the social planner's allocation (dotted green). Parameters: $a=1 / 10, \rho=4 \%, \pi=2 \%, \delta=1 \%$, $\beta=1.7 \%$

Figure 4 compares the competitive equilibrium and the planner's allocation. ${ }^{43}$ Investment $\hat{x}$ and consumption risk $\sigma_{c}$ in the planner's allocation are below the competitive equilibrium for low $\sigma$, and above for high $\sigma$. The planner allocation always delivers more utility than the competitive equilibrium. First, because it implements the Friedman rule and gives agents large real balances $m$. But it also improves the utility derived from consumption. Figure 4 also shows the behavior of the equilibrium interest rate $r$ in the competitive equilibrium and the planner's allocation. Perhaps surprisingly, the real interest rate is very close in both allocations (and higher than in the nonmonetary economy). There are two conflicting forces. Lower investment $\hat{x}$ lowers the growth rate of consumption and therefore $r$; but lower idiosyncratic risk $\sigma_{c}$ dampens the precautionary saving motive, raising $r$.

To understand why the competitive equilibrium is inefficient, we can compare the planner's FOC for $\hat{x}$, given by (29), with investment in the competitive equilibrium

$$
\begin{array}{lr}
\hat{x}=a-\rho-\sigma^{2} \times\left(\sigma_{c} / \sigma\right)^{2} & \text { Social Planner } \\
\hat{x}=a-\rho-\sigma^{2} \times\left(\sigma_{c} / \sigma\right) \times\left(1-\sigma_{c} / \sigma\right) & \text { Competitive Equilibrium }
\end{array}
$$

\footnotetext{
${ }^{43}$ I also include the non-monetary equilibrium as a reference, but they are different environments so we can't really compare welfare between the monetary and non-monetary economies.
} 
Both share the same expression for incentive compatibility

$$
\sigma_{c} / \sigma=\frac{\rho(1-\beta)}{a-\hat{x}}
$$

which pins down the set of $\hat{x}$ and $\sigma_{c} / \sigma$ that are incentive compatible. But the planner and the competitive equilibrium disagree on which $\left(\hat{x}, \sigma_{c} / \sigma\right)$ pair to pick. For a fixed $\sigma$, we can interpret (30) and (31) as the desired investment $\hat{x}$ for a given $\sigma_{c}$; the intersection with (32) gives the planner solution or the competitive equilibrium, respectively. Figure 5 captures the situation. For the planner, reducing investment below the first best is a way of improving idiosyncratic risk sharing, so the bigger $\sigma_{c}$ is the more he will want to reduce investment. But in the competitive equilibrium it's all about the difference between the precautionary motive $\sigma_{c} \times \sigma_{c}$ and the risk premium $\sigma_{c} \times \sigma$, which is non-monotonic in $\sigma_{c}{ }^{44}$

At $\sigma_{c}=0$ the precautionary motive and the risk premium are equal and cancel each other out, so investment wouldn't be depressed in the competitive equilibrium, and the planner agrees with this. If we increase $\sigma_{c}$ the precautionary motive falls behind the risk premium, so investment would fall in the competitive equilibrium, and it would do so by more than in the planner's solution because $\sigma>\sigma_{c}$ initially. However, after $\sigma_{c}>\frac{1}{2} \sigma$, the difference between the precautionary motive and the risk premium starts to shrink. In fact, we know that if $\sigma_{c}=\sigma$ the two would be exactly the same and we would be back to the first best investment. So investment in the competitive equilibrium as a response to $\sigma_{c}$ is non-monotonic. For the planner, meanwhile, higher $\sigma_{c}$ always increases his desire to reduce investment. The planner and the competitive equilibrium only agree on $\hat{x}$ as a response to $\sigma_{c}$ when $\sigma_{c}=0$ or $\sigma_{c}=\frac{1}{2} \sigma$. For $\sigma_{c} / \sigma \in(0,1 / 2)$ the planner wants more investment and less risk sharing than the competitive equilibrium; for $\sigma_{c} / \sigma \in(1 / 2,1-\beta)$ the planner wants less investment and more risk sharing than the competitive equilibrium.

Of course, $\sigma_{c}$ is endogenous, given by the intersection of (32) with (30) and (31) respectively. Money improves risk sharing and dampens the precautionary motive relative to the risk premium, reducing investment below the first best. Whether investment in the competitive equilibrium is too high or too low depends on how much risk sharing money provides in equilibrium. If $\beta \geq 1 / 2$ the value of liquidity is very large, so there is too much risk sharing and too little investment in the competitive equilibrium for any $\sigma$. For the quantitatively relevant case with $\beta<1 / 2$, the value of liquidity is too small for low $\sigma$, so there is too little risk sharing and too much investment. But for high $\sigma$ the value of liquidity is too large, so there is too much risk sharing and too little investment.

Proposition 8. If $\beta \in(0,1 / 2)$, there is a $\sigma^{*}=2 \sqrt{\rho(1-2 \beta)}>0$ such that for $\sigma \in\left(0, \sigma^{*}\right)$ investment and consumption risk are too high in the competitive equilibrium, compared to the planner's allocation; that is, $\hat{x}^{C E}>\hat{x}^{S P}$ and $\sigma_{c}^{C E}>\sigma_{c}^{S P}$. For $\sigma>\sigma^{*}$ investment and consumption risk

\footnotetext{
${ }^{44}$ One may wonder how Figure 5 captures the situation if $\beta=0$. In that case the IC curve shifts down so that it touches $\hat{x}=a-\rho$ at $\sigma_{c} / \sigma=1$ (in general it touches $a-\rho$ at $1-\beta$ ). This is of course the non-monetary equilibrium. There may also be another intersection between $\hat{x}^{C E}$ and the IC curve for $\sigma_{c} / \sigma<1$, but this violates the No-Ponzi conditions. It corresponds to a bubble equilibrium of the non-monetary economy. See Section 5 on bubbles and the discussion on the cashless limit in Section 2.4.
} 


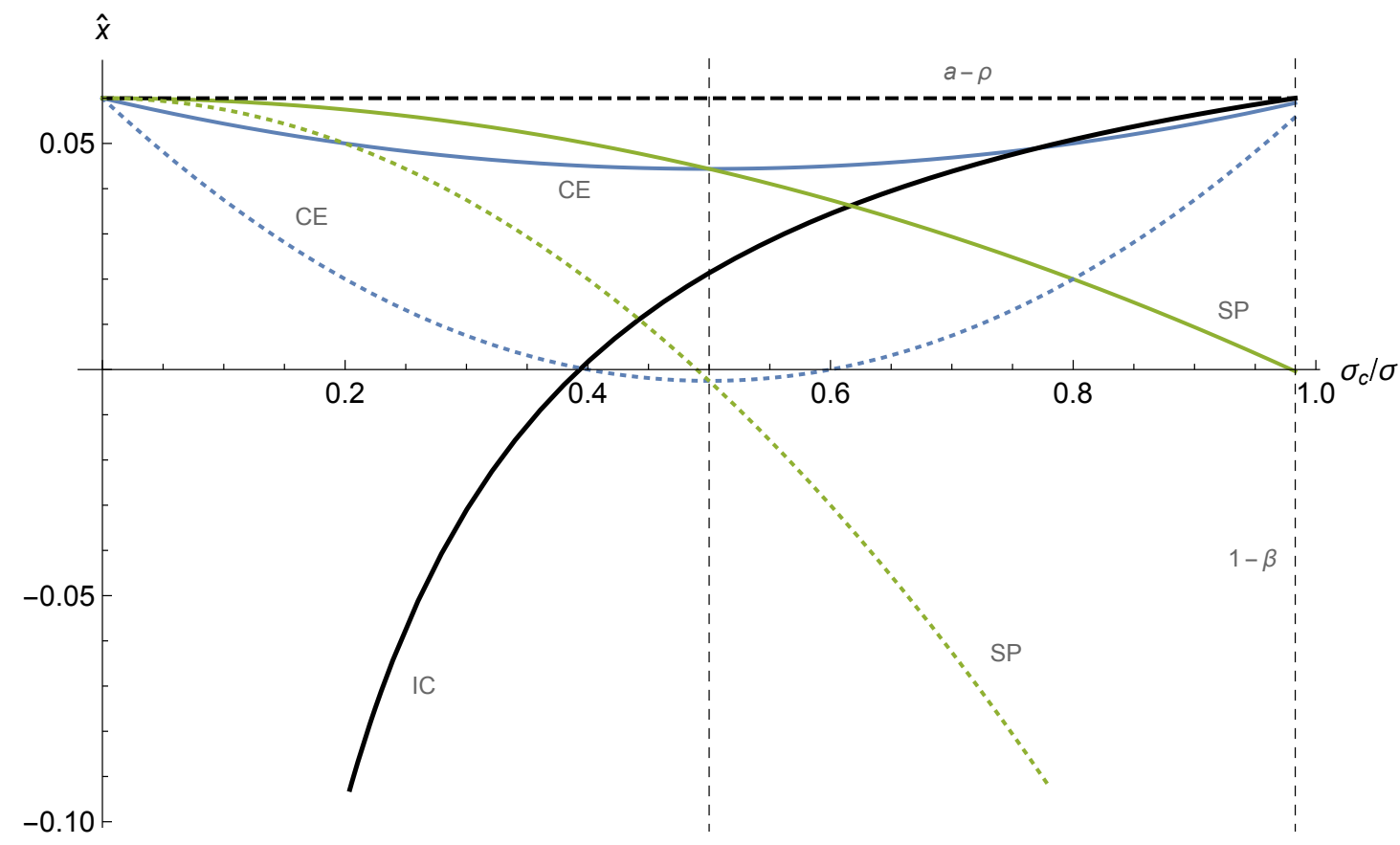

Figure 5: Thick black line is the locus of IC $\left(\hat{x}, \sigma_{c}\right)$. The blue line is the $\hat{x}$ in the CE as a function of $\sigma_{c} / \sigma$ corresponding to (31), the green line for the SP corresponding to (30). Solid is for $\sigma=0.2$, dotted for $\sigma=0.5$. Parameters: $a=1 / 10, \rho=4 \%, \pi=2 \%, \delta=1 \%, \beta=1.7 \%$

are too low in the competitive equilibrium; that is, $\hat{x}^{C E}<\hat{x}^{S P}$ and $\sigma_{c}^{C E}<\sigma_{C}^{S P}$. If $\beta \in[1 / 2,1)$ investment and consumption risk are too low in the competitive equilibrium for any $\sigma>0$.

\subsection{Implementation of the optimal allocation}

We can implement the social planner's optimal allocation as a competitive equilibrium with a tax on capital income $\tau^{k}$, rebated lump-sum to agents (in addition to the Friedman rule, $i \approx 0$ ). ${ }^{45}$ Total wealth now includes not only money, but also the lump-sum rebates $w_{t}=k_{t}+m_{t}+h_{t}+$ $\int_{t}^{\infty} e^{-r s} \tau_{s}^{k} k_{s} d s$. The only equilibrium condition that changes is the asset pricing equation for capital (6) which becomes

$$
\underbrace{a-\tau^{k}-\delta-r}_{\alpha}=\sigma_{c} \sigma
$$

The competitive equilibrium still has an Euler equation $r=\rho+(\hat{x}-\delta)-\sigma_{c}^{2}$, and idiosyncratic risk sharing is given by ${ }^{46}$

$$
\sigma_{c}=\frac{\rho(1-\beta)}{a-\hat{x}} \sigma
$$

\footnotetext{
${ }^{45}$ This is consistent with the hidden trade in the environment. The planner is taxing or subsidizing all capital, regardless of who holds it.

${ }^{46}$ This comes from the IC constraint (22). Alternatively, use $c_{t}=\rho(1-\beta) w_{t}$ and $\sigma_{c}=\sigma_{w}=\frac{k_{t}}{w_{t}} \sigma=\frac{\rho(1-\beta)}{c_{t}} k_{t} \sigma=$ $\frac{\rho(1-\beta)}{a-\hat{x}} \sigma$.
} 
Putting together the pricing equation for capital and the Euler equation, we obtain equilibrium investment

$$
\hat{x}=a-\rho-\tau^{k}+\sigma_{c}^{2}-\sigma_{c} \sigma
$$

Taxing capital $\tau^{k}>0$ produces less investment.

Recall that the planner's solution has $\hat{x}=a-\rho-\sigma_{c}^{2}$, and $\sigma_{c}=\frac{\rho(1-\beta)}{a-\hat{x}} \sigma$. So the wedge between the planner's condition and the competitive equilibrium is given by $\tau^{k}-2 \sigma_{c}^{2}+\sigma_{c} \sigma$. If we set the tax on capital

$$
\tau^{k}=2 \sigma_{c}^{2}-\sigma_{c} \sigma
$$

we internalize the externality produced by hidden trade. This allows us to implement the planner's allocation as a competitive equilibrium, provided that the required real interest rate is not too low. Of course, we also need to choose the inflation target to deliver the Friedman rule $i=r+\pi \approx 0$.

A Balanced Growth Path Equilibrium with tax $\tau^{k}$ and inflation $\pi$ is an interest rate $r$, investment $\hat{x}$, and real money $\hat{m}$ such satisfying the Euler equation (5), the asset pricing equation (33), risk sharing equation (34), and money demand equation (9), as well as $i=r+\pi>0$ and $r>\hat{x}-\delta$.

Proposition 9. Let $\hat{x}$ be investment in the planner's allocation, with associated idiosyncratic consumption risk $\sigma_{c}$. If $r=\rho+\hat{x}-\delta-\sigma_{c}^{2}>\hat{x}-\delta$, and $r+\pi>0$, then $r, \hat{x}$, and $\hat{m}=\frac{\beta}{1-\beta} \frac{a-\hat{x}}{r+\pi}$ are $a$ $B G P$ equilibrium with tax $\tau^{k}$ given by (35) and inflation $\pi$. The optimal inflation target $\pi$ satisfies $i=r+\pi \approx 0$ (Friedman rule).

Notice that $r>\hat{x}-\delta$ also ensures that the privately optimal contract that takes prices $r$, $\alpha$, and $i$ as given can be implemented as the consumption-portfolio problem from Section $2 .{ }^{47}$ We know that $r-(\hat{x}-\delta)=\rho-\sigma_{c}^{2}$ falls with $\sigma$ from Proposition 7 , so there is a maximum $\bar{\sigma}=\frac{2 \sqrt{\rho}}{1-\beta}$ such that the optimal allocation can be implemented as a competitive equilibrium with a tax $\tau^{k}$ for all $\sigma \in[0, \bar{\sigma})$.

When idiosyncratic risk $\sigma$ is low, the competitive equilibrium has too much investment and too little risk sharing. The optimal allocation requires a tax on capital $\tau^{k}>0$. But when idiosyncratic risk $\sigma$ is high, the competitive equilibrium has too little investment, and too much risk sharing. The optimal allocation requires a subsidy to capital $\tau^{k}<0$.

Proposition 10. The optimal allocation can be implemented as a BGP with tax $\tau^{k}$ for all $\sigma \in$ $[0, \bar{\sigma})$, with $\bar{\sigma}=\frac{2 \sqrt{\rho}}{1-\beta}$. If $\beta<\frac{1}{2}$, there is a $\sigma^{*}=2 \sqrt{\rho(1-2 \beta)} \in(0, \bar{\sigma}]$ such that for $\sigma \leq \sigma^{*}$ the implementation of the optimal allocation requires $\tau^{k} \geq 0$, and for $\sigma^{*}<\sigma<\bar{\sigma}$ it requires a $\tau^{k}<0$. If $\beta \geq \frac{1}{2}$, we have $\tau^{k} \leq 0$ for all $\sigma \in[0, \bar{\sigma})$.

\section{Dynamic model with risk shocks}

In this Section I incorporate aggregate risk shocks that increase idiosyncratic risk $\sigma_{t}$. I also add TFP shocks that affect the level of effective capital. This dynamic extension allows me to obtain

\footnotetext{
${ }^{47}$ Of course, it we add aggregate risk the real interest rate can be lower that the growth rate of the economy.
} 
a general formula for the value of liquidity $\lambda$, that highlights the role of the stochastic discount rate - the asset pricing of liquidity plays a prominent role. A deep liquidity trap must be persistent, at least in risk-adjusted expectations. It also clarifies the role of idiosyncratic and aggregate risk. What matters about money is that it improves idiosyncratic risk sharing; aggregate risk sharing is complete.

\subsection{Setting}

The "capital quality" shock for an agent is now

$$
\Delta_{i, t}^{k}=\sigma_{t} k_{i, t} d W_{i, t}+\tilde{\sigma}^{T F P} d Z_{t}^{T F P}
$$

where $Z^{T F P}$ is an aggregate TFP shock. Aggregate TFP risk $\tilde{\sigma}^{T F P}$ is constant, but idiosyncratic risk $\sigma_{t}$ follows an autoregressive process

$$
d \sigma_{t}=\phi\left(\bar{\sigma}-\sigma_{t}\right) d t+\sqrt{\sigma_{t}} \nu d Z_{t}^{R S}
$$

where $Z^{R S}$ is another aggregate shock that raises idiosyncratic risk. For theoretical clarity, assume that $Z^{R S}$ and $Z^{T F P}$ are independent.

Idiosyncratic shocks wash away in the aggregate, so the aggregate capital stock follows

$$
d k_{t}=\left(g k_{t}+x_{t}-\delta k_{t}\right) d t+k_{t} \tilde{\sigma}^{T F P} d Z_{t}^{T F P}
$$

where $g$ is the exogenous growth rate of TFP. Markets are complete for aggregate risk, with endogenous price $\theta_{t}^{T F P}$ and $\theta_{t}^{R S}$ for $Z^{T F P}$ and $Z^{R S}$ respectively. Let $Q$ be the equivalent martingale measure associated with these prices.

As in the baseline model, the government prints money and distributes it lump-sum to agents in order to hit the inflation target. Because we know that the inflation target itself has no real effects (besides real money holdings) we can allow the inflation target $\pi_{t}$ to depend on the whole history of aggregate shocks $Z^{T F P}$ and $Z^{R S}$. For example, it may follow the Friedman rule such that $i_{t}=r_{t}+\pi_{t} \approx 0$. To achieve its inflation target, the government must be ready to introduce or take out money in response to aggregate shocks to accommodate demand for money so that nominal prices grow at rate $\pi_{t}: 48$

$$
\frac{d M_{t}}{M_{t}}=\mu_{M t} d t+\tilde{\sigma}_{M t}^{T F P} d \tilde{Z}_{t}^{T F P}+\tilde{\sigma}_{M t}^{R S} d \tilde{Z}_{t}^{R S}
$$

Let $h_{t}$ be the present value of future money transfers: $h_{t}=\mathbb{E}_{t}^{Q}\left[\int_{t}^{\infty} e^{-\int_{t}^{s} r_{u} d u} \frac{d M_{s}}{p_{s}}\right]$. Total wealth is

\footnotetext{
${ }^{48}$ Here while the inflation rate $\pi_{t}$ can be stochastic, the price level is locally deterministic (no volatility). This simplifies things so that, for example, $i=r+\pi$ holds in equilibrium (otherwise we would need to take a risk-premium for nominal bonds into account). But since money is neutral, we could also allow for volatility in the price level without changing the main results. What matters about money is that it does not have idiosyncratic risk; aggregate risk sharing is already complete.
} 
$w_{t}=k_{t}+m_{t}+h_{t}$.

Just as in the baseline model, the value of liquidity plays a central role. But instead of working with $\lambda_{t}=\frac{m_{t}+h_{t}}{k_{t}+m_{t}+h_{t}}$, it is easier to work with $\psi_{t}=\hat{m}_{t}+\hat{h}_{t}$, with law of motion

$$
d \psi_{t}=\mu_{\psi t} d t+\tilde{\sigma}_{\psi}^{R S} d \tilde{Z}_{t}^{R S}
$$

$\psi_{t}$ is not exposed to TFP shocks because the economy is scale invariant to effective capital $k_{t}$. Total wealth is $w_{t}=k_{t}\left(1+\psi_{t}\right)$, and we can recover $\lambda_{t}=\frac{\psi_{t}}{1+\psi_{t}}$.

With this definition of $\psi$, the competitive equilibrium is a process for the real interest rate $r$ and price of risk $\theta^{T F P}$ and $\theta^{R S}$, investment $\hat{x}$, and real money holdings $\hat{m}$, all contingent on the history of shocks $Z^{T F P}$ and $Z^{R S}$ and satisfying the equilibrium conditions:

$$
\begin{array}{rlr}
r_{t} & =\rho+\left(\hat{x}_{t}+g-\delta\right)+\mu_{\psi t} /\left(1+\psi_{t}\right)-\sigma_{c t}^{2}-\left(\tilde{\sigma}_{c t}^{T F P}\right)^{2}-\left(\tilde{\sigma}_{c t}^{R S}\right)^{2} & \text { Euler } \\
r_{t} & =a+g-\delta-\sigma_{c t} \sigma_{t}-\theta_{t}^{T F P} \tilde{\sigma}^{T F P} & \text { Asset Pricing } \\
\sigma_{c} & =\sigma_{t} /\left(1+\psi_{t}\right) & \text { Id. risk } \\
\tilde{\sigma}_{c}^{T F P} & =\theta_{t}^{T F P}=\tilde{\sigma}^{T F P} & \text { TFP risk } \\
\tilde{\sigma}_{c t}^{R S} & =\theta_{t}^{R S}=\tilde{\sigma}_{\psi t}^{R S} /\left(1+\psi_{t}\right) & \text { RS risk } \\
\hat{m}_{t} & =\beta /(1-\beta) \times\left(a-\hat{x}_{t}\right) /\left(r_{t}+\pi_{t}\right) & \text { Money }
\end{array}
$$

as well as $\lim _{t \rightarrow \infty} \mathbb{E}^{Q}\left[e^{-\int_{0}^{t} r_{u} d u} w_{t}\right]=0$ and $i_{t}=r_{t}+\pi_{t}>0$.

There is now a precautionary motive for idiosyncratic risk $\sigma_{c t}^{2}$, for aggregate TFP risk $\left(\tilde{\sigma}_{c t}^{T F P}\right)^{2}$, and for aggregate risk shocks $\left(\tilde{\sigma}_{c t}^{R S}\right)^{2}$. In addition, the growth rate of consumption in the Euler equation $\mu_{c t}=\hat{x}_{t}+g-\delta+\mu_{\psi t} /\left(1+\psi_{t}\right)$ comes from writing $c_{t}=\rho(1-\beta) w_{t}$ and $w_{t}=k_{t}\left(1+\psi_{t}\right)$, and computing the drift of $c_{t}$. Likewise, capital pays a risk premium for its idiosyncratic risk $\sigma_{c t} \sigma_{t}$ and for aggregate TFP risk $\theta_{t}^{T F P} \tilde{\sigma}^{T F P}=\left(\tilde{\sigma}^{T F P}\right)^{2}$ (its return is not correlated with aggregate risk shocks, so there's no risk premium for that). Idiosyncratic risk sharing is still given by $\sigma_{c t}=\left(1-\lambda_{t}\right) \sigma=\frac{\sigma}{1+\psi_{t}}$. Money provides a safe store of value that improves idiosyncratic risk sharing. But aggregate shocks cannot be shared. Since the economy is scale invariant to effective capital, TFP shocks don't affect $\hat{x}_{t}=x_{t} / k_{t}$ or $\hat{c}_{t}=c_{t} / k_{t}$, so $\tilde{\sigma}_{c t}^{T F P}=\tilde{\sigma}^{T F P}$. In contrast, risk shocks don't affect the level of effective capital, but can affect the value of liquidity and therefore $\hat{x}_{t}$ and $\hat{c}_{t}$. So the price of the aggregate risk shock $\theta_{t}^{R S}=\tilde{\sigma}_{c t}^{R S}$ is endogenous and depends on how the shock affects $\psi_{t}$. Equation (44) comes from writing $c_{t}=\rho(1-\beta) w_{t}$ and $w_{t}=k_{t}\left(1+\psi_{t}\right)$ and computing the exposure of consumption to aggregate risk shocks.

If we know the behavior of $\psi_{t}$ we can then obtain every other equilibrium object from (40)-(45). In contrast to the baseline model, the value of liquidity is not a constant. It will be characterized by an ODE. Reasoning as before, the value of money is equal to the present value of expenditures on liquidity services. 
Proposition 11. The equilibrium value of money satisfies

$$
m_{t}+h_{t}=\mathbb{E}_{t}^{Q}\left[\int_{t}^{\infty} e^{-\int_{t}^{s} r_{u} d u} m_{s} i_{s} d s\right]
$$

From this it is easy to obtain a BSDE for $\psi_{t}$

$$
\hat{m}_{t} i_{t}+\mu_{\psi t}+\psi_{t}\left(\hat{x}_{t}+g-\delta-r_{t}\right)=\theta_{t}^{T F P} \tilde{\sigma}^{T F P} \psi_{t}+\theta_{t}^{R S} \tilde{\sigma}_{\psi t}^{R S}
$$

and transversality condition $\lim _{T \rightarrow \infty} \mathbb{E}^{Q}\left[e^{-\int_{0}^{T} r_{u} d u} k_{T} \psi_{T}\right]=0$.

It is worth noting that because of the log preferences, dynamics only matter through the value of liquidity $\psi$. Without money we have $\psi_{t}=0$, and the competitive equilibrium does not depend on the stochastic process for $\sigma_{t}$, as can be seen from inspecting equations (40)-(45) (only on the current $\sigma_{t}$ ). For any given value of $\sigma_{t}$ the competitive equilibrium without money is the same as in the static economy with a constant $\sigma=\sigma_{t}$. With money, the only reason this is not the case is because $\psi_{t}$ is forward-looking, as shown in equation (46). As we will see below, the planner's optimal allocation for a given value of $\sigma_{t}$ also coincides with the static case with a constant $\sigma=\sigma_{t}$.

We can subtract equation (40) from (41) and re-arrange to obtain an expression for investment $\hat{x}_{t}$, analogous to $(15)$ :

$$
\hat{x}=a-\rho+\sigma_{c t}^{2}-\sigma_{c t} \sigma+\left(\frac{\tilde{\sigma}_{\psi t}^{R S}}{1+\psi_{t}}\right)^{2}-\frac{\mu_{\psi t}}{1+\psi_{t}}
$$

Idiosyncratic and aggregate risk play very different roles. Money provides a safe store of value that improves idiosyncratic risk sharing. As before, it dampens the idiosyncratic precautionary motive $\sigma_{c t}^{2}$ relative to the idiosyncratic risk premium $\sigma_{c t} \sigma$ and depresses investment. Aggregate risk, on the other hand, simply cannot be shared. As a result, aggregate TFP risk $\tilde{\sigma}^{T F P}$ reduces the equilibrium real interest rate $r$, but does not affect investment $\hat{x}$, just as in the non-monetary economy. The risk premium $\tilde{\sigma}_{c t}^{T F P} \tilde{\sigma}^{T F P}$ and precautionary motive $\left(\tilde{\sigma}_{c t}^{T F P}\right)^{2}$ produced by aggregate TFP risk exactly cancel each other out even when there is money. Likewise, the exogenous growth rate of TFP $g$ affects only the equilibrium real interest rate $r$, but has no effect on the value of liquidity $\psi$ or investment $\hat{x} .^{49}$

The stochastic behavior of $\sigma_{t}$ matters through the equilibrium behavior of the value of liquidity $\psi_{t}$, which is forward-looking. Even conditional on the current value of $\psi_{t}$, if $\psi_{t+s}$ is expected to be high in the future, this means the idiosyncratic precautionary motive will be weaker than the idiosyncratic risk premium and therefore consumption will be higher relative to capital; that is, $\hat{c}_{t+s}$ will be higher. As a result, for a given interest rate $r_{t}$, pinned down by the asset pricing equation (41), agents want less investment $\hat{x}_{t}$ to achieve their desired intertemporal consumption smoothing. This is why $\mu_{\psi t}$ appears in (48). Likewise, aggregate risk shocks matter because they induce aggregate volatility in agents' consumption. Since capital is not exposed to risk shocks, it is

\footnotetext{
${ }^{49}$ This is a property of preferences with EIS of one. In general $\tilde{\sigma}^{T F P}$ and $g$ could affect investment $\hat{x}$ even without money, and can affect the value of liquidity $\psi$ because $r+\theta^{T F P} \tilde{\sigma}^{T F P}-g$ is not invariant to changes in $g$ and $\tilde{\sigma}^{T F P}$.
} 

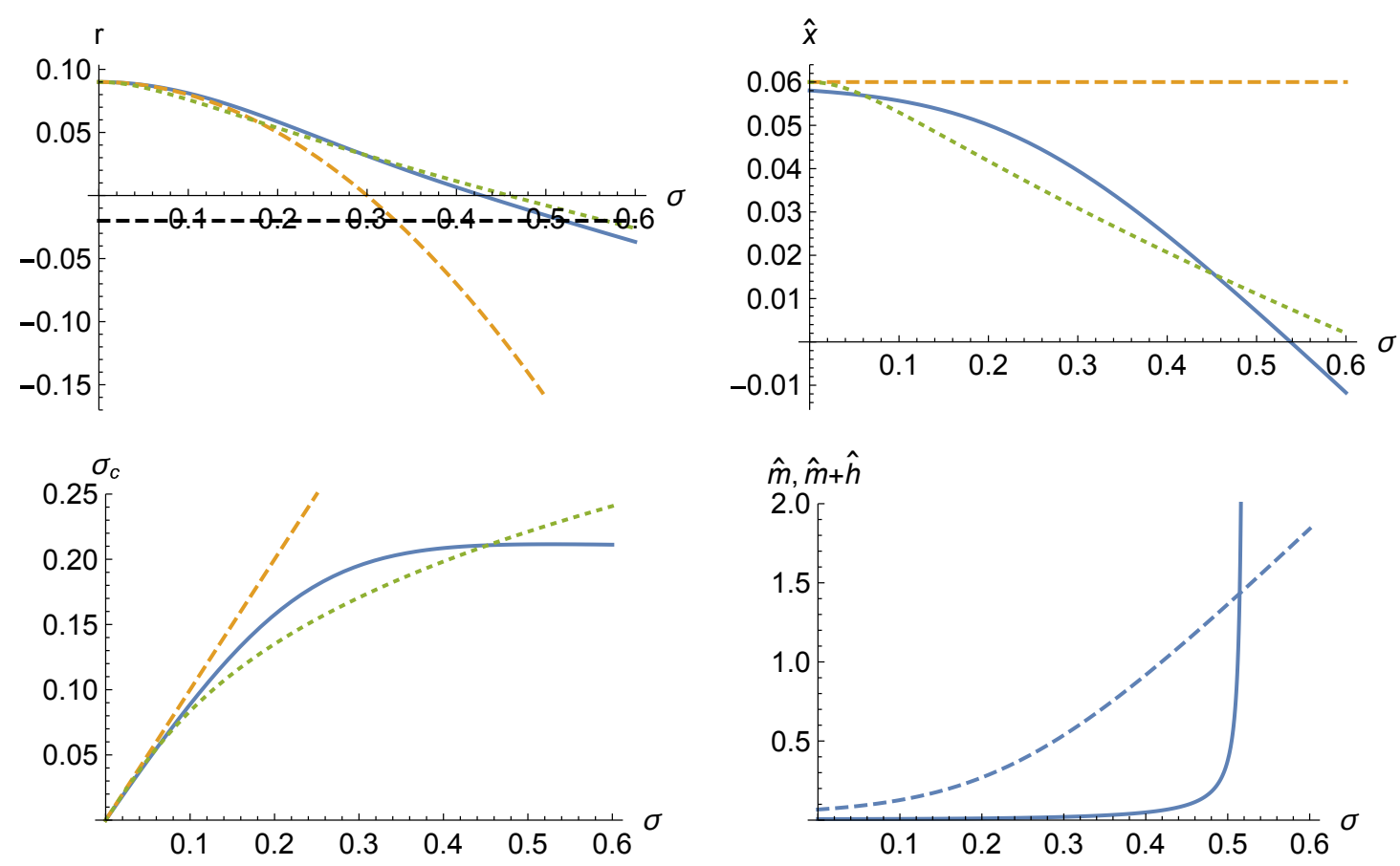

Figure 6: Interest rate $r$, investment $\hat{x}$, idiosyncratic risk $\sigma_{c}$, and monetary variables $\hat{m}$ and $\psi=\hat{m}+\hat{h}$ in the dynamic model for the non-monetary economy (dashed orange), monetary competitive equilibrium (solid blue), and the social planner's allocation (dotted green). Parameters: $a=1 / 10, \rho=4 \%, \pi=2 \%, \delta=1 \%, \beta=1.7 \%, \bar{\sigma}=0.3, \phi=0.02, \nu=0.01, \tilde{\sigma}^{T F P}=0$.

an attractive hedge. This is why $\tilde{\sigma}_{\psi t}^{R S}$ appears in (48).

Recursive Equilibrium. We look for a recursive equilibrium with $\sigma_{t}$ as the state variable, so $\psi_{t}=\psi\left(\sigma_{t}\right)$ can be characterized as the solution to an ODE derived from (47). Use Ito's lemma to compute the drift and volatility of $\psi$, the Euler equation (40) to eliminate $r$ and $\hat{x}$ terms, and $\hat{m}_{t} i_{t}=\rho \beta w_{t} / k_{t}=\rho \beta\left(1+\psi_{t}\right)$.

Proposition 12. The equilibrium value of $\psi(\sigma)$ solves the $O D E$

$$
\rho \beta(1+\psi)+\frac{\psi^{\prime} \phi(\bar{\sigma}-\sigma)+\frac{1}{2} \psi^{\prime \prime} \sigma \nu^{2}}{1+\psi}=\psi\left(\rho-\left(\frac{\sigma}{1+\psi}\right)^{2}\right)+\left(\frac{\psi^{\prime} \sqrt{\sigma} \nu}{1+\psi}\right)^{2}
$$

With a solution $\psi(\sigma)$ to (49) we can obtain all the other equilibrium objects using (40)-(45). If we also satisfy the transversality conditions, we have a competitive equilibrium.

Figure 6 shows the competitive equilibrium in the dynamic model, with and without money. It has essentially the same properties as in the BGP economy with constant idiosyncratic risk $\sigma$. Money improves idiosyncratic risk sharing but depresses investment. After a risk shock increases $\sigma_{t}$ the value of liquidity goes up, so the real interest rate falls less than it would without money and investment falls. The effects of the shock are as persistent as the shock itself, and inflation is always on target $\pi_{t}$. The target itself doesn't affect any real variable other than real money holdings 
$m_{t}$ through the interest rate, and this is valid for time-varying inflation targets. As a result, the optimal inflation target satisfies the Friedman rule $i_{t}=r_{t}+\pi_{t} \approx 0$, so $\pi_{t}$ must go up during periods of high idiosyncratic risk $\sigma_{t}$ (because the real interest rate $r_{t}$ is then low). ${ }^{50}$

\subsection{Planner's problem}

As in the static case, the incomplete idiosyncratic risk sharing can be micro-founded by a moral hazard problem with hidden trade (see Online Appendix for details). The incentive compatibility constraints are

$$
\begin{aligned}
\sigma_{c t} & =\rho(1-\beta) c_{t}^{-1} k_{t} \sigma & \text { "skin in the game" } \\
\mu_{c t} & =r_{t}-\rho+\sigma_{c t}^{2}+\left(\tilde{\sigma}_{c t}^{T F P}\right)^{2}+\left(\tilde{\sigma}_{c t}^{R S}\right)^{2} & \text { Euler equation } \\
\alpha_{t} & =\sigma_{c t} \sigma_{t} & \text { demand for capital } \\
\tilde{\sigma}_{c t}^{T F P} & =\theta_{t}^{T F P} & \text { TFP shocks } \\
\tilde{\sigma}_{c t}^{R S} & =\theta_{t}^{R S} & \text { Risk shocks } \\
m_{t} / c_{t} & =\beta /(1-\beta) i_{t}^{-1} & \text { demand for money }
\end{aligned}
$$

As before, the planner does not take prices $r, \alpha, \theta^{T F P}, \theta^{R S}$, and $i$ as given, so the only true IC constraint is that he must treat all agents the same (up to scale) and must expose them to their own idiosyncratic risk to provide incentives. This yields a tradeoff between investment $\hat{x}_{t}$ and idiosyncratic risk sharing $\sigma_{c t} / \sigma_{t}$

$$
\sigma_{c t} / \sigma_{t}=\frac{\rho(1-\beta)}{a-\hat{x}_{t}}
$$

which is the same as in the static version of the model given by (32).

Since all agents must be treated the same up to scale, and because of homothetic preferences everything will be proportional to $k$, the value function of the planner takes the form $V(\sigma, k)=$ $A(\sigma)+\frac{1}{\rho} \log (k)$, satisfying the HJB equation ${ }^{51}$

$$
\begin{gathered}
\rho A(\sigma)+\log (k)=\max _{\hat{x}, i}\left\{\log (k)+\log (a-\hat{x})+\beta \log \left(\frac{\beta}{1-\beta} \frac{1}{i}\right)+A^{\prime}(\sigma) \phi(\bar{\sigma}-\sigma)+\frac{1}{2} A^{\prime \prime}(\sigma) \sigma \nu^{2}\right. \\
\left.+\frac{1}{\rho}\left(\hat{x}+g-\delta-\frac{1}{2}\left(\tilde{\sigma}^{T F P}\right)^{2}-\frac{1}{2}\left(\frac{\rho(1-\beta)}{a-\hat{x}} \sigma\right)^{2}\right)\right\}
\end{gathered}
$$

where the last term $-\frac{1}{\rho} \frac{1}{2}\left(\frac{\rho(1-\beta)}{a-\hat{x}} \sigma\right)^{2}$ captures the cost of exposing agents to idiosyncratic risk.

\footnotetext{
${ }^{50}$ It's worth noting that the central bank might be unable to deliver a fixed inflation target $\pi_{t}=\bar{\pi}$, because for high enough $\sigma_{t}$ the real interest rate becomes very negative. When this happens the central bank is forced to abandon its inflation target. The competitive equilibrium with money only exists for inflation targets $\pi_{t}$ that take this into account (such as $\pi_{t}=\max \left\{\tilde{\pi}_{t},-r_{t}\right\}$ for an arbitrary $\tilde{\pi}_{t}$ ), but the inflation target doesn't matter otherwise for the real side of the economy.

${ }^{51}$ We can also obtain an explicit intertemporal expression like (27).
} 
The nominal interest rate should be zero $i \approx 0$, and $\hat{x}$ must satisfy the FOC

$$
\hat{x}_{t}=a-\rho-\sigma_{c t}^{2}
$$

which is the same as in the stationary baseline model. The source of inefficiency is the same as in the stationary model, but it now has a dynamic dimension. As before, the planner and the competitive equilibrium share the same locus of incentive compatible combinations of investment $\hat{x}$ and idiosyncratic risk sharing $\sigma_{c}$ given by $(56)$, but they choose different $\left(\hat{x}, \sigma_{c}\right)$ combinations. However, while the planner only cares about the current value of idiosyncratic risk $\sigma_{t}$, the competitive equilibrium picks a $\left(\hat{x}_{t}, \sigma_{c t}\right)$ that depends on the future behavior of idiosyncratic risk $\sigma_{t}$ through the value of liquidity today $\psi_{t}$.

Figure 6 also shows the planner's optimal allocation. An important difference with the static case is that it is possible for investment to be too low in the competitive equilibrium for very low $\sigma_{t}$, too high for intermediate $\sigma_{t}$, and again too low for high $\sigma_{t}$ (and the same goes for $\sigma_{c}$ through (56)). The reason for this is that while the planner's allocation coincides with the static case with a constant $\sigma=\sigma_{t}$, the competitive equilibrium depends on the stochastic behavior of $\sigma_{t}$ through the value of liquidity $\psi_{t}$. If $\sigma_{t}$ today is very low but is expected to go up to $\bar{\sigma}$ very fast, the value of $\psi_{t}$ will be closer to the value in the static case with $\sigma=\bar{\sigma}$ rather than $\sigma=\sigma_{t}$. So the competitive equilibrium chooses a $\left(\hat{x}_{t}, \sigma_{c t}\right)$ on the locus on incentive compatible constraints given by (56) that is closer to what it would choose in the static case with $\sigma=\bar{\sigma}$. This is captured in equation (48) through the role of $\mu_{\psi t}$ and $\sigma_{\psi t} .{ }^{52}$

We can still implement the planner's optimal allocation with a tax on capital $\tau^{k}$ that internalizes the externality produced by hidden trade. Introducing the tax only changes the asset pricing equation

$$
r_{t}=a+g-\delta-\tau_{t}^{k}-\sigma_{c t} \sigma_{t}-\theta_{t}^{T F P} \tilde{\sigma}^{T F P}
$$

and therefore the equilibrium investment

$$
\hat{x}_{t}=a-\rho-\tau_{t}^{k}+\sigma_{c t}^{2}-\sigma_{c t} \sigma_{t}-\mu_{\hat{c} t}+\left(\tilde{\sigma}_{c t}^{R S}\right)^{2}
$$

Comparing this expression to (57) we find the wedge

$$
\tau_{t}^{k}=2 \sigma_{c t}^{2}-\sigma_{c t} \sigma_{t}-\mu_{\hat{c} t}+\left(\tilde{\sigma}_{c t}^{R S}\right)^{2}
$$

Proposition 13. Let $\mathcal{P}$ be an optimal allocation with processes for investment $\hat{x}$, aggregate consumption $\hat{c}$, and idiosyncratic consumption risk $\sigma_{c}$. Then $r_{t}=\rho+\mu_{c t}-\sigma_{c t}^{2}-\left(\tilde{\sigma}_{c t}^{T F P}\right)^{2}-\left(\tilde{\sigma}_{c t}^{R S}\right)^{2}$, $\theta_{t}^{T F P}=\tilde{\sigma}_{c}^{T F P}, \theta_{t}^{R S}=\tilde{\sigma}_{c}^{R S}, \hat{x}$ and $\hat{m}_{t}=\frac{\beta}{1-\beta} \frac{a-\hat{x}_{t}}{r_{t}+\pi_{t}}$ is a competitive equilibrium with $\tau_{t}^{k}$ given by (58) and inflation target $\pi_{t}$, provided that $\lim _{t \rightarrow \infty} \mathbb{E}^{Q}\left[e^{-\int_{0}^{t} r_{u} d u} k_{t} \hat{c}_{t}\right]=0$ and $i_{t}=r_{t}+\pi_{t}>0$. The optimal inflation target satisfies $i_{t}=r_{t}+\pi_{t} \approx 0$ (Friedman rule).

\footnotetext{
${ }^{52}$ In this solution, $\sigma_{\psi} \rightarrow 0$ as $\sigma \rightarrow 0$, so it's all really about the drift $\mu_{\psi}$ which does not vanish as $\sigma \rightarrow 0$.
} 


\section{Discussion}

\subsection{Liquidity premium and bubbles.}

In the model the liquidity premium comes from the fact that liquid assets appear in the utility function, so agents are willing to hold them even if their yield is below the interest rate. This is the simplest and most transparent way of introducing assets with a liquidity premium, and it is meant to capture that money and other assets are useful for transactions. In the Appendix I also solve the model with a cash-in-advance constraint and a more flexible CES specification for MIU, and obtain the same results except that the expenditure share on liquidity depends on the nominal interest rate. We could also use a more microfounded model of monetary exchange, as in Lagos and Wright (2005). The liquidity premium can also reflect the use of some securities, such as Treasuries, in financial transactions. In fact, at least part of the liquidity premium on Treasuries is likely to reflect this. ${ }^{53}$ As long as money has a liquidity premium - that is, its yield is below the risk-free rate - the results will go through.

There is also a large literature modeling money as a bubble in the context of OLG or incomplete risk sharing models. ${ }^{54}$ The closest paper is Brunnermeier and Sannikov (2016b) who develop a version of the Bewley (1980) model that is tractable and yields closed-form solutions. In contrast, here bubbles are explicitly ruled out. ${ }^{55}$ The liquidity view in this paper has differences and similarities with the bubble view. Many of the results here are likely to go through in a setting with bubbles. Intuitively, a safe bubble can provide a safe store of value that improves idiosyncratic risk sharing and depresses investment, just like money does in this paper. But there are also important differences.

To understand the link with bubbles, we can ignore the government bonds and deposits, $b_{t}=$ $d_{t}=0$, and assume money is not printed, $d M_{t}=0$, and therefore in a BGP inflation is simply minus the growth rate of the economy. Write equation (18) without the No-Ponzi condition

$$
w_{t}=k_{t}+\underbrace{\int_{t}^{\infty} e^{-\int_{t}^{s} r_{u} d u} m_{t} i_{t} d t}_{\text {liquidity services }}+\underbrace{\lim _{T \rightarrow \infty} e^{-\int_{0}^{T} r_{s} d s} m_{T}}_{\text {bubble }}
$$

In this paper, the No-Ponzi condition eliminates the last term, $\lim _{T \rightarrow \infty} e^{-\int_{0}^{T} r_{s} d s} m_{T}=0$. Money is not a bubble - it derives its value from it's liquidity premium, which arises because money provides liquidity services. In models with bubbles, instead, money doesn't have a liquidity premium, so the nominal interest rate must be zero $i_{t}=0$. Money is an asset that doesn't pay any dividend, but still yields the arbitrage-free market return; $r_{t}$ if there is no aggregate risk. It has positive value

\footnotetext{
${ }^{53}$ See Krishnamurthy and Vissing-Jorgensen (2012).

54 See Samuelson (1958), Bewley (1980), Aiyagari (1994), Diamond (1965), Tirole (1985), Asriyan et al. (2016), Santos and Woodford (1997).

${ }^{55}$ In addition, they introduce money proportionally to wealth, so high inflation acts as a subsidy to saving. They find that the optimal inflation rate rises with risk. Here instead money is distributed lump-sum, so it is superneutral - changes in the inflation rate don't have real effects. The model here converges to theirs in the cashless limit $\beta \rightarrow 0$ in the special case where money supply is constant, $\mu=0$.
} 
only because the last term doesn't vanish. In a BGP, this requires $r=$ growth rate. But in both the liquidity and the bubble views, money provides a store of value that improves risk sharing, $\sigma_{c}=\frac{k_{t}}{w_{t}} \sigma<\sigma$.

Modeling money as an asset with a liquidity premium has several advantages. First, money does have a liquidity premium. The bubble view cannot explain why people hold money when they can hold safe nominal bonds that pay interest. If the bubble is really money, then the equilibrium nominal interest rate must be zero and the real interest rate must be equal to the growth rate of the economy. The liquidity view instead can provide a more flexible account of inflation and interest rates. In addition, the bubble only exists for high enough levels of idiosyncratic risk, while here money always has real effects which gradually grow as interest rates fall.

Alternatively, the bubble may not really be money. It could be housing, the stock market, government debt, social security, or even tulips. This can potentially be very interesting, but it is difficult to determine if asset values really have a bubble component. In contrast, it's relatively straightforward to establish that some assets have a liquidity premium. Linking the value of money to liquidity premiums also allows us to understand its behavior in response to shocks and policy interventions, since it is more readily grounded in fundamentals.

Finally, it's worth pointing out that bubbles may have idiosyncratic risk. To the extent that agents cannot diversify this idiosyncratic risk, the bubble will not perform the same role as money, which is safe. For example, suppose there is a housing bubble, so that house prices are $10 \%$ above their fundamental value, but each agent must buy one house whose value has idiosyncratic risk. Then the bubble may not be able to produce a liquidity trap, since it is not a safe store of value.

There is also a link between the liquidity view and the bubble view in the cashless limit. As explained in Section 2.4, the liquidity trap in this paper does not hinge on large expenditures on liquidity services (large $\beta$ ). This can be formalized by noting that the monetary economy does not converge to the non-monetary one as $\beta \rightarrow 0$. The reason is that for high enough $\sigma$, the real interest rate in the non-monetary economy can be below the growth rate of the economy. This is not a problem in the non-monetary economy, since the only asset is risky capital. But in an economy with safe money, the value of liquidity will become very large as the real interest rate approaches the growth rate of the economy. The result will be a liquidity trap with high interest rates and depressed investment, relative to the non-monetary economy, even for vanishingly small $\beta$. The cashless limit of the monetary economy therefore coincides with a bubbly equilibrium of the non-monetary economy, since it only violates the No-Ponzi condition when $\beta=0$. For $\beta>0$ it doesn't violate the No-Ponzi conditions, but gets arbitrarily close.

\subsection{Sticky prices and the zero lower bound on interest rates}

An alternative view of liquidity traps in the context of New Keynesian models with sticky prices is

that money creates a zero lower bound for the nominal interest rate. The natural interest rate $r_{t}^{n}$ is the equilibrium real interest rate under flexible prices. The central bank could achieve its inflation target $\bar{\pi}$ and zero output gap by setting the nominal interest rate $i_{t}=r_{t}^{n}+\bar{\pi}$, this reproducing 
the flexible-price allocation. But if the natural interest rate is very negative this could require a negative nominal interest rate. To fix ideas, imagine the inflation target is zero, $\bar{\pi}=0$, so that the real and nominal interest rates are the same. If the natural rate $r_{t}^{n}$ is negative, the central bank is forced to miss its inflation target, allow the economy to operate with an output gap, or both. ${ }^{56}$

In contrast, this is a flexible-price model of liquidity traps. Both approaches are complementary. In the short-run prices may well be sticky, markets segmented, and information imperfect. I abstract from these short-run frictions to focus on the real, frictionless aspect of liquidity traps. The model in this paper can be regarded as the flexible-price version of a richer model with nominal rigidities, and the real interest rate here as the natural rate in that model.

This has important consequences for the role of the zero lower bound. If there is money then interest rates must be positive even with flexible prices, $r_{t}^{n} \geq 0$. It is perfectly possible for the interest rate to be negative without money but positive with money, even if prices are flexible. Under these circumstances the zero lower bound will not be a problem - the central bank will be able to hit its inflation target and a zero output gap; that is, to reproduce the flexible-price allocation. ${ }^{57}$ Furthermore, since money is superneutral, a higher inflation target will always "fix" the zero lower bound problem, but it will not affect the real side of the economy. In fact, under the optimal monetary policy, with $i \approx 0$, the zero lower bound is never an issue.

However, the flexible price equilibrium is only optimal if a tax/subsidy on investment is used to correct the externality produced by hidden trade. If it is not, or if it cannot be adjusted fast enough, reproducing the flexible-price allocation is not optimal. Investment is too depressed during liquidity traps. The central bank may then lower the interest rate below the natural level in order to stimulate investment. I conjecture that this is in fact the optimal policy in this environment (with nominal rigidities) but this is beyond the scope of this paper.

\subsection{The role of the risk premium}

The model in this paper is driven by exogenous shocks to idiosyncratic risk $\sigma_{t}$ for the sake of concreteness. But the mechanism actually hinges on the idiosyncratic risk premium and precautionary motives, which might go up for other reasons. For example, suppose we generalize preferences to EZ with intertemporal elasticity one but risk aversion $\gamma>1$ (see Appendix for details). The only thing that changes in the equations is that the risk premium is now $\alpha=\gamma \sigma_{c} \times \sigma$, and the precautionary motive is $\gamma \sigma_{c}^{2}$ (in other words, the "price" of idiosyncratic risk is $\gamma \sigma_{c}$ ). We obtain a system of equations analogous to (14), (15), and (8) (with $\gamma=1$ we recover the original equations):

$$
r=a-\delta-\gamma \sigma^{2}(1-\lambda)
$$

\footnotetext{
${ }^{56}$ See Werning (2011) for a characterization of the optimal monetary policy in a New Keynesian model where the zero lower bound is binding.

${ }^{57}$ As explained in Section 2.4, the zero lower bound can only be binding if the flexible price equilibrium with money requires a negative interest rate. While this is possible, it is a much more stringent condition than having the interest rate without money be negative.
} 


$$
\begin{aligned}
& \hat{x}=a-\rho-\rho \frac{\lambda-\beta}{1-\lambda} \\
& \lambda=\frac{\rho \beta}{\rho-\gamma \sigma^{2}(1-\lambda)^{2}}
\end{aligned}
$$

Clearly, $\gamma \sigma^{2}$ is the relevant parameter. An increase in risk aversion $\gamma$ has the same effect as an increase in idiosyncratic risk $\sigma^{2}$. An increase in risk aversion could represent changes in wealth distribution between risk averse and risk tolerant agents after a negative shock (see Longstaff and Wang (2012)) or the health of the balance sheets of specialists who invest in risky assets such as entrepreneurs or financial intermediaries (see He and Krishnamurthy (2013) and He et al. (2015))). It could also represent habits (see Campbell and Cochrane (1999)) or an increase in ambiguity aversion after a shock that upends agents' beliefs about how the economy works (see Barillas et al. $(2009))$.

\subsection{Measuring the value of liquidity}

The value of liquidity $\lambda$ plays a central role and captures the real effects of money on the economy. The model produces a simple formula for $\lambda$ in terms of fundamentals, and the cashless limit in Proposition 5 ensures that the liquidity trap survives even when $\beta \rightarrow 0$. But we might also like to measure $\lambda$ directly. Unfortunately, since $\lambda$ represents the present value of liquidity, it cannot the directly measured. We must specify a model of the liquidity premium and a model of asset pricing. The covariance of the liquidity premium with the pricing kernel is especially important because it tells us what is the appropriate discount rate. This paper provides such a model, of course, but it is too stylized to get the asset pricing right (e.g. the equity premium puzzle). A quantitatively serious asset pricing model of the value of liquidity is beyond the scope of this paper, but is a natural next step to evaluate this theory.

Alternatively, we can specify a model of government surpluses and use the budget equation of the government,

$$
m_{t}+b_{t}=\mathbb{E}_{t}^{Q}\left[\int_{t}^{\infty} e^{-\int_{t}^{s} r_{u} d u} d \tau_{s}\right]+\mathbb{E}_{t}^{Q}\left[\int_{t}^{\infty} e^{-\int_{t}^{s} r_{u} d u}\left(m_{s} i_{s}+b_{s}\left(i_{s}-i_{s}^{b}\right)\right) d s\right]
$$

to obtain a measure of at least the part of the value of liquidity corresponding to government liabilities (currency, reserves, and government bonds - this leaves out private liquidity). What this budget constraint says is that the current value of government liabilities $m_{t}+b_{t}$ must be financed by the present value of government surpluses (the first term), plus the present value of the liquidity premium (the second term, and the object we are interested in). Since $m_{t}+b_{t}$ can be observed, if we specify a model of government surpluses and an asset pricing model, we can back out the present value of the liquidity premium. Notice that if we expect large deficits for a long time, we will back out a very large value of liquidity. In other words, if the government has large liabilities and plans to run a deficit, then through the lens of the government's intertemporal budget constraint, it must mean that the value of liquidity is very large. But this measure hinges on a model of government 
surpluses and asset pricing; it could be that the market expects the government to start running very large surpluses at some point in the future.

\section{Conclusions}

Liquidity traps are associated with some of the deepest and most persistent slumps in modern history. Money provides a safe store of value that prevents equilibrium interest rates from falling during downturns, and the economy enters a persistent slump with depressed investment. But how can money have such large and persitent real effects? This is an old question. In this paper I provide an equilibrium theory of liquidity traps and the real effects of money with perfectly flexible prices. The main insight is that money improves idiosyncratic risk sharing and drives a wedge between the risk premium on capital and agents' precautionary saving motive, which keeps interest rates high and depresses investment. While the value of money, and other safe assets with a liquidity premium, is pretty small during normal times, during persistent slumps with low interest rates its value can become very large. The result is a liquidity trap.

The liquidity trap is an equilibrium outcome - prices are flexible, markets clear, and inflation is on target-but it's not efficient. In contrast to most of the literature on liquidity traps, the inefficiency does not arise from sticky prices and the zero lower bound on interest rates. Money is superneutral, Ricardian equivalence holds, and the zero lower bound on nominal rates is not binding. The inefficiency comes from the inability of private contracts to prevent agents from engaging in hidden trade. During booms investment is too high and money doesn't provide enough risk sharing; during downturns investment is too depressed and money provides too much risk sharing. Perhaps surprisingly, while money has large real effects, monetary policy is ineffective. The optimal allocation can be implemented with a tax or subsidy on capital and the Friedman rule. When investment is too high, tax it; when it's too low, subsidize it.

\section{References}

Aiyagari, S. R. (1994). Uninsured idiosyncratic risk and aggregate saving. The Quarterly Journal of Economics, 659-684.

Aiyagari, S. R. and E. R. McGrattan (1998). The optimum quantity of debt. Journal of Monetary Economics 42(3), 447-469.

Aiyagari, S. R. and N. Wallace (1991). Existence of steady states with positive consumption in the kiyotaki-wright model. The Review of Economic Studies 58(5), 901-916.

Angeletos, M. (2006, November). Uninsured idiosyncratic investment risk and aggregate saving. forthcoming in Review of Economic Dynamics.

Asriyan, V., L. Fornaro, A. Martin, and J. Ventura (2016, September). Monetary Policy for a Bubbly World. NBER Working Papers 22639, National Bureau of Economic Research, Inc. 
Bansal, R., D. Kiku, I. Shaliastovich, and A. Yaron (2014). Volatility, the macroeconomy, and asset prices. Journal of Finance.

Bansal, R. and A. Yaron (2004). Risks for the long run: A potential resolution of asset pricing puzzles. The Journal of Finance 59(4), pp. 1481-1509.

Barillas, F., L. P. Hansen, and T. J. Sargent (2009). Doubts or variability? journal of economic theory 144(6), 2388-2418.

Bemanke, B. and H. James (1991). The gold standard, deflation, and financial crisis in the great depression: An international comparison. In Financial markets and financial crises, pp. 33-68. University of Chicago Press.

Bewley, T. (1980). The optimum quantity of money. Models of monetary economies, 169-210.

Bloom, N. (2009). The impact of uncertainty shocks. Econometrica 77(3), pp. 623-685.

Bloom, N., M. Floetotto, N. Jaimovich, I. Saporta-Eksten, and S. Terry (2012). Really uncertain business cycles. NBER working paper 18245.

Brunnermeier, M. K. and Y. Sannikov (2016a). The i theory of money. Technical report, National Bureau of Economic Research.

Brunnermeier, M. K. and Y. Sannikov (2016b, May). On the optimal inflation rate. American Economic Review 106(5), 484-89.

Buera, F. and J. P. Nicolini (2014). Liquidity traps and monetary policy: Managing a credit crunch.

Caballero, R. J. and A. Simsek (2017). A risk-centric model of demand recessions and macroprudential policy. Technical report, National Bureau of Economic Research.

Campbell, J., S. Giglio, C. Polk, and R. Turley (2012, March). An intertemporal capm with stochastic volatility. working paper.

Campbell, J., M. Lettau, B. G., and Y. Xu (2001). Have individual stocks become more volatile? an empirical exploration of idiosyncratic risk. The Journal of Finance 56(1), pp. 1-43.

Campbell, J. Y. and J. H. Cochrane (1999). By force of habit: A consumption-based explanation of aggregate stock market behavior. Journal of political Economy 107(2), 205-251.

Christiano, L., R. Motto, and M. Rostagno (2014). Risk shocks. American Economic Review 104(1).

Cochrane, J. H. (2011). Presidential address: Discount rates. The Journal of finance 66(4), 10471108.

Cole, H. L. and N. R. Kocherlakota (2001). Efficient allocations with hidden income and hidden storage. The Review of Economic Studies 68(3), 523-542. 
Di Tella, S. (2016). Optimal regulation of financial intermediaries. Working paper - Stanford GSB.

Di Tella, S. (2017, August). Uncertainty shocks and balance sheet recessions. Forthcoming Journal of Political Economy.

Di Tella, S. and Y. Sannikov (2016). Optimal asset management contracts with hidden savings. Working paper, Stanford GSB and Princeton University.

Diamond, P. A. (1965). National debt in a neoclassical growth model. The American Economic Review 55(5), 1126-1150.

Eggertsson, G. B. et al. (2003). Zero bound on interest rates and optimal monetary policy. Brookings papers on economic activity 2003(1), 139-233.

Eggertsson, G. B. and P. Krugman (2012). Debt, deleveraging, and the liquidity trap: A fisherminsky-koo approach. The Quarterly Journal of Economics 127(3), 1469-1513.

Eggertsson, G. B. and M. Woodford (2004). Policy options in a liquidity trap. The American Economic Review 94(2), 76-79.

Eichengreen, B. and J. Sachs (1985). Exchange rates and economic recovery in the 1930s. The Journal of Economic History 45(4), 925-946.

Farhi, E., M. Golosov, and A. Tsyvinski (2009). A theory liquidity and regulation of financial intermediation. The Review of Economic Studies 76, 973-992.

He, Z., B. T. Kelly, and A. Manela (2015). Intermediary asset pricing: New evidence from many asset classes. Available at SSRN 2662182.

He, Z. and A. Krishnamurthy (2013). Intermediary asset pricing. The American Economic Review 103(2), 732-770.

Karatzas, I. and S. Shreve (2012). Brownian motion and stochastic calculus, Volume 113. Springer Science \& Business Media.

Kehoe, T. and D. Levine (1993). Debt-constrained asset markets. The Review of Economic Studies $60,865-888$.

Kiyotaki, N. and R. Wright (1993). A search-theoretic approach to monetary economics. The American Economic Review, 63-77.

Krishnamurthy, A. and A. Vissing-Jorgensen (2012). The aggregate demand for treasury debt. Journal of Political Economy 120(2), 233-267.

Krugman, P. R., K. M. Dominquez, and K. Rogoff (1998). It's baaack: Japan's slump and the return of the liquidity trap. Brookings Papers on Economic Activity 1998(2), 137-205. 
Lagos, R. and R. Wright (2005). A unified framework for monetary theory and policy analysis. Journal of political Economy 113(3), 463-484.

Longstaff, F. A. and J. Wang (2012). Asset pricing and the credit market. The Review of Financial Studies 25(11), 3169-3215.

Samuelson, P. A. (1958). An exact consumption-loan model of interest with or without the social contrivance of money. Journal of political economy 66(6), 467-482.

Santos, M. S. and M. Woodford (1997). Rational asset pricing bubbles. Econometrica: Journal of the Econometric Society, 19-57.

Shi, S. (1997). A divisible search model of fiat money. Econometrica: Journal of the Econometric Society, $75-102$.

Svensson, L. E. (2000). The zero bound in an open economy: A foolproof way of escaping from a liquidity trap. Technical report, National Bureau of Economic Research.

Tirole, J. (1985). Asset bubbles and overlapping generations. Econometrica: Journal of the Econometric Society, 1071-1100.

Werning, I. (2011). Managing a liquidity trap: Monetary and fiscal policy. Technical report, National Bureau of Economic Research.

\section{Appendix}

\section{Omitted Proofs}

\section{Proposition 1}

Proof. The properties of $\lambda$ and $\sigma_{c}$ are straightforward from equation (8), noticing only that $\rho-$ $((1-\lambda) \sigma)^{2}=r-(\hat{x}-\delta)>0$ in equilibrium.

\section{Proposition 2}

Proof. Straightforward from equilibrium conditions $r=a-\delta-\sigma^{2}$ and $\hat{x}=a-\rho$.

\section{Proposition 3}

Proof. We know from Proposition 1 that $\lambda$ and $\sigma_{c}=(1-\lambda) \sigma$ are increasing in $\sigma$. So the real interest rate $r=a-\delta-(1-\lambda) \sigma^{2}$ falls when $\sigma$ increases, but less so than without money, since in that case $r=a-\delta-\sigma^{2}$. Investment $\hat{x}$ falls because the term $\rho \frac{\lambda-\beta}{1-\lambda}>0$ is increasing in $\lambda$. Real money balances $\hat{m}=\frac{\beta}{1-\beta} \frac{a-\hat{x}}{r+\pi}$ therefore increase.

If $\sigma=0$, we have $r=a-\delta, \lambda=\frac{\rho \beta}{\rho}=\beta$, and $\hat{x}=a-\rho$ which coincide with the non-monetary economy. 


\section{Proposition 4}

Proof. From individual optimization we know that the expenditure share of liquidity is $\beta$, invariant to $b$. Since $r, \hat{x}$, and $\lambda$ are pinned down by (14), (15), and (8), they are not affected by changes in $b$.

\section{Proposition 5}

Proof. It suffices to look at the behavior of $\lambda$ defined by (8), which we can rewrite

$$
\lambda\left(\rho-((1-\lambda) \sigma)^{2}\right)=\rho \beta
$$

As $\beta \rightarrow 0$ the lhs converges to zero, and so must the rhs. This means that either a) $\lambda \rightarrow 0$ or b) $\lambda \rightarrow 1-\frac{\sqrt{\rho}}{\sigma}$. If $\sigma<\sqrt{\rho}$, then $1-\frac{\sqrt{\rho}}{\sigma}<0$. Since $\lambda>\beta$ always, b) cannot be, so we are left with a) $\lambda \rightarrow 0$. From (14) and (15) we see that $r$ and $x$ converge to the values on the non-monetary economy with $\lambda=\beta=0$.

If instead $\sigma \geq \sqrt{\rho}$, we cannot have $\lambda \rightarrow 0$, because it implies that $\rho-((1-\lambda) \sigma)^{2} \leq 0$ at some point along the way (for $\lambda$ small enough). Since $\lambda>\beta$ always, this requires $\rho \beta<0$, which is not true. So we have b) $\lambda \rightarrow 1-\frac{\sqrt{\rho}}{\sigma} \geq 0$, and the inequality is strict if $\sigma>\sqrt{\rho}$. From (14) and (15) we see that the real interest rate $r$ is high and investment $\hat{x}$ low relative to the economy without money $(\beta=0)$.

\section{Proposition 6}

Proof. See Online Appendix

\section{Proposition 7}

Proof. Combine (29) with $\sigma_{c}=\frac{\rho(1-\beta) \sigma}{a-\hat{x}}$ to obtain

$$
\sigma_{c}=\frac{\rho(1-\beta)}{\rho+\sigma_{c}^{2}} \sigma
$$

It follows that when $\sigma=0$ we get $\sigma_{c}=0$, and $\sigma_{c}$ is increasing in $\sigma$. Rewrite it

$$
\frac{\sigma_{c}}{\sigma}=\frac{\rho(1-\beta)}{\rho+\left(\frac{\sigma_{c}}{\sigma}\right)^{2} \sigma^{2}}
$$

It follows that $\sigma_{c} / \sigma$ is decreasing in $\sigma$. The properties of $\hat{x}$ follow from equation (29). Finally, write

$$
r=\rho+\hat{x}-\delta-\sigma_{c}^{2}=a-\delta-2 \sigma_{c}^{2}
$$

It follows that $r$ falls with $\sigma$. 


\section{Proposition 8}

Proof. First take the $\beta \in(0,1 / 2)$ case. Rewrite (30) and (31) in terms of $y=\sigma_{c} / \sigma$

$$
\begin{array}{lr}
\hat{x}_{S P}=a-\rho-y^{2} \sigma^{2} & \text { Social Planner } \\
\hat{x}_{C E}=a-\rho-y \sigma^{2} \times(1-y) & \text { Competitive Equilibrium }
\end{array}
$$

and the incentive compatible combinations

$$
\hat{x}_{I C}=a-\frac{\rho(1-\beta)}{y}
$$

The competitive equilibrium lies at the intersection of $\hat{x}_{C E}$ and $\hat{x}_{I C}$; call the corresponding $y_{C E} \in$ $[0,1-\beta]$. The planner's allocation lies at the intersection of $\hat{x}_{S P}$ and $\hat{x}_{I C}$, call the corresponding $y_{S P} \in[0,1-\beta]$.

We know that $y=\sigma_{c} / \sigma$ can range from 0 to $1-\beta$, in both the $\mathrm{CE}$ and $\mathrm{SP}$ (the upper bound comes from knowing that investment is below the first best in both the CE and the SP, and using $\hat{x}_{I C}$.

$\hat{x}_{I C}$ is increasing, strictly concave, and ranges from $-\infty$ when $y=0$ to the first best $a-\rho$ when $y=1-\beta$. It does not depend on $\sigma$, so it will be fixed when we do comparative statics.

$\hat{x}_{C E}$ and $\hat{x}_{S P}$ do depend on $\sigma$. They both start at the first best $a-\rho$ when $y=0 . \hat{x}_{S P}$ is strictly decreasing and concave (it's an inverted parabola) with vertex at $(0, a-\rho)$. So it must cross $\hat{x}_{I C}$ exactly once.

$\hat{x}_{C E}$ is a parabola with vertex at $\left(\frac{1}{2}, a-\rho-\frac{1}{4} \sigma^{2}\right)$. Importantly, it intersects with $\hat{x}_{S P}$ at this point. For $\sigma>0$ they intersect at exactly two points, corresponding to $y=0$ and $y=1 / 2$, and this implies that $\hat{x}_{C E}<\hat{x}_{S P}$ for all $y \in(0,1 / 2)$, and $\hat{x}_{C E}>\hat{x}_{S P}$ for all $y \in(1 / 2,1-\beta)$. Finally, $\hat{x}_{C E}<a-\rho$ for all $y \in(0,1-\beta)$. In particular, $\hat{x}_{C E}(1-\beta)=a-\rho-\sigma^{2} \beta(1-\beta)<a-\rho$. Since $\hat{x}_{C E}$ is strictly convex and $\hat{x}_{I C}$ is strictly concave they intersect at tow points at most. Since $\hat{x}_{I C}=\infty$ for $y=0$, $\hat{x}_{I C}$ crosses $\hat{x}_{C E}$ first from below, and the from above. But since $\hat{x}_{I C}(1-\beta)=1-\rho>\hat{x}_{C E}(1-\beta)$, the second intersection has $y>1-\beta$, so it is not in the range on $y$. There is then only one valid intersection between $\hat{x}_{C E}$ and $\hat{x}_{I C}$; we called it $y_{C E} \in[0,1-\beta]$ and $\hat{x}_{I C}<\hat{x}_{C E}$ for all $y<y_{C E}$ and $\hat{x}_{I C}>\hat{x}_{S P}$ for all $y>y_{C E}$ in the range of $y$.

Now the lower envelope of $\hat{x}_{C E}$ and $\hat{x}_{S P}, \hat{x}_{L}=\min \left\{\hat{x}_{C E}, \hat{x}_{S P}\right\}$ coincides with $\hat{x}_{C E}$ for $y \in[0,1 / 2]$ and with $\hat{x}_{S P}$ for $y \in[1 / 2,1-\beta]$. This implies that if $\hat{x}_{I C}$ first intersects with the lower envelope for $y<1 / 2$, it must do so at $y_{C E}$, and if it first intersects at $y>1 / 2$, it must do so at $y_{S P}$. In the first case, since $\hat{x}_{S P}>\hat{x}_{C E}$ for $y<1 / 2$, it is strictly decreasing, and goes from $a-\rho$ for $y=0$ to $a-\rho-\frac{1}{4} \sigma^{2}=\min \hat{x}_{C E}$ for $y=1 / 2$; and $\hat{x}_{I C}$ is strictly increasing and goes to $1-\rho$; then it means that $y_{S P}<1 / 2$ as well and $y_{S P}>y_{C E}$. In the second case, obviously $y_{C E}>y_{S P}>1 / 2$. If it first intersects at $y=1 / 2$ then $y_{C E}=y_{S P}$.

It follows immediately that if $y_{C E}<y_{S P}$ and both below $1 / 2$, then $\hat{x}_{C E}<\hat{x}_{S P}$ and $\sigma_{c}^{C E}<\sigma_{c}^{S P}$. On the other hand, if $y_{C E}>y_{S P}$ and both above $1 / 2$, then $\hat{x}_{C E}>\hat{x}_{S P}$ and $\sigma_{c}^{C E}>\sigma_{c}^{S P}$. 
It only remains to see which will hold for a given $\sigma$. Since both $\hat{x}_{C E}$ and $\hat{x}_{S P}$ are decreasing for $y \in(0,1 / 2)$, and $\hat{x}_{I C}$ is always increasing, it is enough to compare their values at $y=1 / 2$. If $\hat{x}_{C E}=\hat{x}_{S P} \geq \hat{x}_{I C}$ at $y=1 / 2$, then $y_{C E}$ and $y_{S P}$ are both in $[1 / 2,1-\beta]$. If instead $\hat{x}_{C E}=\hat{x}_{S P} \leq \hat{x}_{I C}$ at $y=1 / 2$, then $y_{C E}$ and $y_{S P}$ are both in $(0,1 / 2)$.

$$
\begin{gathered}
\hat{x}_{C E}=\hat{x}_{S P} \geq \hat{x}_{I C} \\
\Longleftrightarrow a-\rho-\frac{1}{4} \sigma^{2} \geq a-2 \rho(1-\beta) \\
\Longleftrightarrow \sigma^{2} \leq \sigma^{*}=2 \sqrt{\rho(1-2 \beta)}>0
\end{gathered}
$$

Finally, for the case $\beta \in[1 / 2,1), \hat{x}_{C E}<\hat{x}_{S P}$ for all $y \in[0,1-\beta]$, regardless of $\sigma$, so $\hat{x}_{C E}<\hat{x}_{S P}$ and $\sigma_{c}^{C E}<\sigma_{c}^{S P}$. Notice that in this case the formula for $\sigma^{*}<0$.

\section{Proposition 9}

Proof. We already know that the planner's allocation is a BGP with constant $\hat{x}$ and $\sigma_{c}$. By setting the subsidy/tax $\tau^{k}$ according to (35) we ensure that $r, \hat{x}$, and $\hat{m}$ satisfy all the conditions for a BGP equilibrium.

We can check that the value of total wealth $w=k_{t}+m_{t}+h_{t}-\int_{t}^{\infty} e^{-r s} \tau_{s}^{k} k_{s} d s$ satisfies $c_{t}=$ $\rho(1-\beta) w_{t}$, or equivalently $\sigma_{c}=\frac{k_{t}}{w_{t}} \sigma$. Write

$$
\begin{gathered}
\frac{w_{t}}{k_{t}}=1+\frac{\hat{m} i}{r-(\hat{x}-\delta)}+\frac{\tau^{k}}{r-(\hat{x}-\delta)} \\
\frac{w_{t}}{k_{t}}=\frac{r-(\hat{x}-\delta)+\hat{c} \frac{\beta}{1-\beta}+\tau^{k}}{r-(\hat{x}-\delta)}=\frac{\rho-\sigma_{c}^{2}+\rho \beta \frac{\sigma}{\sigma_{c}}+2 \sigma_{c}^{2}-\sigma_{c} \sigma}{\rho-\sigma_{c}^{2}} \\
\frac{w_{t}}{k_{t}}=\frac{\rho+\rho \beta \frac{\sigma}{\sigma_{c}}+\sigma_{c}^{2}-\sigma_{c} \sigma}{\rho-\sigma_{c}^{2}}=\frac{\sigma}{\sigma_{c}}\left(\frac{\rho \frac{\sigma_{c}}{\sigma}+\rho \beta+\sigma_{c}^{2}\left(\frac{\sigma_{c}}{\sigma}-1\right)}{\rho-\sigma_{c}^{2}}\right)
\end{gathered}
$$

Use the planner's FOC (28) and the skin in the game IC constraint (32)

$$
\begin{gathered}
\frac{w_{t}}{k_{t}}=\frac{\sigma}{\sigma_{c}}\left(\frac{\rho \frac{\sigma_{c}}{\sigma}+\rho \beta+(a-\hat{x}-\rho)\left(\frac{\sigma_{c}}{\sigma}-1\right)}{2 \rho-a-\hat{x}}\right)=\frac{\sigma}{\sigma_{c}}\left(\frac{\rho(1+\beta)+(a-\hat{x}) \frac{\rho(1-\beta)-(a-\hat{x})}{a-\hat{x}}}{2 \rho-a-\hat{x}}\right) \\
\frac{w_{t}}{k_{t}}=\frac{\sigma}{\sigma_{c}}\left(\frac{\rho(1+\beta)+\rho(1-\beta)-(a-\hat{x})}{2 \rho-a-\hat{x}}\right)=\frac{\sigma}{\sigma_{c}} \frac{2 \rho-(a-\hat{x})}{2 \rho-(a-\hat{x})}=\frac{\sigma}{\sigma_{c}}
\end{gathered}
$$




\section{Proposition 10}

Proof. First, to implement the optimal allocation we need $r>\hat{x}-\delta$ which is equivalent to $\rho-\sigma_{c}^{2}>0$. We know $\sigma_{c}$ in the optimal allocation is given by

$$
\sigma_{c}=\frac{\rho(1-\beta)}{\rho+\sigma_{c}^{2}} \sigma
$$

and $\sigma_{c}$ is increasing in $\sigma$. For $\sigma=0$ we have $\sigma_{c}=0$ too, so $\rho-\sigma_{c}^{2}>0$. So we only need to ask at what $\sigma$ we have $\sigma_{c}^{2}=\rho$ :

$$
\sqrt{\rho}=\frac{\rho(1-\beta)}{\rho+\rho} \bar{\sigma} \Longrightarrow \bar{\sigma}=\frac{2 \sqrt{\rho}}{1-\beta}
$$

For $\sigma \geq \bar{\sigma}$ we have $\sigma_{c}^{2} \geq \rho$ and therefore $r \leq \hat{x}-\delta$, so the optimal allocation cannot be implemented as a competitive equilibrium with a tax on capital.

For the sign of $\tau^{k}$, use (35) to get

$$
\tau^{k}=\sigma_{c}\left(2 \sigma_{c}-\sigma\right)
$$

So if $\sigma_{c}>\frac{1}{2} \sigma$ we have $\tau^{k}>0$, and if $\sigma_{c}<\frac{1}{2} \sigma$ we have $\tau^{k}<0$. In the optimal allocation we have

$$
\frac{\sigma_{c}}{\sigma}=\frac{\rho(1-\beta)}{\rho+\left(\frac{\sigma_{c}}{\sigma}\right)^{2} \sigma^{2}}
$$

So $\sigma_{c} / \sigma \rightarrow 1-\beta$ when $\sigma \rightarrow 0$, and $\sigma_{c} / \sigma$ is decreasing in $\sigma$. So if $\beta \geq \frac{1}{2}$ we must have $\sigma_{c} \leq \frac{1}{2} \sigma$ and therefore $\tau^{k} \leq 0$, for all $\sigma \in[0, \bar{\sigma})$. If instead $\beta<\frac{1}{2}$, we have $\tau^{k}>0$ for $\sigma$ close to 0 . We only need to find $\sigma^{*}$ such that $\sigma_{c}=\frac{1}{2} \sigma^{*}$.

$$
\frac{1}{2}=\frac{\rho(1-\beta)}{\rho+\frac{1}{4}\left(\sigma^{*}\right)^{2}} \Longrightarrow \sigma^{*}=2 \sqrt{\rho(1-2 \beta)}
$$

It only remains to show that $\sigma^{*} \in(0, \bar{\sigma}] . \sigma^{*}>0$ follows from $\beta<\frac{1}{2}$. Now write

$$
\sigma^{*}=2 \sqrt{\rho(1-2 \beta)} \leq 2 \sqrt{\rho} \leq \frac{2 \sqrt{\rho}}{1-\beta}=\bar{\sigma}
$$

\section{Proposition 11}

Proof. From the definition of $h$, 


$$
m_{t}+h_{t}=m_{t}+\mathbb{E}_{t}^{Q}\left[\int_{t}^{T} e^{-\int_{t}^{s} r_{u} d u} \frac{d M_{s}}{p_{s}}\right]+\mathbb{E}_{t}^{Q}\left[e^{-\int_{t}^{T} r_{u} d u} h_{T}\right]
$$

use $d m_{t}=\frac{d M_{t}}{p_{t}}-m_{t} \pi_{t} d t$ to write

$$
=m_{t}+\mathbb{E}_{t}^{Q}\left[\int_{t}^{T} e^{-\int_{t}^{s} r_{u} d u}\left(d m_{s}+\pi_{s} m_{s} d s\right)\right]+\mathbb{E}_{t}^{Q}\left[e^{-\int_{t}^{T} r_{u} d u} h_{T}\right]
$$

We can write

$$
e^{-\int_{t}^{T} r_{u} d u} m_{T}=m_{t}+\int_{t}^{T} e^{-\int_{t}^{s} r_{u} d u}\left(-r_{s} m_{s} d s+d m_{s}\right)
$$

and plug it in to obtain

$$
m_{t}+h_{t}=\mathbb{E}_{t}^{Q}\left[\int_{t}^{T} e^{-\int_{t}^{s} r_{u} d u}\left(\left(r_{s}+\pi_{s}\right) m_{s} d s\right)\right]+\mathbb{E}_{t}^{Q}\left[e^{-\int_{t}^{T} r_{u} d u}\left(m_{T}+h_{T}\right)\right]
$$

Then take the limit $T \rightarrow \infty$ and use the transversality condition

$$
\lim _{T \rightarrow \infty} \mathbb{E}_{t}^{Q}\left[e^{-\int_{t}^{T} r_{u} d u}\left(m_{T}+h_{T}\right)\right]=0
$$

and the monotone convergence theorem $\left(r_{t}+\pi_{t}=i_{t} \geq 0\right)$ to obtain

$$
m_{t}+h_{t}=\mathbb{E}_{t}^{Q}\left[\int_{t}^{\infty} e^{-\int_{t}^{s} r_{u} d u} m_{s} i_{s} d s\right]
$$

\section{Proposition 12}

Proof. From (47), we plug in $\theta^{T F P}=\tilde{\sigma}^{T F P}$, and $\theta^{R S}=\frac{\sigma_{\psi}}{1+\psi}$, as well as $\hat{m} i=\rho \beta w / k=\rho \beta(1+\psi)$ from (45) and

$$
\hat{x}+g-\delta-r=-\left(\rho+\frac{\mu_{\psi}}{1+\psi}-\left(\frac{\sigma}{1+\psi}\right)^{2}-\left(\tilde{\sigma}^{T F P}\right)^{2}-\left(\frac{\sigma_{\psi}}{1+\psi}\right)^{2}\right)
$$

Then use Ito's lemma to obtain

$$
\begin{gathered}
\mu_{\psi}=\psi^{\prime} \phi(\bar{\sigma}-\sigma)+\frac{1}{2} \psi^{\prime \prime} \sigma \nu^{2} \\
\sigma_{\psi}=\psi^{\prime} \sqrt{\sigma} \nu
\end{gathered}
$$

The ODE (49) has the $\mu_{\psi}$ terms together, and the $\tilde{\sigma}^{T F P}$ terms cancel out. I also simplified the terms involving $\sigma_{\psi}$ into one term.

\section{Proposition 13}

Proof. The equations for the competitive equilibrium are a modified version of (40)-(45), taking into account that total wealth now includes the present value of taxes/subsidies that are rebated 
lump-sum and the tax $\tau^{k}$ :

$$
\begin{array}{rlr}
r_{t} & =\rho+\left(\hat{x}_{t}+g-\delta\right)+\mu_{\hat{c}, t}-\sigma_{c t}^{2}-\left(\tilde{\sigma}_{c t}^{T F P}\right)^{2}-\left(\tilde{\sigma}_{c t}^{R S}\right)^{2} & \text { Euler } \\
r_{t} & =a+g-\delta-\tau_{t}^{k}-\sigma_{c t} \sigma_{t}-\theta_{t}^{T F P} \tilde{\sigma}^{T F P} & \text { Asset Pricing } \\
\sigma_{c t} & =\frac{k_{t}}{w_{t}} \sigma_{t}=(1-\beta) \rho k_{t} c_{t}^{-1} \sigma_{t} & \text { Id. risk } \\
\tilde{\sigma}_{c}^{T F P} & =\theta_{t}^{T F P} & \text { TFP risk } \\
\tilde{\sigma}_{c t}^{R S} & =\theta_{t}^{R S} & \text { RS risk } \\
\hat{m}_{t} & =\beta /(1-\beta) \times\left(a-\hat{x}_{t}\right) /\left(r_{t}+\pi_{t}\right) & \text { Money }
\end{array}
$$

Since the planner's allocation satisfies (50)-(55) and the FOC (57), it satisfies also the equilibrium conditions (62)-(67). Equations (62), (65), (66), and (67) are immediate. Equation (63) follows from plugging the definition of $\hat{x}_{t}$ from (57), $\tau_{t}^{k}$ from (58), and $\theta_{t}^{T F P}=\tilde{\sigma}_{c t}^{T F P}$ into the Euler equation (51). (64) comes from the skin in the game constraint (50), using the fact that $\sigma_{U t}=\frac{1}{\rho} \sigma_{c t}$. Finally, $\lim _{t \rightarrow \infty} \mathbb{E}^{Q}\left[e^{-\int_{0}^{t} r_{u} d u} k_{t} \hat{c}_{t}\right] \Longrightarrow \lim _{t \rightarrow \infty} \mathbb{E}^{Q}\left[e^{-\int_{0}^{t} r_{u} d u} w_{t}\right]=0$ and $i_{t}=r_{t}+\pi_{t}>0$ ensure that this is in fact an equilibrium.

\section{CES utility for money and cash in advance}

In this Appendix I generalize the baseline model to allow a more flexible demand for money. In particular, we are interested in allowing the expenditure share on liquidity services to vary with the interest rate. First I generalize the log utility with a CES aggregator between money and consumption. This allows me to introduce an interest-elasticity of money demand $\eta$ different from one (in particular, $\eta<1$ ). This means that as $i \rightarrow 0$ the expenditure share on liquidity vanishes. However, $i$ must always be strictly positive. The second specification is a cash-in-advance model. Again, the expenditure share on liquidity vanishes as $i \rightarrow 0$, but in this case we can actually have $i=0$.

These cases are interesting on their own, since they allow a more flexible account of money demand. But they also help understand if the liquidity trap hinges on a constant expenditure share on liquidity, as in the baseline model. In light of the cashless limit result in Proposition 5, it should come as no surprise that the liquidity trap survives even when the expenditure share on liquidity vanishes. It survives even if $i=0$ in the cash-in-advance model.

CES utility. We can introduce a more flexible CES specification for money demand

$$
\mathbb{E}\left[\int_{0}^{\infty} e^{-\rho t} \log \left(\left((1-\beta)^{\frac{1}{\eta}} c_{t}^{\frac{\eta-1}{\eta}}+\beta^{\frac{1}{\eta}} m^{\frac{\eta-1}{\eta}}\right)^{\frac{\eta}{\eta-1}}\right) d t\right]
$$

where $\eta$ is the demand elasticity of money. With $\eta=1$ we recover the baseline setting. 
The FOC for consumption and money demand are now slightly different:

$$
\begin{gathered}
c=\rho \frac{1-\beta}{1-\beta+\beta i^{1-\eta}} w \\
m i=\rho \frac{\beta i^{1-\eta}}{1-\beta+\beta i^{1-\eta}} w
\end{gathered}
$$

so the expenditure share on money services

$$
\frac{m i}{\rho w}=\tilde{\beta}(i)=\frac{\beta i^{1-\eta}}{1-\beta+\beta i^{1-\eta}}
$$

is a function of the nominal interest rate, and therefore the inflation target $i=r+\pi$. The same reasoning as in the baseline yields

$$
\hat{m}+\hat{h}=\frac{\hat{m} \times(r+\pi)}{r-(\hat{x}-\delta)}
$$

The real value of money is still the present value of liquidity services. But with $\eta \neq 1$, the target inflation rate $\pi$ affects this value. If $\eta<1$, a higher nominal interest rate $i$ leads to higher expenditures on money services $\hat{m} i$, and therefore higher real value of liquidity (for fixed $r$ and $\hat{x}$ ); if $\eta>1$ the opposite result holds.

The system of equations takes the same form as before, except that the share of expenditures on money services $\tilde{\beta}(r+\pi)$ is a function of the nominal interest rate, and therefore the real interest rate and the inflation target.

$$
\begin{gathered}
r=a-\delta-(1-\lambda) \sigma^{2} \\
\hat{x}=a-\rho-\rho \frac{\lambda-\tilde{\beta}(r+\pi)}{1-\lambda}
\end{gathered}
$$

with

$$
\lambda=\frac{\rho \tilde{\beta}(r+\pi)}{\rho-((1-\lambda) \sigma)^{2}}
$$

Now we need to solve the system of three equations simultaneously, because $r$ appears in (70).

We can verify that when $\sigma \approx 0$, we obtain the RBC limit where we can ignore money. Indeed, in this case we get $r=a-\delta, \hat{x}=a-\rho$, and $\lambda=\tilde{\beta}(r+\pi)$. While the inflation target matters for monetary variables, the real interest rate and investment are the same as in the non-monetary economy. Higher inflation targets still lead to one-for-one increases in the nominal interest rate, leaving the real interest rate and investment unaffected.

The reader may wonder if the liquidity trap survives with CES preferences. In the baseline model with log preferences, the expenditure share on liquidity services $\beta$ is constant. This implies that as $\sigma$ increases and the equilibrium real interest rate $r$ drops, the value of liquidity becomes very large $(\lambda \rightarrow 1)$ (we are "dividing by zero"). With CES preferences and demand elasticity of money $\eta<1$, the share of expenditures on liquidity services $\tilde{\beta}(i)$ falls as the equilibrium real interest rate $r$ falls 
(inflation $\pi$ is constant). But we can use the same reasoning as in the cashless limit of Proposition 5 to see that the liquidity trap must survive. In particular, if $\sigma>\sqrt{\rho}$, the equilibrium real interest rate would be below the growth rate of the economy if $\lambda=0$, which cannot be. Suppose we reduce the inflation target $\pi$ so that $i(\pi)=r(\pi)+\pi \rightarrow 0$, and therefore the expenditure share on liquidity services $\tilde{\beta}(i) \rightarrow 0$. The value of $\lambda$ must converge to $1-\sqrt{\rho} / \sigma>0$, not to zero. The equilibrium real interest rate will be high and investment depressed relative to the non-monetary economy. The liquidity trap survives.

Cash in advance. Now instead of money in the utility function, suppose we have a cash-inadvance (CIA) constraint

$$
c_{t} \leq v m_{t}
$$

The utility is now exclusively over consumption, $\log \left(c_{t}\right)$. This is a well know setting. Since we are looking only at BGP, in an economy with perfect risk sharing, $\sigma=0$, the CIA constraint does not affect the equilibrium. But with incomplete risk sharing, the CIA constraint will create a liquidity trap. These results are analogous to the case with log and CES utility over money.

The competitive equilibrium is still characterized by the Euler equation (5), the Asset Pricing equation (6), and the expression for risk sharing (7). What changes is the demand for money, which now takes the form $m=c / v$ from the CIA constraint. From log preferences, we know the agent consumes $c+m i=\rho w$; the expenditure flow is still $\rho$, but the total cost of consuming includes the forgone interest because money must be held to consume. So we obtain

$$
m_{t} i=\rho \frac{i}{i+v} w=\rho \tilde{\beta}(i) w
$$

The expenditure share on liquidity $\tilde{\beta}(i)=i /(i+v)$ is increasing in the nominal interest rate $i$ (just as in the CES case with $\eta<1)$. When $i=0$, the expenditure on liquidity services is zero, $\tilde{\beta}(0)=0$. But the demand for money is bounded: any $m_{t} \geq c_{t} / v$ is consistent with individual optimization.

For $i>0$, the value of money $m_{t}+h_{t}$ still satisfies the valuation

$$
m_{t}+h_{t}=\frac{m_{t} i}{r-(\hat{x}-\delta)}
$$

and the same reasoning as in the baseline model yields the same expression for $\lambda$ :

$$
\lambda=\frac{\rho \tilde{\beta}(i)}{\rho-((1-\lambda) \sigma)^{2}},
$$

with the same modification as in the CES case; the expenditure share $\tilde{\beta}(i)$ depends on the interest rate, so we cannot solve the model one equation at a time (it's a system of simultaneous equations).

Notice that just as in the CES case, with perfect risk sharing $\sigma=0$, money doesn't matter because $\lambda$ doesn't matter. The real interest rate and investment are completely pinned down by the Euler equation and the Asset Pricing equation. We can eliminate money by setting $v=\infty$ so 
that $\tilde{\beta}(i)=0$ and the allocation is not affected. It's not surprising then that in this case money is superneutral; the inflation target doesn't have any real effects.

But with incomplete risk sharing, $\sigma>0$, money can create a liquidity trap. The competitive equilibrium is characterized by equations (68), (69), and (70). The same reasoning as in the CES case shows that if $\sigma>\sqrt{\rho}$, even if we lower the inflation target $\pi$ so that $i(\pi)=r(\pi)+\pi \rightarrow 0$, the value of liquidity $\lambda$ cannot converge to zero because in that case the real interest rate would be below the growth rate of the economy. With $r<\hat{x}-\delta$, achieving $i=0$ requires $\mu>0$ a positive growth rate of money. So the present value of money transfers would be infinity and agents' optimization problem would be ill defined. Instead, as $i \rightarrow 0$ we must have $\lambda \rightarrow 1-\sqrt{\rho} / \sigma>0$. From (68) and (69) we see this means that the real interest rate will be higher than in the non-monetary economy, and investment lower. The liquidity trap survives, for the same reasons it survives in the cashless limit $\beta \rightarrow 0$.

In fact, this is true even if $i=0$ (rather than the limit). This may seem surprising, since in this case $m_{t}=v c_{t}$ is bounded, so (71) seems to imply that $m_{t}+h_{t}=0$. But in this case the denominator in (71) must also be zero. What is going on is that the no-Ponzi condition is being violated here, and we get a bubble. This is not that surprising, since we know that as $\beta \rightarrow 0$ the monetary economy converges to the non-monetary economy with a bubble.

The equilibrium with $i=0$ then takes the following form. We know $r=\hat{x}-\delta$, which together with $i=0$ implies zero growth rate of money, $\mu=0$. So we need the value of money $m_{t}$ plus a bubble $b_{t}$ to satisfy

$$
\frac{m_{t}+b_{t}}{k_{t}+m_{t}+b_{t}}=1-\sqrt{\rho} / \sigma>0
$$

Expenditures on liquidity services is zero, $\tilde{\beta}(i)=0$. Equations (68) and (69) pin down $r$ and $\hat{x}$ :

$$
\begin{gathered}
r=a-\delta-\sqrt{\rho} \sigma \\
\hat{x}=a-\sqrt{\rho} \sigma
\end{gathered}
$$

The CIA constraint pins down only a lower bound on money, because with $i=0$ agents are willing to hold money beyond their transaction needs,

$$
m_{t} \geq c_{t} / v \Longrightarrow \hat{m} \geq(a-\hat{x}) / v
$$

If they hold money beyond their transaction needs, money is acting like a bubble. So the conceptually cleanest decomposition is to set $\hat{m}=(a-\hat{x}) / v$ and then use (72) to pin down the value of the bubble $b_{t}$

$$
\hat{b}=\sigma / \sqrt{\rho}-1-(a-\hat{x}) / v
$$

Notice that $\hat{b}$ could be negative. This is the case if $v$ is very small, so money holding for transaction purposes $\hat{m}$ must be large. This amount of money would create too much risk sharing, so we need 
a negative bubble. ${ }^{58}$

\section{The role of intertemporal elasticity and risk aversion}

The baseline model has log preferences, which yield clean results and are quantitatively reasonable. In this Appendix I extend the baseline model to allow for EZ preferences to understand the role of intertemporal elasticity and risk aversion.

Suppose agents have recursive EZ preferences with discount $\rho$, risk aversion $\gamma$, and intertemporal elasticity $\psi$. If $\psi=1 / \gamma$ we have the standard CRRA preferences. If $\psi=\gamma=1$ we have the baseline model with log preferences.

The equilibrium equations are now modified as follows

$$
\begin{aligned}
r & =\rho+(\hat{x}-\delta) / \psi-(1+1 / \psi)(\gamma / 2) \sigma_{c}^{2} & \text { Euler equation } \\
r & =a-\delta-\gamma \sigma_{c} \sigma & \text { Asset Pricing } \\
\sigma_{c} & =(1-\lambda) \sigma & \text { Risk Sharing } \\
\hat{m} & =\frac{\beta}{1-\beta} \frac{a-\hat{x}}{r+\pi} & \text { Money }
\end{aligned}
$$

The expression for the value of liquidity, $\lambda$, must be solved simultaneously with $r$ and $\hat{x}$.

$$
\lambda=\frac{\rho \beta}{\rho+(1 / \psi-1)(\hat{x}-\delta)-(1+1 / \psi)(\gamma / 2)((1-\lambda) \sigma)^{2}}
$$

We can check that if $\psi=\gamma=1$ we recover the equation in the baseline model.

First Best. If there is no idiosyncratic risk, $\sigma=0$, we get closed form expressions for $r$ and $\hat{x}$

$$
\begin{gathered}
r=a-\delta \\
\hat{x}=(a-\delta-\rho) \psi+\delta
\end{gathered}
$$

Incomplete risk sharing and no money, $\beta=0$. The non-monetary economy also allows for closed form expressions, because $\lambda=\beta=0$ and $\sigma_{c}=\sigma$.

$$
\begin{gathered}
r=\underbrace{a-\delta}_{\text {first best }}-\gamma \sigma^{2} \\
\hat{x}=\underbrace{(a-\delta-\rho) \psi+\delta}_{\text {first best }}+\psi \underbrace{\left[(1+1 / \psi)(\gamma / 2) \sigma^{2}\right.}_{\text {precautionary }}-\underbrace{\gamma \sigma^{2}}_{\text {risk pr. }}]
\end{gathered}
$$

\footnotetext{
${ }^{58}$ We can interpret the negative bubble by taking the accounting value of money as $m$ for the purpose of the CIA constraint, but the market value of money (the goods you could actually buy if you only had money) as $m+b<m$. But this is pushing the limits of the CIA constraint as a foundation for monetary trade.
} 
After a risk shock increases idiosyncratic risk $\sigma$, the real interest rate falls to accommodate the higher risk premium $\alpha=\gamma \sigma_{c} \sigma=\gamma \sigma^{2}$. But investment may go up or down, depending on the intertemporal elasticity $\psi$. If $\psi>1$, investment falls when idiosyncratic risk $\sigma$ goes up; if $\psi<1$, investment raises. This can be understood in terms of the risk premium and precautionary motive. If $\psi>1$, the precautionary motive is smaller than the risk premium, and the difference increases with $\sigma((1+1 / \psi) / 2<1)$. Intuitively, capital is less attractive because it is more risky, and since agents are very intertemporally elastic, they substitute towards consuming instead (accepting a big change in the growth rate of their consumption). But if $\psi<1$, the precautionary motive dominates. Agents really want to smooth out their utility, and since they face more risk, they make it up by accumulating more capital. If $\psi=1$, as in the baseline, the two effects cancel out and investment does not change when $\sigma$ goes up.

The important variable is the intertemporal elasticity. Risk aversion, $\gamma$, just makes the idiosyncratic risk matter more. In fact, both enter jointly $\gamma \sigma^{2}$ in the equations. The role of intertemporal elasticity is well understood, and is the reason that the literature on time varying risk typically assumes high intertemporal elasticity, $\psi>1$. Empirically, evidence about $\psi$ is mixed, but $\psi=1$ is considered a quantitatively reasonable benchmark.

Incomplete risk sharing and money, $\beta>0$. Now let's see what happens when we add money. First, take the value of liquidity $\lambda>0$ as given. Idiosyncratic risk sharing improves, $\sigma_{c}=(1-\lambda) \sigma$, so we get

$$
\begin{gathered}
r=\underbrace{a-\delta}_{\text {first best }}-\gamma(1-\lambda) \sigma^{2} \\
\hat{x}=\underbrace{(a-\delta-\rho) \psi+\delta}_{\text {first best }}+\psi[\underbrace{(1+1 / \psi)(\gamma / 2) \sigma^{2}(1-\lambda)^{2}}_{\text {precautionary }}-\underbrace{\gamma \sigma^{2}(1-\lambda)}_{\text {risk pr. }}]
\end{gathered}
$$

Money weakens the risk premium, so the real interest rate is higher than without money. Money also weakens the precautionary motive more than the risk premium, just as in the baseline model. But since investment can go up or down with risk, depending on $\psi$, it is useful to decompose the effect of higher risk into the effect without money, and what money adds relative to the non-monetary economy:

$$
\begin{gathered}
r=\underbrace{a-\delta-\gamma \sigma^{2}}_{\text {non-monetary }}+\underbrace{\lambda \gamma \sigma^{2}}_{\Delta r} \\
\hat{x}=\underbrace{(a-\delta-\rho) \psi+\delta+\psi\left[(1+1 / \psi)(\gamma / 2) \sigma^{2}-\gamma \sigma^{2}\right]}_{\text {non-monetary }}+\underbrace{\gamma \sigma^{2} \psi\left(\left(\lambda^{2}-2 \lambda\right)(1+1 / \psi) / 2+\lambda\right)}_{\Delta \hat{x}}
\end{gathered}
$$

The second terms are the effect of money on the real interest rate, $\Delta r$, and investment, $\Delta \hat{x}$, relative to the economy without money.

In general it is possible for investment in the monetary economy to be higher than in the nonmonetary one. For very large $\psi, \Delta \hat{x} \approx \gamma \sigma^{2} \psi \lambda^{2} / 2>0$. There are two forces at work. Remember that if $\psi>1$, the risk premium dominates, so high risk $\sigma$ can have a very large negative effect on investment $\hat{x}$. Money improves risk sharing and weakens the risk premium $\alpha=\gamma \sigma^{2}(1-\lambda)$, so it 
dampens the fall in investment from this channel. It also weakens the precautionary motive relative to the risk premium, which reduces investment just like in the baseline model. The two forces work in opposite directions. In the baseline setting the direct effect of high risk in the absence of money is zero, so money must depress investment.

For $\psi \leq 1$ we can obtain a clean characterization, such that the main properties of the baseline model go through. ${ }^{59}$ Money keeps the real interest rate from falling during downturns with high risk, and depresses investment. Risk aversion $\gamma$ and idiosyncratic risk $\sigma$ enter together as $\gamma \sigma^{2}$, so all our results apply as well to increases in risk aversion.

Proposition 14. For $\psi \leq 1$, the monetary economy has higher interest rate and lower investment than the non-monetary one; i.e. $\Delta r>0$ and $\Delta \hat{x}<0$. Higher $\gamma \sigma^{2}$ leads to higher risk premium $\alpha=\gamma \sigma^{2}(1-\lambda)$, higher value of liquidity $\lambda$, and larger $\Delta r$ and $|\Delta \hat{x}|$.

The case $\psi \leq 1$ covers two very salient classes of preferences. First, CRRA preferences with risk aversion $\gamma=1 / \psi \geq 1$. This is the most common specification in macroeconomic models. In the context of models with time varying risk, it has the unappealing feature that, without money, higher risk leads to more investment.

Second, the cleanest and quantitatively salient specification has $\psi=1$ and $\gamma>1$. The $\gamma>1$ can be interpreted either as high risk aversion, or as ambiguity aversion as in Barillas et al. (2009). This specification has the advantage that the equations boils down to those of the baseline model, with the only modification of replacing $\sigma^{2}$ by $\gamma \sigma^{2}$,

$$
\begin{gathered}
r=\underbrace{a-\delta-\gamma \sigma^{2}}_{\text {non-monetary }}+\underbrace{\lambda \gamma \sigma^{2}}_{\Delta r} \\
\hat{x}=\underbrace{(a-\rho)}_{\text {non-monetary }}-\underbrace{\rho \frac{\lambda-\beta}{1-\lambda}}_{\Delta \hat{x}} \\
\lambda=\frac{\rho \beta}{\rho-\gamma \sigma^{2}(1-\lambda)^{2}}
\end{gathered}
$$

\section{Proof of Proposition 14}

Proof. Write the equation for $\lambda$, replacing $r$ and $\hat{x}$ from (75) and (76) to obtain

$$
\lambda=\frac{\rho \beta}{\rho+(1 / \psi-1)(a-\delta-\rho) \psi-\alpha[(1-\psi)+\psi(1+1 / \psi)(1-\lambda) / 2]}
$$

where $\alpha=\gamma \sigma^{2}(1-\lambda)>0$ is the risk premium. The denominator is strictly decreasing in $\alpha$ (here we use $\psi \leq 1$ ) and strictly increasing in $\lambda$ (for $\alpha>0$ which must be the case for $\sigma>0$ ). So if there is a solution $\lambda(\alpha)$ to this equation, it is increasing in $\alpha$. From $\alpha /(1-\lambda)=\gamma \sigma^{2}$, since the lhs is increasing in $\alpha$, it follows that $\alpha$ is increasing in $\gamma \sigma^{2}$, and therefore so is $\lambda$.

\footnotetext{
${ }^{59} \psi \leq 1$ is sufficient, but not necessary.
} 
Now $\Delta r=\lambda \gamma \sigma^{2}>0$ and increasing in $\gamma \sigma^{2}$ is straightforward. For $\Delta \hat{x}$ we write it after some algebra

$$
\Delta \hat{x}=\gamma \sigma^{2} \lambda\left(\lambda \frac{1+\psi}{2}-1\right)=\alpha \lambda \frac{\lambda \frac{1+\psi}{2}-1}{1-\lambda}<0
$$

If $\gamma \sigma^{2}$ increases, so does $\alpha$ and $\lambda$. The derivative of the last factor with respect to $\lambda$ is

$$
\partial_{\lambda}\left\{\frac{\lambda \frac{1+\psi}{2}-1}{1-\lambda}\right\}=\frac{\frac{1+\psi}{2}(1-\lambda)+\lambda \frac{1+\psi}{2}-1}{(1-\lambda)^{2}}=\frac{\frac{1+\psi}{2}-1}{(1-\lambda)^{2}} \leq 0
$$

(using $\psi \leq 1$ again). So $\Delta \hat{x}$ is negative and becomes even more negative. 


\section{Online Appendix: Contractual setting}

In this Appendix I develop the contractual environment that yields the incomplete idiosyncratic risk sharing problem in the baseline model as the optimal contract. I also allow aggregate risk with complete risk sharing, which is the setting in the dynamic model in Section 4. The setting in the baseline model is a special case with no aggregate risk.

The setting is essentially a special case of the environment in Di Tella and Sannikov (2016) with perfect misreporting ( $\phi=1$ in the terms of that paper), generalized to allow for aggregate shocks. I discuss the similarities and differences below.

\section{Setting}

The setting is as in the dynamic model in Section 4. The "capital quality" shock for an agent is

$$
\Delta_{i, t}^{k}=\sigma_{t} k_{i, t} d W_{i, t}+\tilde{\sigma}^{T F P} d Z_{t}^{T F P}
$$

where $Z^{T F P}$ is an aggregate TFP shock. Aggregate TFP risk $\tilde{\sigma}^{T F P}$ is constant, but idiosyncratic risk $\sigma_{t}$ follows an autoregressive process

$$
d \sigma_{t}=\mu_{\sigma}\left(\sigma_{t}\right) d t+\tilde{\sigma}_{\sigma}\left(\sigma_{t}\right) d Z_{t}^{R S}
$$

where $Z^{R S}$ is the aggregate risk shock. $Z^{T F P}$ and $Z^{R S}$ are independent Brownian motions.

There is a complete financial market with real interest rate $r$, nominal interest rate $i$, capital's excess return $\alpha$, and price of aggregate shocks $\theta^{T F P}$ and $\theta^{R S}$, all adapted to the history of aggregate shocks $Z^{T F P}$ and $Z^{R S}$. Let $Q$ be the equivalent martingale measure associated with $r, \theta^{T F P}$ and $\theta^{R S}$, and $\tilde{Q}$ the equivalent martingale measure associated with $r, \theta^{T F P}, \theta^{R S}$, and $\alpha .{ }^{60}$

The agent receives consumption $c$ and money holdings $m$ from the principal, and manages capital $k$, all contingent on the history of aggregate shocks $Z^{T F P}$ and $Z^{R S}$ and the agent's report of his idiosyncratic shock $Y^{s}$. The idiosyncratic shock is not observable by the principal, so the agent can misreport at rate $s$, such that his reports are $Y_{t}^{s}=W_{t}-\int_{0}^{t} \frac{s_{u}}{\sigma_{u}} d u$. Furthermore, the agent has access to hidden trade that allows him to choose his consumption $\tilde{c}$, money $\tilde{m}$, capital holdings $\tilde{k}$, and to trade aggregate risk $\tilde{\sigma}_{n}^{T F P}$ and $\tilde{\sigma}_{n}^{R S}{ }^{61}$ His hidden savings $n$ start at $n_{0}=0$ and satisfy the dynamic budget constraint

$$
\begin{aligned}
d n_{t} & =\left(n_{t} r_{t}+c_{t}-\tilde{c}_{t}+\left(m_{t}-\tilde{m}_{t}\right) i_{t}+\left(\tilde{k}_{t}-k_{t}\right) \alpha_{t}+\theta_{t}^{T F P} \sigma_{n t}^{T F P}+\theta_{t}^{R S} \tilde{\sigma}_{n t}^{R S}+k_{t} s_{t}\right) d t \\
& +\left(\tilde{k}_{t}-k_{t}\right) \sigma_{t} d W_{t}+\tilde{\sigma}_{n t}^{T F P} d Z_{t}^{T F P}+\tilde{\sigma}_{n t}^{R S} d Z^{R S}
\end{aligned}
$$

\footnotetext{
${ }^{60}$ That is, $Q$ is defined by the SPD $d \xi_{t} / \xi_{t}=-r_{t}-\theta_{t}^{T F P} d Z_{t}^{T F P}-\theta_{t}^{R S} d Z_{t}^{R S}$ and $\tilde{Q}$ by $d \tilde{\xi}_{t} / \tilde{\xi}_{t}=-r_{t}-\theta_{t}^{T F P} d Z_{t}^{T F P}-$ $\theta_{t}^{R S} d Z_{t}^{R S}-\frac{\alpha_{t}}{\sigma_{t}} d W_{t}$.

${ }^{61}$ To keep things simple, allow $\tilde{k}<0$, but we can also restrict it to $\tilde{k} \geq 0$, as in Di Tella and Sannikov (2016). This doesn't change the optimal contract.
} 
with solvency constraint $n_{t} \geq \underline{n}_{t}$ where $\underline{n}_{t}$ is the natural debt limit

$$
\underline{n}_{t}=-\max _{s \in \mathbb{S}} \mathbb{E}_{t}^{\tilde{Q}}\left[\int_{t}^{\infty} e^{\int_{t}^{u} r_{\tau} d \tau}\left(c_{u}\left(Y^{s}\right)+m_{u}\left(Y^{s}\right) i_{u}+s_{u} k_{u}\left(Y^{s}\right)\right) d u\right]
$$

where $\mathbb{S}=\left\{s: \mathbb{E}^{\tilde{Q}}\left[\int_{0}^{\infty} e^{\int_{t}^{u} r_{\tau} d \tau}\left|c_{u}\left(Y^{s}\right)+m_{u}\left(Y^{s}\right) i_{u}+s_{u} k_{u}\left(Y^{s}\right)\right| d u\right]<\infty\right\}$ is the set of feasible stealing plans for a given contract. The natural debt limit $\underline{n}_{t}$ is the maximum amount that the agent can pay back for sure at time $t$. The lender is not taking any risk as long as he enforces the natural debt limit.

Lemma 1. Assume $\left|\underline{n}_{0}\right|<\infty$. If $n_{t} \geq \underline{n}_{t}$ always, then $\liminf \operatorname{in}_{t \rightarrow \infty} e^{-\int_{0}^{t} r_{u} d u} n_{t} \geq 0$ a.s.

A contract $\mathcal{C}=(c, m, k)$ is admissible if $\mathbb{E}^{Q}\left[\int_{0}^{\infty} e^{-\int_{0}^{t} r_{u} d u}\left|c_{t}+m_{t} i_{t}+k_{t} \alpha_{t}\right| d t\right]<\infty$. It is always optimal to implement no misreporting or hidden trade. ${ }^{62}$ An admissible contract is incentive compatible if the agent chooses to report truthfully and not engage in hidden trade,

$$
(c, m, k, 0,0,0) \in \arg \max _{\mathcal{P}} U(c, m) \quad s t:
$$

where $\mathcal{P}=\left(\tilde{c}, \tilde{m}, \tilde{k}, \tilde{\sigma}_{n}^{T F P}, \tilde{\sigma}_{n}^{R S}, s\right)$. An incentive compatible contract is optimal if it minimizes the cost of delivering utility to the agent

$$
\begin{gathered}
J_{0}\left(u_{0}\right)=\min _{(c, m, k) \in I C} \mathbb{E}^{Q}\left[\int_{0}^{\infty} e^{-\int_{0}^{t} r_{u} d u}\left(c_{t}+m_{t} i_{t}-k_{t} \alpha_{t}\right) d t\right] \\
\text { st }: \quad U(c, m) \geq u_{0}
\end{gathered}
$$

We pin down the agent's initial utility $u_{0}$ with a free-entry condition for principals. If the agent has initial wealth $w_{0}$, he gives it to the principal in exchange for the full-commitment contract, and the principal breaks even, $J_{0}\left(u_{0}\right)=w_{0}$.

\section{Incentive compatibility and optimal contract}

Given contract $\mathcal{C}=(c, m, k)$, the agent's problem is to choose a misreporting and hidden trade strategy $\mathcal{P}=\left(\tilde{c}, \tilde{m}, \tilde{k}, \tilde{\sigma}_{n}^{T F P}, \tilde{\sigma}_{n}^{R S}, s\right)$ to maximize his utility subject to his dynamic budget constraint. With the natural debt limit, the dynamic budget constraint is equivalent to the following intertemporal budget constraint

$$
\mathbb{E}^{\tilde{Q}}\left[\int_{0}^{\infty} e^{-\int_{0}^{t} r_{u} d u}\left(\tilde{c}_{t}+\tilde{m}_{t} i_{t}\right) d t\right] \leq \max _{s \in \mathbb{S}} \mathbb{E}^{\tilde{Q}}\left[\int_{0}^{\infty} e^{-\int_{0}^{t} r_{u} d u}\left(c_{t}\left(Y^{s}\right)+m_{t}\left(Y^{s}\right) i_{t}+k_{t}\left(Y^{s}\right) s_{t}\right) d t\right]
$$

The rhs is the present value of the agent's income from the principal, including what he "steals" from him, and is equal to (minus) the natural debt limit $-\underline{n}_{0}$. Of course, if the rhs is infinity the agent can achieve infinite utility. This corresponds to the case where the natural debt limit $\underline{n}_{0}=-\infty$ so the agent can get infinite utility under the dynamic constraint as well.

\footnotetext{
${ }^{62}$ See Di Tella and Sannikov (2016).
} 
Lemma 2. Assume $\left|\underline{n}_{0}\right|<\infty$. If $\left(\tilde{c}, \tilde{m}, \tilde{k}, \tilde{\sigma}_{n}^{T F P}, \tilde{\sigma}_{n}^{R S}, s\right)$ and $n$ satisfy the dynamic budget constraint (79) with $n_{t} \geq \underline{n}_{t}$ always, then $(\tilde{c}, \tilde{m})$ satisfy the intertemporal budget constraint (81).

If $(\tilde{c}, \tilde{m})$ satisfy the intertemporal budget constraint (81), then there are processes $\left(\tilde{k}, \tilde{\sigma}_{n}^{T F P}, \tilde{\sigma}_{n}^{R S}, s\right)$ and $n$ that satisfy the dynamic budget constraint (79) with $n_{t} \geq \underline{n}_{t}$ always.

We can split the agent's problem into two parts. First, pick a misreporting strategy that maximizes the value of the rhs. Second, choose $\tilde{c}$ and $\tilde{m}$ to maximize utility subject to the intertemporal budget constraint (81).

If $s^{*}=0$ is optimal, then

$$
\int_{0}^{t} e^{-\int_{0}^{u} r_{\tau} d \tau}\left(c_{u}\left(Y^{s}\right)+m_{u}\left(Y^{s}\right) i_{u}+k_{u}\left(Y^{s}\right) s_{u}\right) d u-e^{-\int_{0}^{t} r_{u} d u} \underline{n}_{t}\left(Y^{s}\right)
$$

must be a $\tilde{Q}$-martingale for $s=0$ and a supermartingale for any other $s$. So we can write

$$
\begin{aligned}
d\left(e^{-\int_{0}^{t} r_{u} d u} \underline{n}_{t}\left(Y^{s}\right)\right) & =e^{-\int_{0}^{t} r_{\tau} d \tau}\left\{\left(c_{t}\left(Y^{s}\right)+m_{t}\left(Y^{s}\right) i_{t}\right) d t+\sigma_{\underline{n} t}\left(Y^{s}\right)\left(d Y_{t}^{s}+\alpha_{t} d t\right)\right. \\
& \left.+\tilde{\sigma}_{\underline{n} t}^{T F P}\left(Y^{s}\right)\left(d Z_{t}^{T F P}+\theta_{t}^{T F P} d t\right)+\tilde{\sigma}_{\underline{n} t}^{R S}\left(Y^{s}\right)\left(d Z_{t}^{R S}+\theta_{t}^{R S} d t\right)\right\}
\end{aligned}
$$

If the agent misreports $s$, then

$$
\begin{array}{r}
\int_{0}^{t} e^{-\int_{0}^{u} r_{\tau} d \tau}\left\{\left(c_{u}\left(Y^{s}\right)+m_{u}\left(Y^{s}\right) i_{u}+k_{u}\left(Y^{s}\right) s_{u}\right) d u-\left(c_{u}\left(Y^{s}\right)+m_{u}\left(Y^{s}\right) i_{u}\right) d u\right. \\
\left.-\sigma_{\underline{n} u}\left(Y^{s}\right)\left(d Y_{u}^{s}+\alpha_{u} d u\right)-\tilde{\sigma}_{\underline{n} u}^{T F P}\left(Y^{s}\right)\left(d Z_{u}^{T F P}+\theta_{u}^{T F P} d u\right)-\tilde{\sigma}_{\underline{n} u}^{R S}\left(Y^{s}\right)\left(d Z_{u}^{R S}+\theta_{u}^{R S} d u\right)\right\}
\end{array}
$$

or simplifying,

$$
\begin{array}{r}
\int_{0}^{t} e^{-\int_{0}^{u} r_{\tau} d \tau}\left\{k_{u}\left(Y^{s}\right) s_{u} d u-\sigma_{\underline{n} u}\left(Y^{s}\right)\left(d Y_{u}^{s}+\alpha_{u} d u\right)-\tilde{\sigma}_{\underline{n} u}^{T F P}\left(Y^{s}\right)\left(d Z_{u}^{T F P}+\theta_{u}^{T F P} d u\right)\right. \\
\left.-\tilde{\sigma}_{\underline{n} u}^{R S}\left(Y^{s}\right)\left(d Z_{u}^{R S}+\theta_{u}^{R S} d u\right)\right\}
\end{array}
$$

must be a $\tilde{Q}$-supermartingale. Since $d Y_{t}^{s}=d W_{t}-\frac{s_{t}}{\sigma_{t}} d t$, this requires

$$
k_{t}+\sigma_{\underline{n} t} \frac{1}{\sigma_{t}}=0 \Longrightarrow \sigma_{\underline{n} t}=-k_{t} \sigma_{t}
$$

In other words, for every dollar the agent misreports he must lose a dollar in present value of future income.

Second, taking the rhs of the intertemporal budget constraint as given and choosing $\tilde{c}$ and $\tilde{m}$ is a standard consumption-portfolio problem. The FOC are

$$
\begin{array}{rlr}
\mu_{c t} & =r_{t}-\rho+\sigma_{c t}^{2}+\left(\tilde{\sigma}_{c t}^{T F P}\right)^{2}+\left(\tilde{\sigma}_{c t}^{R S}\right)^{2} & \text { Euler equation } \\
\alpha_{t} & =\sigma_{c t} \sigma_{t} & \text { demand for capital } \\
\tilde{\sigma}_{c t}^{T F P} & =\theta_{t}^{T F P} & \text { TFP shocks }
\end{array}
$$




$$
\begin{array}{rlr}
\tilde{\sigma}_{c t}^{R S} & =\theta_{t}^{R S} & \text { Risk shocks } \\
m_{t} / c_{t} & =\beta /(1-\beta) i_{t}^{-1} & \text { demand for money }
\end{array}
$$

In addition, optimality and zero hidden savings, $n_{t}=0$, imply that

$$
\mathbb{E}_{t}^{\tilde{Q}}\left[\int_{t}^{\infty} e^{-\int_{t}^{u} r_{\tau} d \tau}\left(\tilde{c}_{u}+\tilde{m}_{u} i_{u}\right) d u\right]=\mathbb{E}_{t}^{\tilde{Q}}\left[\int_{t}^{\infty} e^{-\int_{t}^{u} r_{\tau} d \tau}\left(c_{u}\left(Y^{0}\right)+m_{u}\left(Y^{0}\right) i_{u}\right) d t\right]=-\underline{n}_{t}
$$

and $c_{t}=(1-\beta) \rho \mathbb{E}_{t}^{\tilde{Q}}\left[\int_{t}^{\infty} e^{-\int_{t}^{u} r_{\tau} d \tau}\left(\tilde{c}_{u}+\tilde{m}_{u} i_{u}\right) d u\right]=(1-\beta) \rho\left(-\underline{n}_{t}\right)$. From this it follows that the geometric volatility of consumption is

$$
\sigma_{c t}=(1-\beta) \rho \frac{k_{t}}{c_{t}} \sigma_{t} \quad \text { "skin in the game" }
$$

It's worth noting that, given (82)-(86), the agent's continuation utility

$$
U_{t}=\mathbb{E}_{t}\left[\int_{t}^{\infty} e^{-\rho u}\left((1-\beta) \log c_{u}+\beta \log m_{u}\right) d u\right]
$$

will admit a representation $U_{t}=A_{t}+\frac{1}{\rho} \log c_{t}$. The skin in the game constraint (87) then implies $\sigma_{U t}=(1-\beta) c_{t}^{-1} k_{t} \sigma_{t}$. If the agent misreports a dollar and immediately consumes it he gets marginal utility $(1-\beta) c_{t}^{-1}$, so his continuation utility must go down by that amount to deter him.

Putting these conditions together we obtain the following result.

Lemma 3. An incentive compatible contract $\mathcal{C}=(c, m, k)$ must satisfy conditions (82)-(87).

The incentive compatibility conditions (82)-(87) are necessary. In general, proving that they are sufficient for global incentive compatibility is a difficult problem, because the hidden trade allows the agent a large set of deviations. The strategy is to first characterize the optimal contract subject only to the necessary incentive compatibility constraints, and then prove that it is indeed incentive compatible. As it turns out, this will be straightforward in this setting because the optimal contract will coincide with letting the agent choose his own consumption, money, and capital (the optimal contract coincides with autarky).

We say that contract $\mathcal{C}=(c, m, k)$ solves the portfolio problem for $w_{0}>0$ if it maximizes $U(c, m)$ subject to the dynamic budget constraint

$$
\begin{aligned}
d w_{t} & =\left(r_{t} w_{t}-c_{t}-m_{t} i_{t}+k_{t} \alpha_{t}+\theta_{t}^{T F P} \tilde{\sigma}_{w t}^{T F P}+\theta_{t}^{R S} \tilde{\sigma}_{w t}^{R S}\right) d t+k_{t} \sigma d W_{t} \\
& +\tilde{\sigma}_{w t}^{T F P} d Z_{t}^{T F P}+\tilde{\sigma}_{w t}^{R S} d Z_{t}^{R S}
\end{aligned}
$$

with solvency constraint $w_{t} \geq 0$. This dynamic budget constraint is equivalent to

$$
\mathbb{E}^{\tilde{Q}}\left[\int_{0}^{\infty} e^{-\int_{0}^{t} r_{u} d u}\left(c_{t}+m_{t} i_{t}\right) d t\right] \leq w_{0}
$$

It is well known that (82)-(86) are the FOCs for this portfolio problem, so we get the following 
result.

Theorem 1. Let $(c, m, k)$ be an optimal contract for initial utility $u_{0}$, with cost $J\left(u_{0}\right)$. Then $(c, m, k)$ solves the portfolio problem for $w_{0}=J\left(u_{0}\right)$.

Conversely, let $(c, m, k)$ solve the portfolio problem for some $w_{0}>0$. If in addition $\lim _{t \rightarrow \infty} \mathbb{E}\left[e^{-r t} w_{t}\right]=$ 0 , then $(c, m, k)$ is an optimal contract for initial utility $u_{0}$ with $J\left(u_{0}\right)=w_{0}$.

Remark. The condition $\lim _{t \rightarrow \infty} \mathbb{E}\left[e^{-r t} w_{t}\right]=0$ must be satisfied in the competitive equilibrium in the paper.

\section{Comparison to Di Tella and Sannikov (2016)}

This setting is essentially the same as in Di Tella and Sannikov (2016), with hidden investment and perfect misreporting ( $\phi=1$ in the context of that paper). The main result here is Theorem 1 , which is analogous to Lemma 28 in that paper. This is therefore a special case of the environment in that paper.

But there are some differences. First, here I allow aggregate risk shocks that affect the investment environment. The setting in Di Tella and Sannikov (2016) is stationary. Second, in Di Tella and Sannikov (2016) the agent faces a no-debt solvency constraint $n_{t} \geq 0$ on his hidden savings $n$. Here I allow the agent to borrow up to the natural borrowing limit, using his income from the contract. As it turns out the optimal contract is the same. The no-debt borrowing constraint relaxes the IC constraints, but the principal does not use this freedom in the optimal contract. Intuitively, with $n_{t} \geq 0$ the principal could backload the agent's consumption if he wanted. But what he really wants to do is to front load it.

Finally, here I allow the agent to short capital in his hidden investment, $\tilde{k}_{t}<0$ and to overreport returns, $s_{t}<0$. This is done for simplicity. In Di Tella and Sannikov (2016) hidden investment and misreporting must be non-negative, $k_{t} \geq 0$ and $s_{t} \geq 0$, and the optimal contract is the same (for the special case with $\phi=1$ ).

\section{Proofs}

\section{Proof of Lemma 1}

Proof. From the definition of the natural debt limit (80), if we take absolute value on both sides we get the following inequality

$$
\left|\underline{n}_{t}\right| \leq S_{t}=\mathbb{E}_{t}^{\tilde{Q}}\left[\int_{t}^{\infty} e^{\int_{t}^{u} r_{\tau} d \tau}\left|c_{u}\left(Y^{s^{*}}\right)+m_{u}\left(Y^{s^{*}}\right) i_{u}+s_{u}^{*} k_{u}\left(Y^{s^{*}}\right)\right| d u\right]<\infty
$$

where $s^{*}$ is the misreporting process that achieves the maximum in (80). The martingale representation theorem yields

$$
d\left(e^{-\int_{0}^{t} r_{u} d u} S_{t}\right)=-e^{-\int_{0}^{t} r_{u} d u}\left|c_{t}\left(Y^{s^{*}}\right)+m_{t}\left(Y^{s^{*}}\right) i_{t}+s_{t}^{*} k_{t}\left(Y^{s^{*}}\right)\right| d t+\tilde{Q} \text {-local mart. terms }
$$


We also know that $\lim _{T \rightarrow \infty} \mathbb{E}^{\tilde{Q}}\left[e^{-\int_{0}^{T} r_{u} d u} S_{T}\right]=0$. To see this, write

$$
S_{0}=\mathbb{E}_{0}^{\tilde{Q}}\left[\int_{0}^{T} e^{\int_{0}^{u} r_{\tau} d \tau}\left|c_{u}\left(Y^{s^{*}}\right)+m_{u}\left(Y^{s^{*}}\right) i_{u}+s_{u}^{*} k_{u}\left(Y^{s^{*}}\right)\right| d u\right]+\mathbb{E}^{\tilde{Q}}\left[e^{-\int_{0}^{T} r_{u} d u} S_{T}\right]
$$

and take the limit $T \rightarrow \infty$, using the MCT on the first term. It follows that $\lim _{T \rightarrow \infty} e^{-\int_{0}^{T} r_{u} d u} S_{T}$ exists and is zero almost surely (see Problem 3.16 in Karatzas and Shreve (2012)). Since $\left|\underline{n}_{t}\right| \leq S_{t}$, the same is true for $\underline{n}_{t}$, and since $n_{t} \geq \underline{n}_{t}$, we obtain $\liminf \operatorname{in}_{T \rightarrow \infty} e^{-\int_{0}^{t} r_{u} d u} n_{t} \geq 0$ a.s.

\section{Proof of Lemma 2}

Proof. In the first direction, use the dynamic budget constraint to compute

$$
\begin{aligned}
\mathbb{E}^{\tilde{Q}}\left[e^{-\int_{0}^{t} r_{u} d u} n_{t}\right] & =\mathbb{E}^{\tilde{Q}}\left[\int_{0}^{t} e^{-\int_{0}^{u} r_{\tau} d \tau}\left(c_{u}\left(Y^{s}\right)+m_{u}\left(Y^{s}\right) i_{u}+k_{u}\left(Y^{s}\right) s_{u}\right) d u\right] \\
& -\mathbb{E}^{\tilde{Q}}\left[\int_{0}^{t} e^{-\int_{0}^{u} r_{\tau} d \tau}\left(\tilde{c}_{u}+\tilde{m}_{u} i_{u}\right) d t\right]
\end{aligned}
$$

Subtract $\mathbb{E}^{\tilde{Q}}\left[e^{-\int_{0}^{t} r_{u} d u} \underline{n}_{t}\right]<\infty$ from both sides. Because $\underline{n}_{0}$ is the maximum value that the agent can get, we obtain an inequality:

$$
\begin{aligned}
& \mathbb{E}^{\tilde{Q}}\left[e^{-\int_{0}^{t} r_{u} d u}\left(n_{t}-\underline{n}_{t}\right)\right] \leq \max _{s} \mathbb{E}^{\tilde{Q}}\left[\int_{0}^{\infty} e^{-\int_{0}^{u} r_{\tau} d \tau}\left(c_{u}\left(Y^{s}\right)+m_{u}\left(Y^{s}\right) i_{u}+k_{u}\left(Y^{s}\right) s_{u}\right) d u\right] \\
&-\mathbb{E}^{\tilde{Q}}\left[\int_{0}^{t} e^{-\int_{0}^{u} r_{\tau} d \tau}\left(\tilde{c}_{u}+\tilde{m}_{u} i_{u}\right) d u\right] \\
& \mathbb{E}^{\tilde{Q}}\left[\int_{0}^{t} e^{-\int_{0}^{u} r_{\tau} d \tau}\left(\tilde{c}_{u}+\tilde{m}_{u} i_{u}\right) d u\right] \leq-\underline{n}_{0}-\mathbb{E}^{\tilde{Q}}\left[e^{-\int_{0}^{t} r_{u} d u}\left(n_{t}-\underline{n}_{t}\right)\right]
\end{aligned}
$$

Take the limit $t \rightarrow \infty$ and use $n_{t} \geq \underline{n}_{t}$ to obtain the intertemporal budget constraint (81).

In the other direction, define

$$
n_{t}=\underline{n}_{t}+\mathbb{E}^{\tilde{Q}}\left[\int_{t}^{\infty} e^{-\int_{t}^{u} r_{\tau} d \tau}\left(\tilde{c}_{u}+\tilde{m}_{u} i_{u}\right) d u\right] \geq \underline{n}_{t}
$$

Define $L_{t}=\mathbb{E}_{t}^{\tilde{Q}}\left[\int_{t}^{\infty} e^{-\int_{t}^{u} r_{\tau} d \tau}\left(\tilde{c}_{u}+\tilde{m}_{u} i_{u}\right) d u\right]$, so that $\int_{0}^{t} e^{-\int_{0}^{u} r_{\tau} d \tau}\left(\tilde{c}_{u}+\tilde{m}_{u} i_{u}\right) d u+e^{-\int_{0}^{t} r_{\tau} d \tau} L_{t}$ is a $\tilde{Q}$-martingale. Likewise, $-\int_{0}^{t} e^{-\int_{0}^{u} r_{\tau} d \tau}\left(c_{u}\left(Y^{s^{*}}\right)+m_{u}\left(Y^{s^{*}}\right) i_{u}+k_{u}\left(Y^{s^{*}}\right) s_{u}^{*}\right) d t+e^{-\int_{0}^{t} r_{\tau} d \tau} \underline{n}_{t}$ is also $\tilde{Q}$-martingale, where $s^{*}$ is the misreporting process that achieves the maximum. So we can write

$$
\begin{aligned}
d n_{t} & =\left(n_{t} r_{t}+c_{t}\left(Y^{s^{*}}\right)+m_{t}\left(Y^{s^{*}}\right) i_{t}+k_{t}\left(Y^{s^{*}}\right) s_{t}^{*}-\left(\tilde{c}_{t}+\tilde{m}_{t} i_{t}\right)\right) d t \\
& +\left(\sigma_{\underline{n} t}+\sigma_{L t}\right)\left(\alpha_{t} d t+d W_{t}\right)+\left(\tilde{\sigma}_{\underline{n} t}^{T F P}+\tilde{\sigma}_{L t}^{T F P}\right)\left(\theta_{t}^{T F P} d t+d \tilde{Z}_{t}^{T F P}\right)+\left(\tilde{\sigma}_{\underline{n} t}^{R S}+\tilde{\sigma}_{L t}^{R S}\right)\left(\theta_{t}^{R S} d t+d \tilde{Z}_{t}^{R S}\right)
\end{aligned}
$$

Letting $\sigma_{\underline{n} t}+\sigma_{L t}=\tilde{k}_{t}-k_{t}, \tilde{\sigma}_{\underline{n} t}^{T F P}+\tilde{\sigma}_{L t}^{T F P}=\tilde{\sigma}_{n t}^{T F P}$, and $\tilde{\sigma}_{\underline{n} t}^{R S}+\tilde{\sigma}_{L t}^{R S}=\tilde{\sigma}_{n t}^{R S}$, we obtain the dynamic budget constraint (79). 


\section{Proof of Lemma 3}

Proof. Immediate from the argument in Section 6, noting that incentive compatibility requires $\left|\underline{n}_{0}\right|<\infty$.

\section{Proof of Theorem 1}

Proof. In the first direction, if $(c, m, k)$ is an optimal contract, then it must satisfy the local IC constraints (82)-(86), which are the FOC for the consumption-portfolio problem. So $c$ and $m$ solve the optimal portfolio problem for some initial $w_{0}$, with an associated wealth process $w$ that satisfies the dynamic budget constraint (88) and $w_{t} \geq 0$. Now the IC constraint (87) pins down the corresponding $k$. We know that $c_{t}=(1-\beta) \rho w_{t}$ in the portfolio problem, so (87) and (83) imply

$$
\begin{gathered}
\sigma_{c}=\frac{\alpha_{t}}{\sigma_{t}}=(1-\beta) \rho \frac{k_{t}}{c_{t}} \sigma_{t} \\
\Longrightarrow \frac{k_{t}}{w_{t}}=\frac{\alpha_{t}}{\sigma_{t}^{2}}
\end{gathered}
$$

which is the expression for capital in the portfolio problem. Finally, we need to show that $w_{0}=J_{0}$. Integrate the dynamic budget constraint (88) and take expectations under $Q$ to obtain

$$
w_{0}=\mathbb{E}^{Q}\left[\int_{0}^{T} e^{-r t}\left(c_{t}+m_{t} i-k_{t} \alpha\right) d t\right]+\mathbb{E}^{Q}\left[e^{-r T} w_{T}\right]
$$

If we take the limit $T \rightarrow \infty$, the first term will converge to $\mathbb{E}\left[\int_{0}^{\infty} e^{-r t}\left(c_{t}+m_{t} i-k_{t} \alpha\right) d t\right]=J_{0}$ (apply dominated converge theorem and use feasibility). For the second term, because everything is proportional to $w$, we must have $J_{t}=A w_{t}$ for some $A>0$ (it will be $A=1$ ). The continuation cost of the contract $J_{t}=\mathbb{E}_{t}\left[\int_{t}^{\infty} e^{-r s}\left(c_{s}+m_{s} i-\alpha k_{s}\right) d s\right]$ must satisfy $\lim _{T \rightarrow \infty} \mathbb{E}\left[e^{-r T} J_{T}\right]=0$, so $\lim _{T \rightarrow \infty} \mathbb{E}\left[e^{-r T} w_{T}\right]=0$ and therefore $w_{0}=J_{0}$. To see why $\lim _{T \rightarrow \infty} \mathbb{E}\left[e^{-r T} J_{T}\right]=0$, write $J_{0}=\mathbb{E}\left[\int_{0}^{T} e^{-r t}\left(c_{t}+m_{t} i-k_{t} \alpha\right) d t\right]+\mathbb{E}\left[e^{-r T} J_{T}\right]$ and take $T \rightarrow \infty$ (using DCT and feasibility again).

In the other direction, suppose $(c, m, k)$ solve the portfolio problem with associated wealth process $w$ and utility utility $U(w)=\frac{1}{\rho}(\log w-\log \xi)$. Notice that this is the only contract that satisfies the local IC constraints and delivers utility $u_{0}=\frac{1}{\rho}\left(\log w_{0}-\log \xi\right)$. (82)-(86) are the FOC for the portfolio problem, and pin down $c$ and $m$ up to an initial constant (corresponding to $w_{0}$ ). We also know that $k_{t} / w_{t}=\frac{\alpha_{t}}{\sigma_{t}^{2}}$ and $c_{t}=(1-\beta) \rho w_{t}$, so from (83) we get the skin in the game IC constraint (87)

$$
\sigma_{c t}=\frac{\alpha_{t}}{\sigma_{t}}=\frac{k_{t}}{w_{t}} \sigma_{t}=(1-\beta) \rho \frac{k_{t}}{c_{t}} \sigma_{t}
$$

The contract $(c, m, k)$ is feasible because $\lim _{T \rightarrow \infty} \mathbb{E}\left[e^{-r T} w_{T}\right]=0$ (each term is proportional to $w$, so it grows slower than $r$ ). The contract is globally incentive compatible, because the agent is only getting risk-free debt from the principal, and doing what he wants.

It only remains to show that we can't achieve more utility. Integrate the dynamic budget 
constraint to obtain

$$
w_{0}=\mathbb{E}\left[\int_{0}^{T} e^{-r t}\left(c_{t}+m_{t} i-k_{t} \alpha\right) d t\right]+\mathbb{E}\left[e^{-r T} w_{T}\right]
$$

and take the limit $T \rightarrow \infty$ to obtain $J_{0}=w_{0}>0$. So giving the agent more utility (scaling up the contract) will cost more. 